\title{
Neurobiological factors modulating H1-antihistamine induced cognitive impairment
}

Citation for published version (APA):

Conen, S. (2012). Neurobiological factors modulating H1-antihistamine induced cognitive impairment.

[Doctoral Thesis, Maastricht University]. Maastricht University. https://doi.org/10.26481/dis.20121123sc

Document status and date:

Published: 01/01/2012

DOI:

10.26481/dis.20121123sc

Document Version:

Publisher's PDF, also known as Version of record

\section{Please check the document version of this publication:}

- A submitted manuscript is the version of the article upon submission and before peer-review. There can be important differences between the submitted version and the official published version of record.

People interested in the research are advised to contact the author for the final version of the publication, or visit the DOI to the publisher's website.

- The final author version and the galley proof are versions of the publication after peer review.

- The final published version features the final layout of the paper including the volume, issue and page numbers.

Link to publication

\footnotetext{
General rights rights.

- You may freely distribute the URL identifying the publication in the public portal. please follow below link for the End User Agreement:

www.umlib.nl/taverne-license

Take down policy

If you believe that this document breaches copyright please contact us at:

repository@maastrichtuniversity.nl

providing details and we will investigate your claim.
}

Copyright and moral rights for the publications made accessible in the public portal are retained by the authors and/or other copyright owners and it is a condition of accessing publications that users recognise and abide by the legal requirements associated with these

- Users may download and print one copy of any publication from the public portal for the purpose of private study or research.

- You may not further distribute the material or use it for any profit-making activity or commercial gain

If the publication is distributed under the terms of Article $25 \mathrm{fa}$ of the Dutch Copyright Act, indicated by the "Taverne" license above, 
Neurobiological factors modulating H1-antihistamine induced cognitive impairment

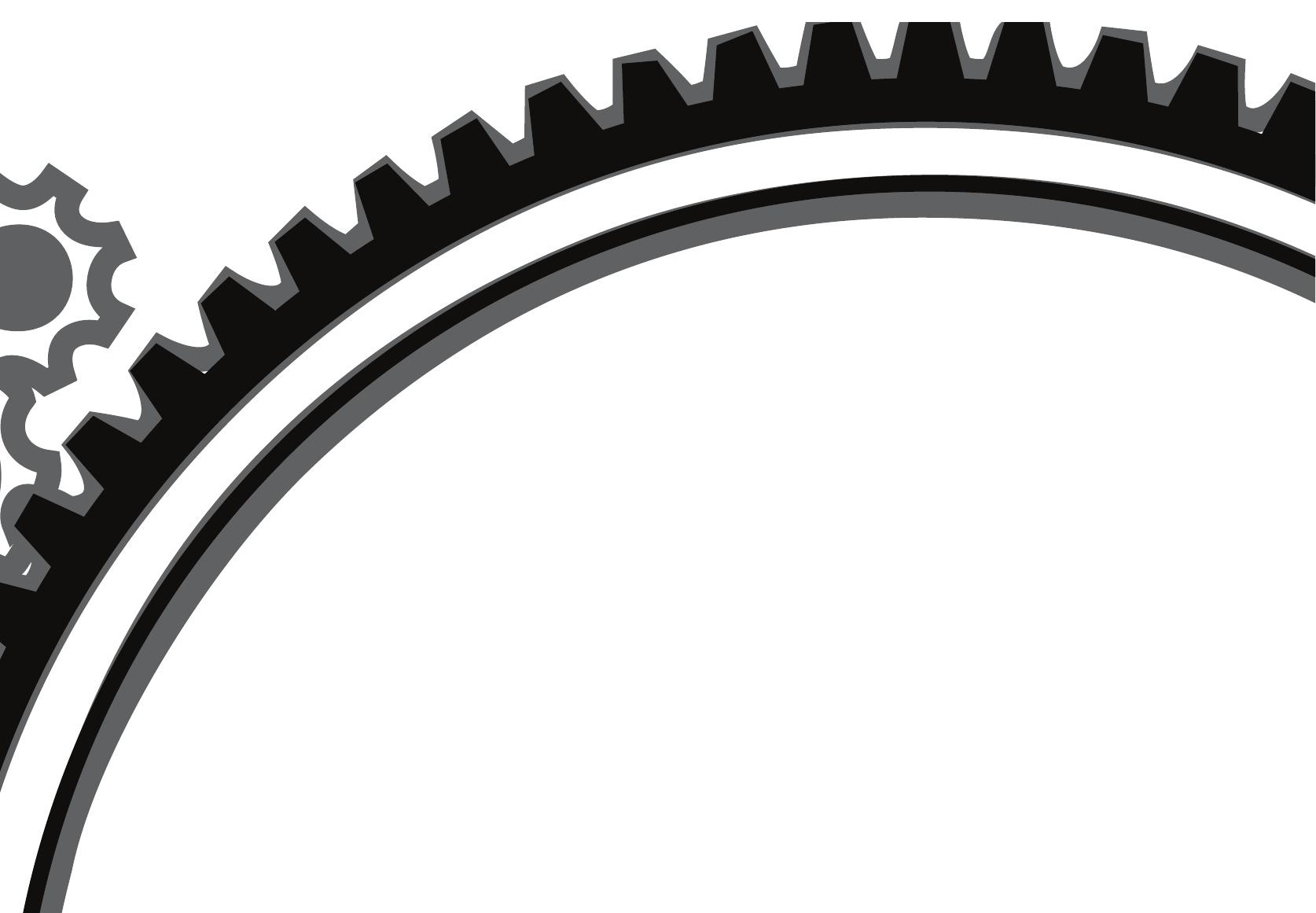




\section{COLOPHON}

(C) S. Conen, Maastricht, 2012

ISBN 978-94-6203-179-1

Neurobiological factors modulating $\mathrm{H} 1$-antihistamine induced cognitive impairment

Thesis with summary in English and Dutch

Cover design: Jaro Wetzer

Typesetting and layout: Joris Igor van Veghel

Printing: Wöhrmann Print Service, Zutphen, The Netherlands 


\section{Neurobiological factors modulating H1-antihistamine induced cognitive impairment}

\section{PROEFSCHRIFT}

ter verkrijging van de graad van doctor aan de Universiteit Maastricht, op gezag van de Rector Magnificus, Prof. Dr. L.L.G. Soete

volgens het besluit van het College van Decanen,

in het openbaar te verdedigen

op vrijdag 23 november 2012 om 12.00 uur

door

Silke Conen 
Promotor:

Prof. Dr. J.G. Ramaekers

Co-promotores:

Dr. E.L. Theunissen

Dr. A. Vermeeren

Beoordelingscommissie:

Prof. Dr. W.J. Riedel (voorzitter)

Dr. A. Blokland

Prof. Dr. K.A. Brookhuis (Rijksuniversiteit Groningen)

Dr. M.A. Mehta (King's College London, London, UK)

Prof. Dr. J.F.M. Smits

The research described in this dissertation was conducted at the

Department of Neuropsychology and Psychopharmacology,

Maastricht University, The Netherlands.

The studies were funded by FAES FARMA S.A., Lejona, Spain (chapter 2)

and Schering-Plough, Oss, The Netherlands (chapter 3).

The research reflects only the author's view.

Publication of this thesis is financially supported by:

FAES FARMA, S.A. Lejona, Spain 


\section{CONTENTS}

$\begin{array}{lll}\text { Chapter } 1 \quad \text { General introduction } & 7\end{array}$

Chapter 2 Acute and subchronic effects of bilastine and hydroxyzine on actual driving performance 17

Chapter 3 Residual effects of esmirtazapine on actual driving performance: overall findings and an exploratory analysis into the role of CYP2D6 phenotype

Chapter 4 Affinity for the P-gp transporter determines CNS sedation of antihistamines

Chapter 5 Short-term effects of morning versus evening dose of hydroxyzine on cognition

Chapter 6 CNS impairing effects of hydroxyzine as a function of histamine availability

Chapter 7 General discussion and concluding remarks

Summary

Samenvatting

Dankwoord

Curriculum Vitae

Publications 


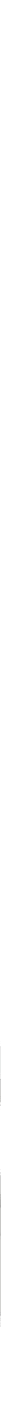




\section{Chapter 1}

\section{General introduction}



$\mathrm{Hl}$-antihistamines are used for the treatment of allergies such as allergic rhinitis or hay fever. They down-regulate allergic inflammation peripherally by inhibiting the effects of histamine. Older generation antihistamines also act on the central nervous system (CNS), thereby reducing the wake-promoting effects of centrally acting histamine, and consequently causing sedation. In case of allergy treatment this sedation is considered an unwanted non-therapeutic effect. However, the same sedative action is widely used and wanted in the treatment of insomnia and anxiety 1 , as both disorders are associated with excessive arousal ${ }^{2-4}$, and this arousal is reduced by the sedative properties of antihistamines. Therefore, older generation antihistamines such as diphenhydramine and hydroxyzine are nowadays used as sleep aids and anxiety treatments ${ }^{5,6}$.

Depending on their clinical use, the central effects of antihistamines are thus either unwanted and therefore should be prevented or may indeed have a therapeutic effect, one which should perhaps be enhanced. On the one hand, for the treatment of allergic rhinitis, the prevention of central antihistamine effects is of importance in order to diminish sedation as this can impair cognitive functions such as attention and car driving ${ }^{7-11}$. This impairment in cognitive functions has far-reaching consequences, because up to $40 \%$ of the population worldwide suffer from allergic rhinitis ${ }^{12}$, and the subsequent use of antihistamines is therefore substantial. On the other hand, in the treatment of insomnia and anxiety, the central effects of antihistamines are of interest and possible enhancement of those effects can be beneficial. For instance, enhancing the central action of $\mathrm{H} 1$-antihistamines and other agents with $\mathrm{H1}$ antihistaminergic properties can lead to possible lower doses of treatment, which in turn might reduce other side-effects.

In order to prevent or enhance central antihistaminergic actions it is important to understand their underlying mechanism, and over the years the improvement of $\mathrm{Hl}$-antihistamines has indeed been drastic because of a significant progress in understanding the role of histamine as a central neurotransmitter ${ }^{13}$. Recent research indicates that several factors modulate the sedative effects of antihistamines such as individual differences in transport across the blood-brain barrier, genetic variation in drug metabolism, and circadian variation in central histaminergic activity. Gaining further knowledge about these mechanisms and their effects in humans may lead to an optimization of antihistaminergic treatments.

\section{Histamine and antihistamines}

Histamine is a chemical messenger synthesized from the amino acid histidine by L-histidine decarboxylase ${ }^{14,15}$. Histamine occurs in various systems such as the 
gastrointestinal system and the immune system where it plays a role in allergy and inflammation. During inflammation, an allergic person comes into contact with an allergen, and the immune system causes IgE antibodies to be secreted which attach to the cell surface of mast cells. Mast cells are the predominant storage sites of histamine in the skin, the bronchial tree and the intestinal mucosa membrane. When IgE antibodies are attached to the mast cells, histamine is released and this release results in rhinitis (hay fever symptoms) and urticaria (skin rash) ${ }^{14,16 .}$

Histamine is also a "wake-promoting" neurotransmitter in the CNS, where it plays a role in the circadian sleep-wake cycle, in the regulation of vigilance, and in cognition ${ }^{13,15}$. Histamine is produced in neurons in the tuberomammillary nucleus (TMN) of the hypothalamus and projects widely throughout the brain, covering the major parts of the cerebrum, cerebellum, posterior pituitary and the spinal cord ${ }^{17}$. Histaminergic neurons fire spontaneously with a variation of firing rate across the sleep-wake cycle. The firing of these neurons is highest during the waking state and less or absent during the sleep stages ${ }^{18-20}$.

There are four histamine receptor subtypes classified: H1R-H4R. H1Rs mediate, amongst others, the afore-mentioned sleep-wake cycles and also play a role in vigilance and learning ${ }^{15}$. The main function of the $\mathrm{H} 2 \mathrm{R}$ is the mediation of gastric release. H3R mediates negative feedback on histamine synthesis and release as an autoreceptor, and plays a role in central and peripheral neurotransmission as it regulates levels of a variety of neurotransmitters as a heteroreceptor ${ }^{21}$. Additionally, it is suggested that H3R might play a role in neurological disorders such as schizophrenia. The H4R is the latest identified member of the histamine receptors and occurs mainly in peripheral tissue ${ }^{14}$. Recent preclinical research indicates that H4R may play a role in allergic asthma and rheumatoid arthritis ${ }^{16}$.

Histamine receptors have a basal activity without ligand binding. This degree of receptor activity in the absence of histamine is called 'constitutive activity'. The active and inactive states of the receptors exist in equilibrium. Histamine acts as an agonist with affinity for the active state and can therefore shift the equilibrium towards this state ${ }^{15,22}$.

$\mathrm{H} 1$-antihistamines act as inverse agonists and bind to the inactive form of the H1R causing a shift in the equilibrium towards the inactive state. They downregulate inflammation and inhibit histamine release ${ }^{15,22}$. H1-antihistamines are generally divided into $1^{\text {st }}$ and $2^{\text {nd }}$ generation antihistamines. The older, $1^{\text {st }}$ generation antihistamines are the more centrally active antihistamines and cause more sedation as compared with the $2^{\text {nd }}$ generation antihistamines. Also other medications can affect H1Rs (such as antidepressants with affinity for the $\mathrm{H} 1 \mathrm{R}$ ) and can subsequently cause sedation. 


\section{Mechanisms of central action}

In order to be centrally active, substances have to cross the blood-brain barrier (BBB). One important function of the BBB is to protect the CNS from the direct influences of potentially unsafe compounds circulating in the blood ${ }^{23}$. The BBB is formed by endothelial cells that are characterized by tight junctions, forming an almost impermeable barrier to fluids ${ }^{24}$. These tight junctions ensure that components that do not dissolve in fats (i.e. lipophobic substances) and that consist of large molecules can not automatically enter the BBB ${ }^{25}$. This mechanism is believed to be involved in the (dis)ability of $\mathrm{H} 1$-antihistamines to enter the brain. However, this mechanism alone can not explain all variations in the amount of sedation caused by $\mathrm{H} 1$-antihistamines. More recent research indicates that other factors might play a role as well 19, 26-29. These factors include, amongst others, (i) the metabolism of $\mathrm{Hl}$-antihistamines; (ii) the ability of antihistamines to bind at the P-glycoprotein transporter; and (iii) time of drug administration relative to circadian fluctuation in brain histamine levels.

\section{Metabolism of H1-antihistamines}

CYP2D6 is the major route of metabolism for, amongst others, antihistamines. The human population can be divided into either poor or extensive metabolizers of CYP2D6, indicating human variability in the kinetics of CYP2D6 substrates 29-31. More precise, about 5-10\% of the Caucasian populations in Europe are poor metabolizers of CYP2D6 substrates which can cause elevated substrate concentrations 30 . This variability in metabolism might be a possible mechanism in variation in central antihistamine actions.

\section{Binding at the P-glycoprotein transporter}

As mentioned before, in order to be centrally active $\mathrm{H} 1$-antihistamines have to enter the BBB. Lipophilicity and consisting of smaller molecules enables certain antihistamines to cross the BBB through diffusion and to block H1 Rs in the CNS ${ }^{9}$. However, P-glycoprotein is another mechanism at the BBB that is believed to play a role in central actions of antihistamines. P-glycoprotein is an active efflux transporter located, amongst others, in the endothelial cells of the BBB and is known to transport a range of different substrates out of the brain ${ }^{27,32,33}$. Even though a substrate for P-glycoprotein can enter the brain through diffusion, 
the penetration of brain tissue can be decreased by this efflux transport. This mechanism is thought to be a reason for the lack of highly sedative effects of non-sedative antihistamines.

\section{Circadian fluctuations in brain histamine levels}

Because histaminergic neurons in the tubero-mammillary nucleus (TMN) fire spontaneously ${ }^{34,35}$ with a variation of firing across the circadian rhythm ${ }^{18-20,36}$. This circadian variation in firing might be the third mechanism playing a role in central antihistamine actions. More precise, it can be expected that the sedative effects of a $1^{\text {st }}$ generation antihistamine would be maximal in the evening when histamine levels are low and less in the morning when histamine levels are high, as a result of increased competition between histamine and the antihistamine in the CNS in the morning.

\section{Aim of the dissertation}

The aim of this dissertation is to improve our understanding of (neuro) pharmacological and pharmacokinetic mechanisms underlying central H1antihistamine effects in humans. These mechanisms are investigated in 4 experimental studies. In the first study, driving performance after administration of a $1^{\text {st }}$ and $2^{\text {nd }}$ generation antihistamine was compared in order to reestablish and confirm the differential sedative profiles between $1^{\text {st }}$ and $2^{\text {nd }}$ generation antihistamines. Next, a study was conducted with similar methodology, but with an additional focus on the role of genetic variation in drug metabolism. Third, a study was conducted in order to elucidate the role of the P-glycoprotein transporter in the impairing effects of antihistamines, focusing on behavior as well as on brain activation as measured with fMRI. Lastly, sedative action of antihistamines was studied as a function of circadian fluctuations in brain histamine levels, focusing on behavior as well as on electro-cortical activity (event-related potentials).

\section{Outline of the dissertation}

In chapter 2 and chapter 3 the role of $\mathrm{Hl}$-antihistamines on actual driving performance is discussed in order to establish the pharmacodynamic effects of $\mathrm{H} 1$-antihistamines and hence to evaluate antihistaminergic effects on real life performance. More precisely, chapter 2 describes a study assessing the difference 
between 1 st and 2nd generation $\mathrm{H1}$-antihistamines on driving performance in 22 healthy volunteers. The effects of two doses of bilastine $(20 \mathrm{an} 40 \mathrm{mg})$ on actual driving after single and repeated administration were compared with placebo and the 1 st generation $\mathrm{H} 1$-antihistamine hydroxyzine $(50 \mathrm{mg})$.

In chapter 3, a study is presented in which the residual effects on driving performance were assessed in 32 healthy volunteers who received nocturnal doses of esmirtazapine (1.5 and $4.5 \mathrm{mg}$ ) during one week treatment. These effects were compared with placebo and the hypnotic zopiclone $(7.5 \mathrm{mg}$ ). Additionally, CYP2D6 phenotyping was determined in order to distinguish poor metabolizers from extensive metabolizers of esmirtazapine.

Chapter 4 presents a study assessing the role of the P-glycoprotein transporter in central antihistamine effects. The effects of combining 2nd generation antihistamine cetirizine with verapamil, a P-gp blocker, in 13 volunteers were investigated. Participants received cetirizine $(15 \mathrm{mg})$, verapamil $(120 \mathrm{mg})$, a combination of cetirizine + verapamil, and a placebo. Brain activity was assessed during an attention task in a 3-T magnetic resonance scanner.

Chapter 5 and chapter 6 present studies investigating the role of time of administration on sedation caused by $1^{\text {st }}$ generation $\mathrm{Hl}$-antihistamine hydroxyzine. Chapter 5 explores the effects of evening and morning doses of hydroxyzine $(50 \mathrm{mg}$ ) on cognition in 18 healthy volunteers. Performance was assessed using attention and impulsivity tasks.

Chapter 6 evaluates to what extend event-related potentials are affected by time of administration of hydroxyzine $(50 \mathrm{mg})$ in 18 healthy volunteers. The effects were measured after an evening dose and after a morning dose, and compared with placebo.

Finally, in chapter 7 the results from the previous chapters are summarized and discussed. Furthermore, clinical implications are discussed and suggestions for further research are proposed.

\section{References}

1. Llorca, P. M. et al. Efficacy and safety of hydroxyzine in the treatment of generalized anxiety disorder: a 3-month double-blind study. J Clin Psychiatry 63, 1020-1027 (2002).

2. Bonnet, M. H. \& Arand, D. L. Hyperarousal and insomnia: state of the science. Sleep Med Rev 14, 9-15 (2010).

3. Nofzinger, E. A. et al. Functional neuroimaging evidence for hyperarousal in insomnia. Am J Psychiatry 161, 2126-2128 (2004).

4. Wilson, S. \& Nutt, D. J. Sleep disorders (Oxford University Press, New York, 2008).

5. Guaiana, G., Barbui, C. \& Cipriani, A. Hydroxyzine for generalised anxiety disorder. Cochrane Database Syst Rev, CD006815 (2010). 
6. Zhang, D. et al. Next-day residual sedative effect after nighttime administration of an over-the-counter antihistamine sleep aid, diphenhydramine, measured by positron emission tomography. J Clin Psychopharmacol 30, 694-701 (2010).

7. Jauregui, I. et al. H1 antihistamines: psychomotor performance and driving. J Invest Allerg Clin 16 Suppl 1, 37-44 (2006).

8. Kay, G. G. The effects of antihistamines on cognition and performance. J Allergy Clin Immun 105, S622-S627. (2000).

9. Montoro, J. et al. Effect of H1 antihistamines upon the central nervous system. J Investig Allergol Clin Immunol 16 Suppl 1, 24-28 (2006).

10. Tashiro, M. et al. Brain histamine H1 receptor occupancy of orally administered antihistamines, bepotastine and diphenhydramine, measured by PET with 11C-doxepin. Brit J Clin Pharmaco 65, 811-821 (2008).

11. Theunissen, E. L., Vermeeren, A. \& Ramaekers, J. G. Repeated-dose effects of mequitazine, cetirizine and dexchlorpheniramine on driving and psychomotor performance. Brit $J$ Clin Pharmaco 61, 79-86 (2006).

12. Katelaris, C. H. et al. Prevalence and diversity of allergic rhinitis in regions of the world beyond Europe and North America. Clin Exp Allergy 42, 186-207 (2011).

13. Stahl, S. M. Selective histamine H1 antagonism: novel hypnotic and pharmacologic actions challenge classical notions of antihistamines. CNS Spectr 13, 1027-1038 (2008).

14. Haas, H. L., Sergeeva, O. A. \& Selbach, O. Histamine in the nervous system. Physiol Rev 88, 1183-1241 (2008).

15. Simons, F. E. \& Simons, K. J. Histamine and H1-antihistamines: celebrating a century of progress. J Allergy Clin Immunol 128, 1139-1150 (2011).

16. Thurmond, R. L., Gelfand, E. W. \& Dunford, P. J. The role of histamine H1 and H4 receptors in allergic inflammation: the search for new antihistamines. Nat Rev Drug Discov 7, 41-53 (2008).

17. Haas, H. \& Panula, P. The role of histamine and the tuberomamillary nucleus in the nervous system. Nat Rev Neurosci 4, 121-130 (2003).

18. Sakai, K., Mansari, M., Lin, J. S., Zhang, J. G. \& Vanni-Mercier, G. in The diencephalon and sleep (eds. Mancia, M. \& Marini, M.) (Raven, New York, 1990).

19. Tuomisto, L., Lozeva, V., Valjakka, A. \& Lecklin, A. Modifying effects of histamine on circadian rhythms and neuronal excitability. Behav Brain Sci 124, 129-135 (2001).

20. Vanni-Mercier, G., Gigout, S., Debilly, G. \& Lin, J. S. Waking selective neurons in the posterior hypothalamus and their response to histamine H3-receptor ligands: an electrophysiological study in freely moving cats. Behav Brain Res 144, 227-241 (2003).

21. Lin, J. S., Anaclet, C., Sergeeva, O. A. \& Haas, H. L. The waking brain: an update. Cell Mol Life Sci 68, 2499-2512 (2011).

22. Leurs, R., Church, M. K. \& Taglialatela, M. H1-antihistamines: inverse agonism, antiinflammatory actions and cardiac effects. Clin Exp Allergy 32, 489-498 (2002).

23. Bernacki, J., Dobrowolska, A., Nierwinska, K. \& Malecki, A. Physiology and pharmacological 
role of the blood-brain barrier. Pharmacol Rep 60, 600-622 (2008).

24. Grant, G. A., Abbott, N. J. \& Janigro, D. Understanding the Physiology of the Blood-Brain Barrier: In Vitro Models. News Physiol Sci 13, 287-293 (1998).

25. Hawkins, B. T. \& Davis, T. P. The blood-brain barrier/neurovascular unit in health and disease. Pharmacol Rev 57, 173-185 (2005).

26. Brockmoller, J., Meineke, I. \& Kirchheiner, J. Pharmacokinetics of mirtazapine: enantioselective effects of the CYP2D6 ultra rapid metabolizer genotype and correlation with adverse effects. Clin Pharmacol Ther 81, 699-707 (2007).

27. Chen, C., Hanson, E., Watson, J. W. \& Lee, J. S. P-glycoprotein limits the brain penetration of nonsedating but not sedating H1-antagonists. Drug Metab Dispos 31, 312-318 (2003).

28. Mahar Doan, K. M. et al. Steady-state brain concentrations of antihistamines in rats: interplay of membrane permeability, P-glycoprotein efflux and plasma protein binding. Pharmacology 72, 92-98 (2004).

29. Tomalik-Scharte, D., Lazar, A., Fuhr, U. \& Kirchheiner, J. The clinical role of genetic polymorphisms in drug-metabolizing enzymes. Pharmacogenomics 8, 4-15 (2008).

30. Dorne, J. L., Walton, K., Slob, W. \& Renwick, A. G. Human variability in polymorphic CYP2D6 metabolism: is the kinetic default uncertainty factor adequate? Food Chem Toxicol 40, 1633-1656 (2002).

31. Ingelman-Sundberg, M., Sim, S. C., Gomez, A. \& Rodriguez-Antona, C. Influence of cytochrome P450 polymorphisms on drug therapies: pharmacogenetic, pharmacoepigenetic and clinical aspects. Pharmacol Ther 116, 496-526 (2007).

32. Bartra, J. et al. Interactions of the H1 antihistamines. J Investig Allergol Clin Immunol 16 Suppl 1, 29-36 (2006).

33. Zhou, S. F., Liu, J. P. \& Chowbay, B. Polymorphism of human cytochrome P450 enzymes and its clinical impact. Drug Metab Rev 41, 89-295 (2009).

34. Haas, H. L. \& Reiner, P. B. Membrane properties of histaminergic tuberomammillary neurones of the rat hypothalamus in vitro. J Physiol 399, 633-646 (1988).

35. Reiner, P. B., Heimrich, B., Keller, F. \& Haas, H. L. Organotypic culture of central histamine neurons. Brain Res 442, 166-170 (1988).

36. Brown, R. E., Stevens, D. R. \& Haas, H. L. The physiology of brain histamine. Prog Neurobiol 63, 637-672 (2001). 


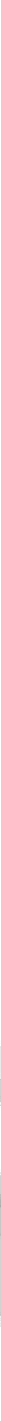




\section{Chapter 2}

\section{Acute and subchronic effects of bilastine and hydroxyzine on actual driving performance}

Published as:

Conen S, Theunissen EL, Van Oers ACM, Valiente R, Ramaekers JG. (2011). Acute and subchronic effects of bilastine (20 and $40 \mathrm{mg}$ ) and hydroxyzine $(50 \mathrm{mg})$ on actual driving performance in healthy volunteers. Journal of Psychopharmacology, 25, 1517-1523. 



\section{Abstract}

Bilastine is a new $2^{\text {nd }}$ generation H1-antihistamine. Although bilastine has been demonstrated to produce no or little performance impairment on laboratory tests, it cannot be excluded that it produces impairments in real life performance such as driving. This study aims to assess the effects of two doses of bilastine (20 and $40 \mathrm{mg}$ ) on actual driving after single and repeated administration. Hydroxyzine $50 \mathrm{mg}$ was included as an active control. Twenty-two participants (11 females and 11 males) were tested in a placebo-controlled, randomized, double blind, 4 way cross-over design. Participants were treated with once daily doses for 8 consecutive days. On day 1 and 8 of each treatment period participants performed an actual highway driving test. The primary variable was the standard deviation of lateral position (SDLP), which is a measure of weaving. Results demonstrated that hydroxyzine significantly increased SDLP on days 1 and 8 of treatment. Bilastine did not affect SDLP. It is concluded that hydroxyzine produces severe driving impairment after single doses and that this impairment only partly mitigates over time due to a lack of complete tolerance. Bilastine did not produce any driving impairment after single and repeated doses and can be safely used in traffic in doses up to $40 \mathrm{mg}$.

\section{Introduction}

Antihistamines are the most commonly used medications for the treatment of allergic rhinitis. $\mathrm{H} 1$-antihistamines can be divided into $1^{\text {st }}$ and $2^{\text {nd }}$ generation antihistamines. $1^{\text {st }}$ generation antihistamines easily penetrate the blood brain barrier and block $\mathrm{H} 1$ receptors in the CNS, causing unwanted side effects such as sleepiness and sedation. $2^{\text {nd }}$ generation antihistamines are less likely to penetrate the brain and produce no or only mild CNS side effects ${ }^{1-5}$.

Bilastine is a new $2^{\text {nd }}$ generation $\mathrm{H} 1$-antihistamine that has been developed for the treatment of allergic rhinoconjunctivitis and chronic urticaria. Bilastine has shown to be rapidly absorbed after oral administration, with a $\mathrm{t}_{\max }$ of 1-1.5 hrs and a half-life of 10-12 hrs ${ }^{6}$. Bilastine is highly selective for the $\mathrm{H} 1$ receptor as demonstrated in in vivo and in vitro studies ${ }^{7,8}$. The latter showed that bilastine is equally potent as cetirizine, so being equally effective in treating allergic 
rhinitis and chronic urticaria, and more potent than fexofenadine. Moreover, bilastine has been found to have a longer duration of action than fexofenadine ${ }^{9}$. First in-man-studies suggest that bilastine $20 \mathrm{mg}$ is safe and well-tolerated with a similar effectiveness as cetirizine and desloratadine, but with less potential to produce adverse events ${ }^{6}$. The most commonly reported adverse events for bilastine were headache, somnolence and fatigue. Bilastine in doses up to $40 \mathrm{mg}$ did not produce psychomotor impairment in healthy volunteers as compared to placebo. Impairments only started to emerge at bilastine doses of $80 \mathrm{mg}{ }^{10}$.

Although bilastine produced no or little performance impairment in laboratory tests of cognitive and psychomotor function, it cannot be excluded that the drug produces performance impairments in real life performance such as driving. Previous studies have demonstrated that tests measuring actual driving performance are more sensitive to sedative properties of psychoactive drugs than standard laboratory tests of psychomotor skills 5, 11-13. Previous driving studies with antihistamines, for example, have demonstrated that even the so called 'non-sedative' antihistamines can produce impairment of driving performance at therapeutic doses and/or double doses. Most of these studies have employed a standardized driving test ${ }^{14}$ that is conducted on a primary highway open to normal traffic, for quantifying antihistamine effects on driving $5,12,13$. The primary outcome measure of the standard driving tests is the standard deviation of lateral position (SDLP), a measure of weaving. The standard driving test has also been calibrated for a wide range of blood alcohol concentrations (BAC) in order to quantify drug effects on driving in BAC equivalents ${ }^{15}$.

The present study was designed to assess the effects of two doses of bilastine (20 and $40 \mathrm{mg}$ ) on actual driving performance after single and repeated dosing, and to assess the safety and tolerability of bilastine 20 and $40 \mathrm{mg}$. Hydroxyzine $50 \mathrm{mg}$, a $~^{\text {st }}$ generation antihistamine, was also included as a control treatment to demonstrate the sensitivity of the driving measure to the sedative effects of antihistamines.

\section{Methods}

\section{Subjects}

Eleven healthy male and 11 healthy female volunteers (age range 21 to 45 years; mean \pm SD: $29.5 \pm 1.8$ years) were recruited through poster advertisement. Participants were screened by means of a medical questionnaire and a physical examination. The latter included a 12-lead electrocardiogram evaluation, blood chemistry and haematology, urinalysis, and drug and pregnancy screening. All participants possessed a valid driver's license for more than 3 years and had 
driving experience of at least $5000 \mathrm{~km}$ per year on average. Furthermore, participants had a body mass index of 19 to $30 \mathrm{~kg} / \mathrm{m}^{2}$, and expressed willingness to use a double barrier contraceptive method.

Volunteers with a history of medical or psychiatric illness, hypersensitivity to H1-antihistamines, and/or seasonal allergic rhinitis or urticaria treated by antihistamines were excluded from the study. Additional exclusion criteria were alcohol consumption of more than 21 units per week; caffeine consumption of more than 6 cups per day; regular drinking of grapefruit juice; treatment by atropine or atropine-like drugs; treatment by a drug depressant of the central nervous system, and regular use of sedatives. Females could not participate when pregnant or breast feeding.

The study was approved by the standing medical ethics committee of Maastricht University and was carried out in compliance with the current revision of the Declaration of Helsinki (Seoul modification, 2008), International Conference on Harmonization guideline for Good Clinical Practice. Participants gave their written informed consent prior to study participation.

\section{Design and treatments}

The study was conducted according to a randomized, double blind, 4 way crossover design with a placebo control, a positive control (hydroxyzine $50 \mathrm{mg}$ ), and bilastine $20 \mathrm{mg}$ and $40 \mathrm{mg}$. Participants were treated with once daily doses for 8 consecutive days. Treatment periods were separated by a washout period of at least 7 days. All treatments were administered as identical encapsulated tablets to ensure blinding.

During day 1 and day 8 , the trial medication was taken at the study site under supervision of a research associate at $12.00 \mathrm{hrs}$. During days 2 to 7 , trial medication was taken during the evening at the participants' home. Time of drug intake was recorded in a diary. As a general rule, trial medication was taken 1 hour before, or 2 hours after dinner on days 2 to 7 .

\section{Procedure}

Participants received a training of the standardized driving tests prior to the first treatment period. At arrival on the study site, on day 1 and day 8 of each treatment period, drug screens and pregnancy tests were conducted. On day 1 blood samples and urinalysis were taken prior to dosing. On day 8 blood samples, urinalysis and ECG measurements were taken after the highway driving test. On day 1 and day 8, approximately 1 hour after intake of the medication $\left(\mathrm{t}_{\max }\right)$ participants commenced the standard highway driving test. A detailed overview of the scheduled assessments is given in Table 1 . 
Table 1 Study overview

\begin{tabular}{|c|c|c|c|c|c|}
\hline \multirow[b]{2}{*}{ Assessments } & \multirow[t]{2}{*}{ Screening } & \multicolumn{2}{|c|}{ Treatment periods } & \multirow[b]{2}{*}{ Day 8} & \multirow{2}{*}{$\begin{array}{c}\text { Washou } \\
\text { Period } \\
\text { Day 9-15 }\end{array}$} \\
\hline & & Day 1 & Day 2-7 & & \\
\hline Dosing ${ }^{1}$ & & • & $\bullet$ & - & \\
\hline Medical history & • & & & & \\
\hline $\begin{array}{l}\text { Physical } \\
\text { examination }\end{array}$ & • & $\bullet$ & & - & \\
\hline $\begin{array}{l}\text { Pregnancy test } \\
\text { (women only) }\end{array}$ & - & - & & - & \\
\hline Drug screen & - & • & & - & \\
\hline ECG & - & & & • & \\
\hline Vital signs & • & • & & - & \\
\hline Highway driving test & Training & • & & • & \\
\hline $\begin{array}{l}\text { Blood sampling / } \\
\text { urinalysis² }\end{array}$ & • & • & & - & \\
\hline $\begin{array}{l}\text { concomitant } \\
\text { medication }\end{array}$ & \multicolumn{5}{|c|}{ Whenever concomitant medication was used } \\
\hline Adverse events & \multicolumn{5}{|c|}{ Whenever a (serious) adverse event occurred } \\
\hline
\end{tabular}

${ }^{1}$ On day 1 and 8 trial medication was ingested at $12.00 \mathrm{hrs}$. On day 2-7 trial medication was ingested 1 hour prior or 2 hours after dinner.

2 On day 1 blood samples and urinalysis were taken prior to dosing. On day 8 blood samples and urinalysis were taken after highway driving test.

\section{Driving performance test}

The highway driving test was standardised in 1982 for drug screening purposes and has since been used for measuring drug effects on driving performance 14, 16. In the highway driving test participants operate a specially instrumented automobile over a $100 \mathrm{~km}$ (62 miles) primary highway circuit ${ }^{17}$. The participants' task is to maintain a constant speed of $95 \mathrm{~km} /$ hour (59 miles/hour), and a steady lateral position between the delineated boundaries of the right (slower) traffic lane. A licensed driving instructor, who has access to dual controls so that he can intervene if necessary, accompanies the participant. A video camera at the back of the car records the lateral position of the automobile relative to the left laneline. This signal is digitised at $4 \mathrm{~Hz}$ and stored on an onboard computer disk-file for editing. The offline editing routine involves the removal of data segments that show signal loss, disturbance, turnarounds or passing manoeuvres. The remaining data is used to calculate the Standard Deviation of Lateral Position 
(SDLP), Speed and Standard Deviation of Speed (SDSP). SDLP is the primary outcome variable. It is a measure of the road tracking error, which in practical terms is a composite index of allowed weaving, swerving and overcorrecting. Speed and SDSP are secondary control measures.

The clinical relevance of a change in SDLP has been previously determined by establishing the dose-effect relationship between blood alcohol concentration (BAC) and the SDLP ${ }^{15}$. The results indicated that with a BAC of $0.5 \mathrm{mg} / \mathrm{ml}$ there is an increase in SDLP of about $2.4 \mathrm{~cm}$. Because a BAC of $0.5 \mathrm{mg} / \mathrm{ml}$ is associated with a significant higher risk for traffic accidents ${ }^{18}$, a SDLP of 2.4 $\mathrm{cm}$ is considered to represent a clinically relevant drug effect.

\section{Subjective measurements}

The Groningen Subjective Quality of Sleep Questionnaire ${ }^{19}$ was filled out every morning in order to asses the participants' sleep quality and sleep duration of the previous night. This questionnaire scores sleep complaints, ranging from 0 (good sleep) to 14 (bad sleep).

Prior to the highway driving test participants were asked to rate their subjective feeling of sedation on a visual analogue scale ranging from $0 \mathrm{~mm}$ (no sedation) to $100 \mathrm{~mm}$ (very much sedation), and to rate their expected driving ability on a visual analogue scale ranging from $0 \mathrm{~mm}$ (no influence from the medication on driving ability) to $100 \mathrm{~mm}$ (very much influence from the medication on driving ability). Furthermore, particpants were asked to rate their subjective driving quality after completion of the test on visual analogue scales ranging from $0 \mathrm{~mm}$ (very good driving) to $100 \mathrm{~mm}$ (very bad driving). The driving instructor also rated the participants' driving ability on $100 \mathrm{~mm}$ visual analogue scales ranging from 0 (very good driving) to 100 (very bad driving), and the amount of sedation on $100 \mathrm{~mm}$ visual analogue scales ranging from 0 (no sedation) to 100 (complete sedation). On days 2 to 7 participants reported their drowsiness on a visual analogue scale 1 hour post dosing. Possible adverse events and concomitant medication were also reported.

\section{Safety assessment}

Only standard biological tests were conducted at the screening visit and at test days as no particular risk has been described with bilastine ${ }^{6,10,20}$. The biological tests included the analysis of haematology parameters, blood chemistry and urinalyses. Vital signs were measured at the screening visit and at test days. Furthermore, an ECG was carried out at the screening visit and at day 8 of each treatment period. 


\section{Statistics}

A power calculation revealed that a sample of 20 participants is sufficient for providing a power of more than $90 \%$ for detecting a clinically relevant effect of $2.4 \mathrm{~cm}$ critical mean difference between a drug and placebo in SDLP.

All driving and subjective parameters were analyzed using repeated measure Analysis of Variance (ANOVA) with Treatment (placebo, bilastine 20 $\mathrm{mg}$, bilastine $40 \mathrm{mg}$, and hydroxyzine $50 \mathrm{mg}$ ) and Time of treatment (day 1 and day 8 ) as within subject factors, and Gender as a between subject factor. Analyses showing a significant main effect $(\mathrm{p}<0.05)$ of Treatment or Treatment $\mathrm{x}$ Time of treatment, were followed by separate drug-placebo contrasts on each separate treatment day. The Statistical Package for the Social Sciences (SPSS) version 15.0 was used for the achievement of all listings, tables and analyses.

\section{Results}

A total of 22 participants entered the study. However, only 18 participants (9 male and 9 female) were included in the per protocol population, which is the sample of interest for the evaluation of efficacy. Two participants were not included because of protocol violations. In one case, the participant was tested positive on a urine drug test for THC. The other case was excluded because of participation in another clinical study in the previous three months. Two other participants were not included because of missing data. For the analysis of safety and adverse events, all 22 participants were included. Demographics are summarized in Table 2. 
Table 2 Demographics for the safety population and the per protocol population

\begin{tabular}{llll}
\hline & & $\begin{array}{l}\text { Safety population } \\
(\mathbf{N}=\mathbf{2 2})\end{array}$ & $\begin{array}{l}\text { Protocol population } \\
\mathbf{( N = 1 8 )}\end{array}$ \\
\hline \multirow{2}{*}{ Gender (N (\%)) } & Female & $11(50)$ & $9(50)$ \\
& Male & $11(50)$ & $9(50)$ \\
\hline Race (N (\%)) & Caucasian & $22(100)$ & $18(100)$ \\
\hline \multirow{2}{*}{ Age (Years) } & Mean (SD) & $29.9(7.9)$ & $29.5(7.7)$ \\
& Median & 26.5 & 26.5 \\
\hline Height (cm) & Min-Max & $21-45$ & $21-45$ \\
\hline Mean (SD) & $175.8(10.5)$ & $175(10.8)$ \\
& Median & 174.5 & 173 \\
& Min-Max & $160-197$ & $160-197$ \\
\hline Bodght (kg) & Mean (SD) & 74.8 & $75.4(11.7)$ \\
& Median & 72.5 & 72.5 \\
& Min-Max & $57-105$ & $57-105$ \\
\hline
\end{tabular}

Note: $\mathrm{N}=$ number of subjects; $\mathrm{SD}=$ standard deviation; Min = minimum; Max = maximum.

\section{Driving performance}

A summary of descriptives and statistics on parameters from the highway driving test is presented in Table 3. There were no significant effects of Gender or Gender by Treatment on any of the driving measures. Consequently, the factor Gender was dropped from the model.

The overall effects of Treatment $\left(\mathrm{F}_{3,15}=12.65 ; \mathrm{p}<0.001\right)$ and Treatment $\mathrm{x}$ Time of treatment $\left(\mathrm{F}_{3,15}=3.64 ; \mathrm{p}<0.05\right)$ on SDLP reached significance. Drugplacebo contrasts revealed that SDLP was significantly increased after treatment with hydroxyzine $50 \mathrm{mg}$ on day 1 (mean increase $4.76 \mathrm{~cm} ; \mathrm{F}_{1,17}=41.82 ; \mathrm{p}<0.001$ ) as well as on day 8 (mean increase $2.24 \mathrm{~cm} ; \mathrm{F}_{1,17}=14.30 ; \mathrm{p}=0.001$ ). Both bilastine $20 \mathrm{mg}$ and bilastine $40 \mathrm{mg}$ did not increase SDLP relative to placebo on both test days. Furthermore, hydroxyzine - induced impairment was significantly higher on day 1 compared to day $8\left(\mathrm{~F}_{1,17}=8.2 ; \mathrm{p}=0.011\right)$. Mean $(+\mathrm{SE})$ SDLP in each condition and for both days is shown in Figure 1. 


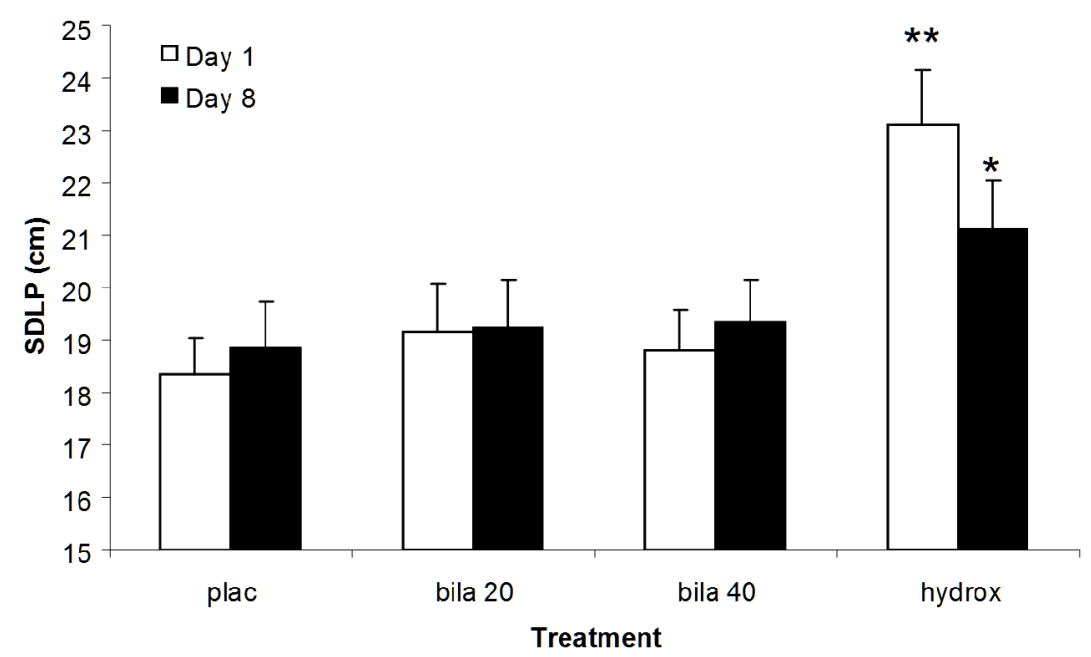

Figure 1 Mean (+ SE) SDLP for each treatment on Day 1 and Day 8. Treatments are Placebo (plac), Bilastine $20 \mathrm{mg}$ (bila 20), bilastine $40 \mathrm{mg}$ (bila 40), and hydroxyzine $50 \mathrm{mg}$ (hydrox). ${ }^{*}=$ significant differences from placebo, $\mathrm{P}<0.01$. ${ }^{* *}=$ significant differences from placebo, $\mathrm{P}<0.001$.

Mean speed was not significantly affected by Treatment, Time of treatment or Treatment $x$ Time of treatment. However, a significant Treatment $x$ Time of treatment interaction was found for $\operatorname{SDSP}\left(\mathrm{F}_{3,15}=4.32 ; \mathrm{p}<0.05\right)$. Drug placebo contrasts revealed that the SDSP for bilastine $40 \mathrm{mg}$ was significantly increased on day $1\left(\mathrm{~F}_{1,17}=5.25 ; \mathrm{p}<0.05\right)$, but not on day $8\left(\mathrm{~F}_{1,17}=2.32 ; \mathrm{p}=0.15\right)$. Similarly, drug placebo contrasts for hydroxyzine showed that the SDSP was significantly increased on day $1\left(\mathrm{~F}_{1,17}=5.87\right.$; $\left.\mathrm{p}<0.05\right)$, but not on day $8\left(\mathrm{~F}_{1,17}=0.26 ; \mathrm{p}=0.62\right)$. Mean (SE) scores on driving and subjective measures, and a summary of overall effects are presented in Table 3. 
Table 3 Mean (SE) scores on driving and subjective measures in all treatment conditions and a summary of overall effects of Treatment, Time of treatment and their interaction. Significant drug-placebo contrast are indicated by $*(\mathrm{p}<.05)$ and $* *(\mathrm{p}<.001)$. Treatments are placebo (Plac), bilastine $20 \mathrm{mg}$ (Bila 20), bilastine $40 \mathrm{mg}$ (Bila 40), and hydroxyzine $50 \mathrm{mg}$ (Hydrox).

\begin{tabular}{|c|c|c|c|c|c|c|c|c|c|}
\hline & \multirow[b]{2}{*}{ SDLP } & \multicolumn{2}{|c|}{ Driving test } & \multicolumn{2}{|c|}{$\begin{array}{l}\text { Subjective Driving } \\
\text { Quality }\end{array}$} & \multirow{2}{*}{$\begin{array}{l}\text { Seda- } \\
\text { tion }\end{array}$} & \multirow{2}{*}{$\begin{array}{l}\text { Driving } \\
\text { Quality } \\
\text { Rated } \\
\text { by } \\
\text { Instruc- } \\
\text { tor }\end{array}$} & \multirow{2}{*}{$\begin{array}{l}\text { Sedation } \\
\text { Rated } \\
\text { by } \\
\text { Instruc- } \\
\text { tor }\end{array}$} & \multirow{2}{*}{$\begin{array}{l}\text { Sleep } \\
\text { Quality }\end{array}$} \\
\hline & & $\begin{array}{l}\text { Mean } \\
\text { speed }\end{array}$ & $S D S P$ & $\begin{array}{l}\text { Pre- } \\
\text { test }\end{array}$ & $\begin{array}{l}\text { Post- } \\
\text { test }\end{array}$ & & & & \\
\hline \multicolumn{10}{|l|}{ Day 1} \\
\hline Plac & $\begin{array}{l}18.6 \\
(0.7)\end{array}$ & $\begin{array}{l}95.2 \\
(0.2)\end{array}$ & $\begin{array}{l}1.7 \\
(0.1)\end{array}$ & $\begin{array}{l}13.9 \\
(3.1)\end{array}$ & $\begin{array}{l}25.1 \\
(4.3)\end{array}$ & $\begin{array}{l}14.3 \\
(2.8)\end{array}$ & $\begin{array}{l}29.6 \\
(2.0)\end{array}$ & $\begin{array}{l}10.6 \\
(1.7)\end{array}$ & $\begin{array}{c}0.6 \\
(1.2)\end{array}$ \\
\hline Bila 20 & $\begin{array}{l}19.2 \\
(0.9)\end{array}$ & $\begin{array}{l}95.3 \\
(0.3)\end{array}$ & $\begin{array}{l}1.7 \\
(0.2)\end{array}$ & $\begin{array}{l}16.3 \\
(3.4)\end{array}$ & $\begin{array}{l}28.2 \\
(3.6)\end{array}$ & $\begin{array}{l}13.3 \\
(2.0)\end{array}$ & $\begin{array}{l}31.8 \\
(3.0)\end{array}$ & $7.8(1.7)$ & $\begin{array}{l}1.3 \\
(0.6)\end{array}$ \\
\hline Bila 40 & $\begin{array}{l}18.8 \\
(0.8)\end{array}$ & $\begin{array}{l}95.3 \\
(0.3)\end{array}$ & $\begin{array}{c}1.9 \\
(0.1)^{*}\end{array}$ & $\begin{array}{l}11.8 \\
(3.0)\end{array}$ & $\begin{array}{l}25.4 \\
(2.7)\end{array}$ & $\begin{array}{l}11.4 \\
(3.7)\end{array}$ & $\begin{array}{c}36.6 \\
(3.7)^{*}\end{array}$ & $\begin{array}{l}10.7 \\
(3.3)\end{array}$ & $\begin{array}{c}0.8 \\
(0.3)\end{array}$ \\
\hline Hydrox & $\begin{array}{c}23.1 \\
(1.0)^{* *}\end{array}$ & $\begin{array}{l}95.3 \\
(0.3)\end{array}$ & $\begin{array}{c}1.9 \\
(0.1)^{*}\end{array}$ & $\begin{array}{l}14.3 \\
(3.1)\end{array}$ & $\begin{array}{c}43.6 \\
(4.5)^{* *}\end{array}$ & $\begin{array}{l}17.3 \\
(3.3)\end{array}$ & $\begin{array}{c}41.4 \\
(3.8)^{* *}\end{array}$ & $\begin{array}{l}25.4 \\
(4.4)^{*}\end{array}$ & $\begin{array}{l}1.6 \\
(0.7)\end{array}$ \\
\hline \multicolumn{10}{|l|}{ Day 8} \\
\hline Plac & $\begin{array}{l}18.9 \\
(0.9)\end{array}$ & $\begin{array}{l}95.6 \\
(0.3)\end{array}$ & $\begin{array}{l}1.9 \\
(0.2)\end{array}$ & $\begin{array}{l}12.7 \\
(3.5)\end{array}$ & $\begin{array}{l}24.6 \\
(3.7)\end{array}$ & $\begin{array}{l}12.2 \\
(3.6)\end{array}$ & $\begin{array}{l}29.2 \\
(1.9)\end{array}$ & $\begin{array}{l}10.0 \\
(1.8)\end{array}$ & $\begin{array}{l}1.2 \\
(0.5)\end{array}$ \\
\hline Bila 20 & $\begin{array}{l}19.3 \\
(0.9)\end{array}$ & $\begin{array}{l}95.4 \\
(0.3)\end{array}$ & $\begin{array}{l}1.9 \\
(0.2)\end{array}$ & $\begin{array}{l}16.1 \\
(3.3)\end{array}$ & $\begin{array}{l}30.7 \\
(4.6)\end{array}$ & $\begin{array}{l}18.2 \\
(3.9)\end{array}$ & $\begin{array}{l}33.3 \\
(3.1)\end{array}$ & $\begin{array}{l}12.6 \\
(4.3)\end{array}$ & $\begin{array}{l}1.4 \\
(0.6)\end{array}$ \\
\hline Bila 40 & $\begin{array}{l}19.4 \\
(0.8)\end{array}$ & $\begin{array}{l}95.7 \\
(0.2)\end{array}$ & $\begin{array}{l}1.7 \\
(0.1)\end{array}$ & $\begin{array}{l}12.8 \\
(3.3)\end{array}$ & $\begin{array}{l}28.2 \\
(3.9)\end{array}$ & $\begin{array}{l}14.6 \\
(3.7)\end{array}$ & $\begin{array}{c}37.7 \\
(3.8)^{*}\end{array}$ & $\begin{array}{l}10.5 \\
(2.0)\end{array}$ & $\begin{array}{l}0.8 \\
(0.3)\end{array}$ \\
\hline Hydrox & $\begin{array}{c}21.1 \\
(1.0)^{*}\end{array}$ & $\begin{array}{l}95.4 \\
(0.3)\end{array}$ & $\begin{array}{c}1.9 \\
(0.2)\end{array}$ & $\begin{array}{l}26.5 \\
(5.1)\end{array}$ & $\begin{array}{c}33.2 \\
(3.6)^{* *}\end{array}$ & $\begin{array}{l}21.3 \\
(3.8)\end{array}$ & $\begin{array}{c}39.6 \\
(4.0)^{* *}\end{array}$ & $\begin{array}{l}18.6 \\
(3.5)^{*}\end{array}$ & $\begin{array}{l}0.7 \\
(0.3)\end{array}$ \\
\hline \multicolumn{10}{|c|}{ ANOVA Overall Treatment effects } \\
\hline \multicolumn{10}{|c|}{ Treatment $(\mathrm{Df}=3,15)$} \\
\hline $\mathrm{F}$ & 12.7 & 1.2 & 0.4 & 2.6 & 5.3 & 2.0 & 20.8 & 4.5 & 0.6 \\
\hline$p$ & $0.00 * *$ & NS & NS & NS & $0.01 * *$ & NS & $0.00 * *$ & $0.02 * *$ & NS \\
\hline \multicolumn{10}{|c|}{ Time of Treatment $(\mathrm{Df}=1,17)$} \\
\hline $\mathrm{F}$ & 0.6 & 2.6 & 2.4 & 4.0 & 0.7 & 1.8 & 0.0 & 0.3 & 0.0 \\
\hline$p$ & NS & NS & NS & NS & NS & NS & NS & NS & NS \\
\hline \multicolumn{10}{|c|}{ Treatment $x$ Time of treatment $(\mathrm{Df}=\mathbf{3 , 1 5})$} \\
\hline $\mathrm{F}$ & 3.6 & 0.5 & 4.3 & 2.6 & 0.9 & 2.1 & 0.08 & 1.3 & 1.2 \\
\hline$p$ & $0.04 *$ & NS & $0.00 * *$ & NS & NS & NS & NS & NS & NS \\
\hline
\end{tabular}




\section{Subjective measurements}

No significant main effects of Treatment, Gender, or Time of treatment were found on the participants' expected driving ability prior to driving. After completion of the driving test, subjective driving quality differed between treatments $\left(\mathrm{F}_{3,15}=5.30 ; \mathrm{p}<0.05\right)$. Drug-placebo contrasts indicated that participants rated their driving quality as significantly worse in the hydroxyzine $50 \mathrm{mg}$ condition compared to placebo $\left(\mathrm{F}_{1,17}=17.42 ; \mathrm{p}<0.01\right)$. The driving quality rated by the instructor was also affected by Treatment $\left(\mathrm{F}_{1,17}=10.94 ; \mathrm{p}<0.01\right)$. The instructor rated driving performance during bilastine $40 \mathrm{mg}$ and hydroxyzine $50 \mathrm{mg}$ as worse $\left(\mathrm{F}_{1,17}=23.47 ; \mathrm{p}<0.001\right)$ compared to placebo. The driving instructor rated the participants' sedation as being worse in the hydroxyzine condition $\left(\mathrm{F}_{1,17}=14.18\right.$; $\mathrm{p}<0.01)$ compared to the placebo condition.

Furthermore, no significant main effects were found for the amount of sedation subjectively scored by the participants on day 1 and 8 . Also, no significant differences between conditions were detected for sleep quality prior to test days.

\section{Adverse events}

No serious adverse events were recorded during the study, and safety laboratory data and vital signs showed no clinically relevant time- or dose- related changes. Treatment with bilastine (20 and $40 \mathrm{mg}$ ) and hydroxyzine $50 \mathrm{mg}$ were generally safe and well tolerated. The most frequently reported in-treatment adverse events were headache and fatigue. Headache was mainly observed after treatment with bilastine $40 \mathrm{mg}$. Fatigue was mainly observed after treatment with hydroxyzine $50 \mathrm{mg}$. A summary of adverse events reported during all treatments is given in Table 4. 
Table 4 Summary of the total amount of adverse events after placebo, bilastine $20 \mathrm{mg}$, bilastine $40 \mathrm{mg}$, and hydroxyzine as indicated by the participants.

\begin{tabular}{lllll}
\hline & $\begin{array}{lll}\text { Placebo } \\
\text { Adverse event }\end{array}$ & $\begin{array}{l}\text { Bilastine } \mathbf{2 0} \\
\mathbf{m g} \\
(\mathrm{N}=22)\end{array}$ & $\begin{array}{l}\text { Bilastine } \mathbf{4 0} \\
\mathbf{m g} \\
(\mathrm{N}=22)\end{array}$ & $\begin{array}{l}\text { Hydroxyzine } \\
(\mathrm{N}=22)\end{array}$ \\
\hline Headache & $3(13.6)$ & $\mathrm{n}(\%)$ & $\mathrm{n}(\%)$ & $\mathrm{n}(\%)$ \\
Dizziness & $0(0.0)$ & $1(4.6)$ & $0(0.0)$ & $3(9.1)$ \\
Drowsiness & $0(0.0)$ & $0(0.0)$ & $1(4.6)$ & $2(9.1)$ \\
Sleeplessness & $0(0.0)$ & $0(0.0)$ & $0(0.0)$ & $1(4.6)$ \\
Migraine & $0(0.0)$ & $0(0.0)$ & $1(4.6)$ & $0(0.0)$ \\
Fatigue & $0(0.0)$ & $1(4.6)$ & $1(4.6)$ & $4(18.2)$ \\
Fever & $0(0.0)$ & $1(4.6)$ & $0(0.0)$ & $0(0.0)$ \\
Dry mouth & $0(0.0)$ & $1(4.6)$ & $1(4.6)$ & $1(4.6)$ \\
Abdominal pain & $1(4.6)$ & $0(0.0)$ & $1(4.6)$ & $1(4.6)$ \\
Vomiting & $1(4.6)$ & $0(0.0)$ & $0(0.0)$ & $0(0.0)$ \\
Esophageal & $1(4.6)$ & $0(0.0)$ & $0(0.0)$ & $0(0.0)$ \\
discomfort & $0(0.0)$ & $1(4.6)$ & $0(0.0)$ & $0(0.0)$ \\
Nausea & $1(4.6)$ & $0(0.0)$ & $0(0.0)$ & $0(0.0)$ \\
Diarrhea & $0(0.0)$ & $1(4.6)$ & $1(4.6)$ & $1(4.6)$ \\
Backache & $2(9.1)$ & $1(4.6)$ & $1(4.6)$ & $1(4.6)$ \\
Cold & $0(0.0)$ & $0(0.0)$ & $0(0.0)$ & $1(4.6)$ \\
Sinusitis NOS & $0(0.0)$ & $0(0.0)$ & $0(0.0)$ & $1(4.6)$ \\
Nasal itching & $0(0.0)$ & $0(0.0)$ & $1(4.6)$ & $0(0.0)$ \\
Dry eyes & $0(0.0)$ & $0(0.0)$ & $1(4.6)$ & $0(0.0)$ \\
Rash & & & &
\end{tabular}

\section{Discussion}

This study has been conducted in order to assess the effects of two doses of bilastine (20 and $40 \mathrm{mg}$ ) and hydroxyzine $50 \mathrm{mg}$ on actual driving performance. The results of this study demonstrate that bilastine $20 \mathrm{mg}$ and $40 \mathrm{mg}$ did not affect any of the driving parameters as compared to placebo, with the exception of bilastine $40 \mathrm{mg}$ on day 1 on SDSP. Hydroxyzine $50 \mathrm{mg}$, on the other hand significantly impaired driving performance on both day 1 and day 8 . Additionally, the results show that treatment with 20 and $40 \mathrm{mg}$ of bilastine was generally safe and well tolerated. Headache and fatigue were the most frequently reported adverse events. 
Bilastine did not affect the primary driving measure (i.e. SDLP) during treatments with 20 and $40 \mathrm{mg}$. The only indication for a bilastine effect on driving came from an increase in SDSP on the first day of treatment with the $40 \mathrm{mg}$ dose. It indicates that the participants' speed was more variable during that treatment. This variability however did not affect the participants' ability to adhere to the instructed mean speed of $95 \mathrm{~km} / \mathrm{h}$ during the driving test. Overall, mean speed was not affected by any treatment. The lack of bilastine effects on driving performance is in line with a previous report by Garcia-Gea et al. ${ }^{10}$. They only observed objective psychomotor impairment after $80 \mathrm{mg}$ of bilastine, but not after 20 and $40 \mathrm{mg}$ of bilastine. Subjective reports of side effects also supported the findings in the standardized driving test. One participant complained of fatigue during bilastine $20 \mathrm{mg}$, whereas only 2 subjects reported drowsiness/ fatigue after bilastine $40 \mathrm{mg}$. Overall, these data indicate that bilastine in doses up to $40 \mathrm{mg}$ can generally be qualified as a 'non-sedative' antihistamine that can be safely used in traffic.

Hydroxyzine $50 \mathrm{mg}$ significantly increased SDLP after single and repeated administration. On day 1, hydroxyzine increased SDLP with $4.5 \mathrm{~cm}$, relative to placebo. This change in SDLP is comparable to driving impairment observed after a BAC of $0.8 \mathrm{mg} / \mathrm{ml}$ in the same driving model ${ }^{15}$. The magnitude of driving impairment decreased after repeated treatment with hydroxyzine. On day 8 , SDLP was increased by $2.2 \mathrm{~cm}$. This change is close to the BAC equivalent of $0.5 \mathrm{mg} / \mathrm{ml}$ (i.e. $2.4 \mathrm{~cm}$ ). These data thus strongly suggest that hydroxyzine 50 mg produces severe driving impairment after single doses and mild to moderate driving impairment after repeated doses.

It is interesting to note that hydroxyzine is the first sedative antihistamine for which full tolerance to its impairing potential on driving performance could not be demonstrated. In general, it has been shown that the acute impairing effects of sedative antihistamines rapidly decrease over time and disappear within one week of treatment due to tolerance ${ }^{13,21-25}$. The reason for this lack of tolerance after sub-chronic treatment with hydroxyzine remains unclear, but may be related to its pharmacological profile and/or to dose. Besides antihistaminergic effects, hydroxyzine is also known for its anticholinergic effects in the CNS. Anticholinergic effects may include memory impairment, impaired concentration as well as drowsiness and fatigue ${ }^{26,27}$. Partial tolerance to the behavioral effects of anticholinergic drugs has been reported ${ }^{28}$ which may explain why hydroxyzine's detrimental effect on driving only partially subsided.

Dose may also contribute to the degree of tolerance after repeated hydroxyzine administration. Previous studies with lower doses of hydroxyzine (i.e. $20 \mathrm{mg}$ ) demonstrated that initial sedative effects as measured with psychomotor tests and visual analogue scales after acute administration, disappeared after 7 days of repeated administration when steady state concentration had been 
achieved ${ }^{29}$. Hydroxyzine has a long elimination half-life of $20+/-4.1$ hrs ${ }^{30}$ and usually reaches steady state concentrations within one week of dosing. However, it cannot be excluded that tolerance to the impairing effects of hydroxyzine builds up more slowly after administration of higher doses, which will lead to higher steady state concentrations.

Subjective measures furthermore indicated that before the driving test participants did not expect that their driving ability would be impaired by any of the treatments. Only after completion of the driving test did the participants acknowledge that their driving performance had been significantly impaired during treatment with hydroxyzine. This is an important finding as it indicates that in normal life, hydroxyzine users will be unaware of potential impairments when taking the decision to drive a car. Similar findings with comparable sedative antihistamines have been reported before ${ }^{13,31}$. It underscores the notion that users of sedative antihistamines should receive explicit warnings about these drugs' deleterious effects on driving.

Although it is clear that the primary measure of the standard driving test reflects a realistic and fundamental aspect of driving, i.e. road tracking control, it should not be taken as a measure of overall driving performance. The latter also includes understanding of traffic, decision-making, risk assessment, responses to changes in traffic control devices, interaction with other road user and involves higher level driving skills demanding effortful processing and attention. Thus, a more complex driving test might provide a better prediction of overall driving performance as compared to the current standard driving test that measures highly automated performance at an operational level.

It is concluded that hydroxyzine produces severe driving impairment after single doses and that this impairment only partly mitigates over time due to a lack of complete tolerance. Bilastine on the other hand did not produce any driving impairment after single and repeated doses and can be safely used in traffic in doses up to $40 \mathrm{mg}$.

\section{References}

1. O'Hanlon, J. F. \& Ramaekers, J. G. Antihistamine effects on actual driving performance in a standard test: a summary of Dutch experience, 1989-94. Allergy 50, 234-242 (1995).

2. Ramaekers, J. G., Uiterwijk, M. M. \& O’Hanlon, J. F. Effects of loratadine and cetirizine on actual driving and psychometric test performance, and EEG during driving. Eur J Clin Pharmacol 42, 363-369 (1992).

3. Theunissen, E. L., van Kroonenburgh, M. J., van Deursen, J. A., Blom-Coenjaerts, C. \& 
Ramaekers, J. G. Stimulating effects of fexofenadine: testing the dopamine transporter hypothesis. Psychopharmacol 187, 95-102 (2006).

4. Theunissen, E. L., Vermeeren, A. \& Ramaekers, J. G. Repeated-dose effects of mequitazine, cetirizine and dexchlorpheniramine on driving and psychomotor performance. Brit $J$ Clin Pharmaco 61, 79-86 (2006).

5. Theunissen, E. L., Vermeeren, A., van Oers, A. C., van Maris, I. \& Ramaekers, J. G. A doseranging study of the effects of mequitazine on actual driving, memory and psychomotor performance as compared to dexchlorpheniramine, cetirizine and placebo. Clin Exp Allergy 34, 250-258 (2004).

6. Bachert, C. et al. Comparison of the efficacy and safety of bilastine $20 \mathrm{mg}$ vs desloratadine 5 $\mathrm{mg}$ in seasonal allergic rhinitis patients. Allergy 64, 158-165 (2009).

7. Corcostegui, R., Labeaga, L., Innerarity, A., Berisa, A. \& Orjales, A. Preclinical pharmacology of bilastine, a new selective histamine $\mathrm{H} 1$ receptor antagonist: receptor selectivity and in vitro antihistaminic activity. Drugs R D 6, 371-384 (2005).

8. Corcostegui, R., Labeaga, L., Innerarity, A., Berisa, A. \& Orjales, A. In vivo pharmacological characterisation of bilastine, a potent and selective histamine $\mathrm{H} 1$ receptor antagonist. Drugs R D 7, 219-231 (2006).

9. Horak, F., Zieglmayer, P., Zieglmayer, R. \& Lemell, P. The effects of bilastine compared with cetirizine, fexofenadine, and placebo on allergen-induced nasal and ocular symptoms in patients exposed to aeroallergen in the Vienna Challenge Chamber. Inflamm Res 59 (5), 391-398 (2010).

10. Garcia-Gea, C., Martinez-Colomer, J., Antonijoan, R. M., Valiente, R. \& Barbanoj, M. J. Comparison of peripheral and central effects of single and repeated oral dose administrations of bilastine, a new $\mathrm{H} 1$ antihistamine: a dose-range study in healthy volunteers with hydroxyzine and placebo as control treatments. J Clin Psychopharmacol 28, 675-685 (2008).

11. Ramaekers, J. G. Antidepressants and driver impairment: empirical evidence from a standard on-the-road test. J Clin Psychiatry 64, 20-29 (2003).

12. Ramaekers, J. G. \& O'Hanlon, J. F. Acrivastine, terfenadine and diphenhydramine effects on driving performance as a function of dose and time after dosing. Eur J Clin Pharmacol 47, 261-266 (1994).

13. Theunissen, E. L., Jonkman, L. M., Kuypers, K. P. \& Ramaekers, J. G. A combined neurophysiological and behavioural study into the stimulating effects of fexofenadine on performance. J Psychopharmacol 20, 496-505 (2006).

14. O’Hanlon, J. F., Haak, T. W., Blaauw, G. J. \& Riemersma, J. B. Diazepam impairs lateral position control in highway driving. Science 217, 79-81 (1982).

15. Louwerens, J. W., Gloerich, A. B. M., de Vries, G., Brookhuis, K. A. \& O’Hanlon, J. F. in International Congres on Alcohol, Drugs and Traffic Safety, T86 (eds. Noordzij, P. C. \& Roszbach, R.) 183-186 (Exerpta Medica, Amsterdam, 1987).

16. Vermeeren, A. \& O'Hanlon, J. F. Fexofenadine's effects, alone and with alcohol, on actual driving and psychomotor performance. J Allergy Clinic Immunol 101, 306-311 (1998). 
17. O'Hanlon, J. F. Are actual driving tests necessary for evaluating drug safety? Int Clin Psychopharmacol 3 Suppl 1, 81-85 (1988).

18. Borkenstein, R. F. Efficacy of law enforcement procedures concerning alcohol, drugs, and driving. Mod Probl Pharmacopsychiatry 11, 1-10 (1976).

19. Mulder-Hajonides van der Meulen, W. R. E. H. in Proceedings of International European Sleep Congress (Elsevier, Amsterdam, 1981).

20. Zuberbier, T. et al. Comparison of the efficacy and safety of bilastine $20 \mathrm{mg}$ vs levocetirizine $5 \mathrm{mg}$ for the treatment of chronic idiopathic urticaria: a multi-centre, double-blind, randomized, placebo-controlled study. Allergy 65 (4), 516-528 (2009).

21. Brookhuis, K. A., De Vries, G. \& De Waard, D. Acute and subchronic effects of the H1histamine receptor antagonist ebastine in 10, 20 and $30 \mathrm{mg}$ dose, and triprolidine $10 \mathrm{mg}$ on car driving performance. Br J Clin Pharmacol 36, 67-70 (1993).

22. Gandon, J. M. \& Allain, H. Lack of effect of single and repeated doses of levocetirizine, a new antihistamine drug, on cognitive and psychomotor functions in healthy volunteers. $\mathrm{Br}$ J Clin Pharmacol 54, 51-58 (2002).

23. Richardson, G. S., Roehrs, T. A., Rosenthal, L., Koshorek, G. \& Roth, T. Tolerance to daytime sedative effects of H1 antihistamines. J Clin Psychopharmacol 22, 511-515 (2002).

24. Verster, J. C. \& Volkerts, E. R. Antihistamines and driving ability: evidence from on-theroad driving studies during normal traffic. Ann Allergy Asthma Immunol 92, 294303; quiz 303-305, 355 (2004).

25. Verster, J. C. et al. Acute and subchronic effects of levocetirizine and diphenhydramine on memory functioning, psychomotor performance, and mood. J Allergy Clin Immunol 111, 623-627 (2003).

26. Lieberman, J. A., 3rd. Managing anticholinergic side effects. Prim Care Companion J Clin Psychiatry 6, 20-23 (2004).

27. Penttila, J., Scheinin, H. \& Syvalahti, E. Measurement of anticholinergic effects of psychotropic drugs in humans. Pharmacopsychiatry 38, 187-193 (2005).

28. Gillin, J. C. et al. Dose dependent inhibition of REM sleep in normal volunteers by biperiden, a muscarinic antagonist. Biol Psychiatry 30, 151-156 (1991).

29. Levander, S., Stahle-Backdahl, M. \& Hagermark, O. Peripheral antihistamine and central sedative effects of single and continuous oral doses of cetirizine and hydroxyzine. Eur J Clin Pharmacol 41, 435-439 (1991).

30. Bartra, J. et al. Interactions of the H1 antihistamines. J Investig Allergol Clin Immunol 16 Suppl 1, 29-36 (2006).

31. Vermeeren, A., Ramaekers, J. G. \& O’Hanlon, J. F. Effects of emedastine and cetirizine, alone and with alcohol, on actual driving of males and females. J Psychopharmacol 16, 57-64 (2002). 


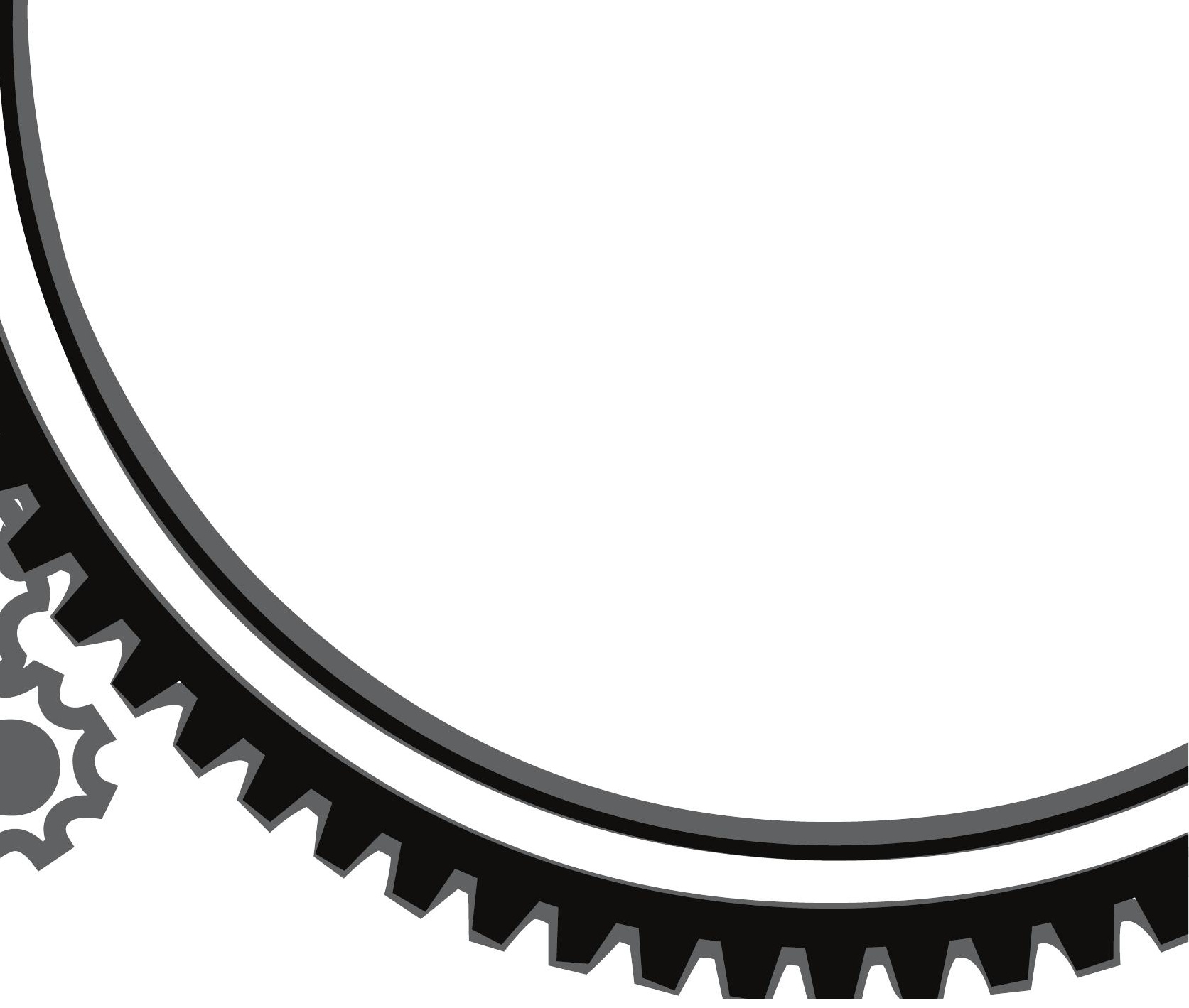




\section{Chapter 3}

\section{Residual effects of esmirtazapine on actual driving performance: overall findings and an exploratory analysis into the role of CYP2D6 phenotype}

Published as:

Ramaekers JG, Conen S, De Kam PJ, Braat S, Peeters P, Theunissen EL, Ivgy-may N. (2011) Residual effects of esmirtazapine on actual driving performance: overall findings and an exploratory analysis into the role of CYP2D6 phenotype. Psychopharmacology (Berl), 215, 321-332. 



\section{Abstract}

Esmirtazapine at low doses is evaluated as a novel drug for the treatment of insomnia. The present study was designed to assess residual effects of single and repeated doses of esmirtazapine $1.5 \mathrm{mg}$ and $4.5 \mathrm{mg}$ on actual driving performance in 32 healthy volunteers in a double-blind, placebo-controlled study. Treatment with single doses of zopiclone $7.5 \mathrm{mg}$ was included as an active control. Driving performance was assessed by means of a standardized on-the-road highway driving test.The primary study parameter was the standard deviation of lateral position (SDLP), a measure of "weaving" measured during the driving test. All subjects were subjected to CYP2D6 phenotyping in order to distinguish poor metabolizers from extensive metabolizers of esmirtazapine. Overall, low doses of esmirtazapine $(1.5 \mathrm{mg})$ did not produce any clinically relevant change in SDLP after single and repeated dosing compared to placebo. Driving impairment (i.e. a rise in SDLP) did occur after a single-dose administration of the higher esmirtazapine dose $(4.5 \mathrm{mg})$, but was resolved after repeated doses. Acute driving impairment was more pronounced after both doses of esmirtazapine in a select group of poor metabolizers $(\mathrm{N}=7)$. A single dose of zopiclone $7.5 \mathrm{mg}$ also increased SDLP as expected. It is concluded that a single dose and repeated administration of $1.5 \mathrm{mg}$ esmirtazapine are generally not associated with residual impairment. Single-dose administration of $4.5 \mathrm{mg}$ esmirtazapine was associated with residual impairment that generally resolved after repeated administration. An exploratory analysis in a small group of poor CYP 2D6 metabolizers suggested that these subjects are more sensitive to the impairing effects of esmirtazapine on car driving. These results emphasize the need to take factors which cause inter-individual variability in either treatment response or drug metabolism into account when investigating drug effects on car driving.

\section{Introduction}

Esmirtazapine maleate (Org 50081) is the maleate salt of the $\mathrm{S}(+)$-enantiomer of the racemic drug mirtazapine. Racemic mirtazapine is marketed for the treatment of major depressive disorder. Mirtazapine is a close analog of its predecessor mianserin that also has been marketed for major depressive disorder. Esmirtazapine and mirtazapine bind to presynaptic $\alpha_{2}$ receptors as well as to postsynaptic $5 \mathrm{HT}_{2}$ and $\mathrm{H}_{1}$ receptors where they act as antagonists of the 
endogeneous ligands ${ }^{1,2}$. However, compared with mirtazapine and R-mirtazapine, esmirtazapine has higher affinity to $5-\mathrm{HT}_{2}$ receptors and low affinity to the $5-\mathrm{HT}_{3}$ receptors and to the muscarinic receptors ${ }^{3,4}$. Esmirtazapine is under development for the treatment of primary insomnia and hot flushes.

Antidepressants such as mirtazapine and mianserin are well known for their sedative properties ${ }^{2,5}$. A range of studies have demonstrated that these drugs produce subjective fatigue and sleepiness and impair psychomotor function, cognition and actual driving performance after acute dosing and to a lesser degree also after repeated dosing ${ }^{6-13}$. Several studies have demonstrated that mirtazapine increases sleep efficiency, total sleep time and slow wave sleep in patients with major depressive disorder and in healthy subjects ${ }^{14-18}$. Most of mirtazapine's abilities to produce daytime sedation come from $\mathrm{H}_{1}$ blockade which is known to reduce arousal in humans. Mirtazapine's action at the $5-\mathrm{HT}_{2 \mathrm{~A}}$ receptor may also contribute to its sedative effect, however, antagonism at the $5-\mathrm{HT}_{2 \mathrm{~A}}$ receptor is not thought to be responsible for the residual sedative effects seen following nighttime administration of mirtazapine. In clinical practice, antidepressant drugs with $\mathrm{H}_{1}$-antihistaminergic properties such as mirtazapine have been frequently used for the treatment of insomnia comorbid with various psychiatric disorders ${ }^{19,20}$. Likewise, $\mathrm{H}_{1}$-antihistamines are commonly sold over the counter as hypnotics drugs to treat insomnia because of their sleep inducing properties? ${ }^{20}$.

Mirtazapine and mianserin clearly have $\mathrm{H}_{1}$ inverse agonism as their most potent pharmacological property. Yet both drugs are dosed far above the minimum dose needed to obtain maximal binding to $\mathrm{H}_{1}$ receptors (i.e. $30 \mathrm{mg}$ or more), in order to achieve sufficient serotonergic and noradrenergic action that is required for an antidepressant response. Mirtazapine has a $>100$ fold higher potency for the $\mathrm{H}_{1}$ receptor than for the $5 \mathrm{HT}_{3}$ and $\alpha_{2}$ receptors, and a 10 fold higher potency for $5 \mathrm{HT}_{2}{ }^{1,20}$. For esmirtazapine, it is postulated that the action on sleep is mediated via antagonism of both, the $\mathrm{H}_{1}$ and the $5-\mathrm{HT}_{2 \mathrm{~A}}$ receptors. The affinity of esmirtazapine to both receptors is high. Considering the action of these drugs on the $\mathrm{H}_{1}$ and $5 \mathrm{HT}_{2}$ receptor alone, sleep promoting doses of these drugs can be far lower than the regular doses prescribed to treat depression. Effective sleep promoting doses of esmirtazapine are expected to range between 1.5 and $4.5 \mathrm{mg}$. The possibility of developing esmirtazapine as a drug for treatment of insomnia however also raises the issue of residual daytime drowsiness and driving impairment since esmirtazapine elimination half life is long (i.e. $>20$ hrs).

The effects of $\mathrm{H}_{1}$ inverse agonism by mianserin and mirtazapine on actual driving performance has been assessed by means of a standardized road tracking task in previous studies ${ }^{8,12}$. Acute, daytime doses of mianserin $10 \mathrm{mg}$ tid produced elevations in the standard deviation of lateral position (SDLP) 
during on-the-road driving that were equivalent to the effects of a blood alcohol concentration (BAC) of more than $1.0 \mathrm{mg} / \mathrm{mL}$ in the same driving test. After sub-chronic dosing the impairing effects of mianserin reduced in magnitude but were still comparable to a BAC between $0.5-0.8 \mathrm{mg} / \mathrm{mL}$. The impairing effects of mianserin (30-60 mg) on daytime SDLP however where much less (i.e. comparable to a BAC $<.05 \mathrm{mg} / \mathrm{mL}$ ) when the drug was administered in the evening, even though blood mianserin concentrations during driving after nocturnal and daytime doses were comparable ${ }^{9}$. Likewise, mirtazapine 15-30 mg also produced mild residual driving impairment when administered as nocturnal doses. Single doses of mirtazapine 15 and $30 \mathrm{mg}$ produced elevations in SDLP that were comparable to BACs of 0.5 and $0.8 \mathrm{mg} / \mathrm{mL}$. However, mirtazapine no longer produced any clinically relevant changes in driving performance after one or two weeks of repeated dosing.

The effect of $5 \mathrm{HT}_{2 \mathrm{~A} / 2 \mathrm{C}}$ antagonism on actual driving has been previously assessed in a study by Van Laar et al ${ }^{21}$. That study demonstrated that single and repeated doses of ritanserin $5 \mathrm{mg}$ b.i.d. increased nocturnal slow wave sleep, but failed to affect driving performance and sleepiness during daytime. This finding supports the present notion that residual impairment from esmirtazapine, if any at all, is more likely to arise from $\mathrm{H}_{1}$ blockade than from $5 \mathrm{HT}_{2}$ blockade.

The present study was designed to assess the effects of low, nocturnal doses of esmirtazapine on next-day actual driving performance of healthy volunteers as assessed in a standardized on-the-road driving test and in laboratory performance tasks. Esmirtazapine is metabolized through CYP2D6 and its clearance is twice as low in poor metabolizers as compared to extensive metabolizers ${ }^{22}$. In the design phase it was decided to select a representative population for this study, without restrictions on CYP2D metabolizer status. This allowed for an additional 'post hoc' explorative analysis on the effects of esmirtazapine on actual driving performance for poor and extensive metabolizers as determined by cytochrome P450 2D6 (CYP2D6) phenotyping.

\section{Methods}

\section{Subjects}

Thirty-two healthy subjects, 16 men and 16 women $($ mean \pm SD age $=33 \pm 9)$ were recruited by advertisement in local newspapers. Subjects were screened by a telephone interview and a health questionnaire, and all underwent a medical examination (including a standard 12-lead electrocardiogram, blood hematology and chemistry, urinalysis, and drug and pregnancy screening). Selection was based on the following inclusion criteria: possession of a valid driving license 
for more than 3 years, driving experience of more than $5000 \mathrm{~km}$ per year on average, normal binocular visual acuity corrected or uncorrected, willingness to use double barrier method of birth control, a body mass index of 18 to $30 \mathrm{~kg} / \mathrm{m} 2$ and a written informed consent.

Subjects who met one or more of the following criteria were excluded from the study: history or present evidence of a serious illness such as renal, hepatic, cardiovascular, pulmonary, endocrine, neurologic or psychiatric, hematologic, or gastrointestinal diseases; insomnia or other sleep disorders; pregnancy (as determined at screening) or breastfeeding; known hypersensitivity to medicinal drugs; treatment with an investigational drug within 3 months prior to screening; use of medicines (except oral contraceptives and paracetamol); excessive smoking (more than 5 cigarettes a day); night work or rotation shift work, overconsumption of alcohol (more than 2 units per day) or caffeine (more than 5 cups of regular coffee a day); a positive result of urine drug screening at the screening visit for alcohol and/or drug of abuse.

The study was approved by the standing medical ethics committee of Maastricht University and was carried out in compliance with the current revision of the Declaration of Helsinki, International Conference on Harmonization (ICH) guideline for Good Clinical Practice (GCP).

\section{Design and treatments}

The study was conducted according to a randomized, double-blind, placebocontrolled, 4-way crossover design. Treatments were administered in separate 7-day series, and treatment orders were balanced following a Williams design and assigned by a predetermined randomization schedule, stratified by gender. The following treatment conditions were defined: nocturnal doses of $1.5 \mathrm{mg}$ esmirtazapine on Day 1-7; nocturnal doses of 4.5 mg esmirtazapine on Day 1-7; nocturnal doses of placebo on Day 1-7; and nocturnal doses of placebo on Day 1-6 and zopiclone $7.5 \mathrm{mg}$ on Day 7. The zopiclone treatment was included to serve as an active control and to demonstrate (assay) sensitivity of the driving test to residual drug effects. Zopiclone $7.5 \mathrm{mg}$ has repeatedly been shown to produce residual driving impairment the in standardized highway driving test ${ }^{23}$. During Days 1-7 of all treatment periods, trial medication was taken by the subjects at their homes. Subjects recorded the time of administration in a diary. On Days 2-6, trial medication was taken in the evening, within 30 minutes before going to bed. On Day 1 and Day 7 trial medication was administered under supervision of a research associate at a fixed time of drug administration (i.e. 21:30 hrs). Subjects went to bed within $1 \mathrm{hr}$ after drug intake. The washout period between treatments was at least 7 days.

Driving tests and cognitive tests were conducted at Day 2 and Day 8 of 
treatment, with the driving test starting on average $11 \mathrm{hrs}$ after drug intake (range: between 10-11.5 hrs) and the cognitive and psychomotor tests starting approximately $13 \mathrm{hrs}$ after drug intake. All subjects scored negative on drug and alcohol screens at all times, that were conducted on test days prior to performance testing. A blood sample was taken between the driving test and the cognitive psychomotor performance tests. Subjects were instructed to refrain from alcohol use 24 hrs prior to and throughout treatment periods. A summary of treatment and performance assessments on Day 2 and 8 is given in Figure 1.

\begin{tabular}{|c|c|c|c|c|c|c|c|c|}
\hline & $\begin{array}{l}\text { Day } \\
1\end{array}$ & 2 & 3 & 4 & 5 & 6 & 7 & 8 \\
\hline Period 1 & ESM 1.5 & ESM 1.5 & ESM 1.5 & ESM 1.5 & ESM 1.5 & ESM 1.5 & ESM 1.5 & \\
\hline Period 2 & ESM 4.5 & ESM 4.5 & ESM 4.5 & ESM 4.5 & ESM 4.5 & ESM 4.5 & ESM 4.5 & \\
\hline Period 3 & PLA & PLA & PLA & PLA & PLA & PLA & PLA & \\
\hline \multirow[t]{2}{*}{ Period 4} & PLA & PLA & PLA & PLA & PLA & PLA & ZOP & \\
\hline & \multicolumn{8}{|c|}{ Performance of the actual highway driving test } \\
\hline
\end{tabular}

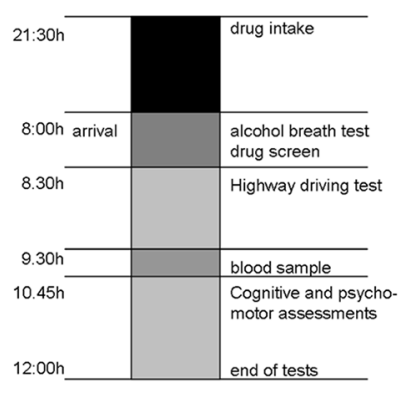

Figure 1 Summary of treatments and activities on Day 2 and Day 8 in every treatment condition (ESM = esmirtazapine, PLA=placebo, $Z \mathrm{ZP}=$ zopiclone $7.5 \mathrm{mg}$ ).

\section{Performance tests}

Driving and psychometric tests were trained during two separate training sessions prior to the first treatment condition in order to minimize learning effects.

\section{Highway driving test}

In the highway driving test ${ }^{24,25}$ the subjects operates a specially instrumented vehicle for about 1 hour over a $100 \mathrm{~km}$ primary highway circuit while maintaining a constant speed $(95 \mathrm{~km} / \mathrm{h})$ and a steady lateral position between the delineated boundaries of the right (slower) traffic lane. An electro-optical device mounted at the rear back of the car continuously measures lateral distance separating the vehicle and the left lane-line. This signal is digitized at a rate of $4 \mathrm{~Hz}$ and stored on an onboard computer disk file for later editing analysis. The off line editing routine involves removal of all data segments that reveal signal loss, disturbance or occurrence of passing manoeuvers. The edited dataset is then used to calculate means and variances for lateral position. The standard deviation of lateral position (SDLP) is taken as the primary outcome variable. SDLP is a measure of road tracking error, which in practical terms is a composite index 
of allowed weaving, swerving and overcorrecting. The highway driving test has been calibrated in a manner allowing expression of any sedative drug effect in terms of the BAC required to achieve the equivalent level of driving impairment 26. The alcohol calibration curve demonstrates that drinkers' mean SDLP rises exponentially with BAC. Results from the alcohol calibration study can be used for describing drugs' effects on SDLP in terms of respective BAC equivalencies. The change in SDLP at a BAC of $0.5 \mathrm{mg} / \mathrm{ml}$ has been used as a criterion level to quantify drug effects. Any drug induced changes in SDLP that exceed this criterion value are defined as clinically relevant impairing drug effect in the present study.

\section{Cognitive and psychomotor tests}

The word learning task is a verbal memory test for the assessment of immediate recall and delayed recall ${ }^{27}$. Fifteen monosyllabic nouns sounded for 2 seconds. At the end of the sequence the subject is asked to recall as many words as possible (recall-order is unimportant). The number of correctly recalled words is scored as the first trial score. This procedure is repeated three times and the summed trial score is referred to as the Immediate Recall Score. After a delay of at least 20 minutes the subject is again asked to recall as many words as possible (without a new presentation of the nouns). This number of correctly recalled words is referred to as the Delayed Recall Score. The word learning task was conducted during the highway driving test.

The stop signal task requires subjects to make quick key responses to visually presented go signals and to inhibit any response when a visual stop signal is suddenly presented. The current test is adapted from an earlier version of Fillmore et al. ${ }^{28}$ and has been validated for showing stimulant and sedative drug effects ${ }^{29,30}$. The go signals were four $1.5 \mathrm{~cm}$ letters (i.e. A, B, C, and D) presented one at a time in the center of a computer screen. Subjects were required to respond to each letter as quickly as possible by pressing one of two response buttons. One button is pressed to indicate that " $\mathrm{A}$ " or " $\mathrm{C}$ " appeared and the other to indicate that "B" or "D" appeared. Letters were displayed for 500 msec and the computer screen was blank for a $1.5 \mathrm{sec}$ inter-stimulus interval before the next letter was displayed. This provides a period of $2 \mathrm{sec}$ during which the subject can respond to a letter. A single test consists of 176 trials in which each of the 4 letter stimuli is presented equally often. A stop signal occurs in 48 trials during a test. The stop signal consists of a visual cue (i.e. "*”), that appears in one of the four corners of the screen. Subjects are required to withhold any response when a stop-signal is presented. The task lasts about 10 minutes. The primary dependant variable is the reaction time in stop trials (msec). Secondary parameters are Response Time (msec) in go trials and number of errors in go and stop trials. 
The critical tracking task measures the subject's ability to control a displayed error signal in a first-order compensatory tracking task. The error is displayed as a horizontal deviation of a cursor from the midpoint on a horizontal linear scale. Compensatory joystick movements null the error by returning the cursor to the midpoint. The frequency at which the subject loses the control is the critical frequency or $\lambda_{\mathrm{c}}(\mathrm{rad} / \mathrm{sec})$. The test includes five trials of which the lowest and the highest score are removed; the average of the remaining scores is taken as the final score.

The divided attention task measures the subject's ability to divide attention between two tasks performed simultaneously. The primary task consist of tracking task as described above but at a constant level of difficulty set at $50 \%$ of the subject's maximum capacity. Tracking error is measured as the difference in mm between the position of the cursor and the midpoint of the scale. In the secondary task, the subject monitors a central display upon which single digits are presented at 1 second intervals. The occurrence of the digit " 2 " is a signal for the subject to remove the foot from a pedal as rapidly as possible. Inter stimulus interval varies between 1-2 sec. Mean Absolute Tracking Error (mm) and Average Reaction Time $(\mathrm{msec})$ are the main performance measures.

\section{CYP2D6 phenotyping}

CYP2D6 characterization was performed prior to the first intake of trial medication in period 1 of the 4-period cross-over sequences. Subjects received one tablet of dextromethorphan $30 \mathrm{mg}$ together with $200 \mathrm{~mL}$ water before bedtime. Subjects had to empty their bladder pre-dose. Subsequently, subjects' morning urine was collected in containers. The excretion ratio dextromethorphan/dextrorphan in urine determined the CYP2D6 metabolizer status of each subject. Subjects with an excretion ratio $>=0.3$ were characterized as poor metabolizers, subject whose excretion ratio $<0.3$ were characterized as extensive metabolizers. In total, 7 (22\%) subjects were classified as poor metabolizers ( 4 males and 3 females) and $25(78 \%)$ subjects (12 males and 13 females) as extensive metabolizers.

\section{Pharmacokinetics}

Blood samples $(5 \mathrm{~mL})$ for esmirtazapine determinations were collected at the time points indicated in Table 1 and processed to plasma. Plasma samples were stored and frozen at $-20{ }^{\circ} \mathrm{C}$ and later analyzed by LC-MS-MS. The lower limit of quantification is $0.02 \mathrm{ng} / \mathrm{mL}$. 


\section{Statistics}

Sample size was based on a power calculation for non-inferiority between esmirtazapine $4.5 \mathrm{mg}$ and placebo after multiple dose administration with respect to actual driving performance as assessed by means of the SDLP. Given a mean population standard deviation of $4.0 \mathrm{~cm}$, and a mean difference in SDLP of 0.5 $\mathrm{cm}$ between multiple doses of esmirtazapine $4.5 \mathrm{mg}$ and placebo, a test-retest $>=0.70$ and a non-inferiority margin of $2.5 \mathrm{~cm}$, a sample size of 26 subjects is sufficient to demonstrate non-inferiority with a power of at least $90 \%$ and a twosided $\alpha$-level of 0.05 . This sample size is also sufficiently large (i.e. power of at least $90 \%$ ) for detecting a clinically relevant effect of $2.5 \mathrm{~cm}$ mean difference in SDLP between single dose zopiclone $7.5 \mathrm{mg}$ and placebo to demonstrate assaysensitivity. Taking into account the possibility of drop-outs the total sample size was set at $\mathrm{N}=32$ or 8 subjects per treatment cross-over sequence stratified by gender (i.e. 4 males and 4 females).

Estimation of differences in SDLP between poor and extensive CYP2D6 metabolizers was not pre-specified as an objective of this study, and hence, the study was not powered for these subgroup analyses. Therefore, the results of these subgroups have to be interpreted in the perspective of the explorative character of these analyses.

Statistical analyses of the driving, cognition and psychomotor function parameters was done using a mixed model including fixed factors for treatment, period, treatment sequence, gender, day, and treatment by day interaction. Kenward-Roger approximation was used to estimate denominator degrees of freedom. Subject was included as a random factor and day as a repeated factor. No fixed structure was assumed for the repeated measures (co)variance. Least-squares estimates of contrasts to placebo and two-sided $95 \%$ confidence intervals (CI) were obtained from this model for single doses and multiple treatment doses separately. Efficacy analyses included all subjects randomly assigned to the treatment sequence, treated, for whom results from at least one driving test during treatment was available, and without any pre-defined protocol violations that might impact efficacy conclusions. Adverse events (AEs) were coded using the MedDRA dictionary. AEs occurring during the washout period were assigned to the treatment taken during the preceding treatment period. AEs that occurred before intake of zopiclone $7.5 \mathrm{mg}$ in the placebo-zopiclone treatment period were assigned to placebo. AE tabulations included the number and percentage of subjects with at least one AE by MedDRA preferred term. Safety analyses included all subjects that were randomly assigned to treatment sequence and treated. For the efficacy evaluation, all complete and incomplete data were included in the statistical analyses (i.e. no imputation was performed 
for missing data). Statistical analyses were performed using $\mathrm{SAS} \AA$ version 9.1.3. The aim of the present study was to compare next-day driving performance, as expressed by the standard deviation of lateral position (SDLP), of esmirtazapine with placebo. The study was designed as a non-inferiority trial, with evaluation of SDLP effects in relation to a reference BAC concentration. For SDLP, noninferiority between treatments was concluded if the upper limit of the two-sided 95\% confidence interval (CI) of the mean difference in SDLP between drug and placebo below $2.5 \mathrm{~cm}$. The upper limit of the non-inferiority margin is chosen such that it excludes with high certainty a drug effect $>$ BAC $0.5 \mathrm{mg} / \mathrm{ml}$, which is considered clinically relevant.

\section{Results}

A total of 32 subjects entered the study. Twenty-nine subjects completed all four treatment periods whereas, 3 subjects prematurely discontinued. Two subjects dropped out during treatment with esmirtazapine $4.5 \mathrm{mg}$ due to adverse events. In one case, the subject complained of asthenia, fatigue and muscular weakness starting 25 minutes after intake of the first dose and decided to stop study participation. This subject was a poor CYP2D6 metabolizer and the adverse events were considered related to study treatment. The other subject was discontinued after being diagnosed with breast cancer. In the judgment of the medical supervisor, this serious adverse event was not likely to be related to study treatments. Another subject dropped out between the $3^{\text {rd }}$ and $4^{\text {th }}$ treatment period because she could no longer adhere to study restrictions related to alcohol intake. Compliance to trial medication was $100 \%$ after single doses and multiple doses of all treatments.

\section{Highway driving, cognition and psychomotor function}

Overall, mean (SD) SDLP after single doses of esmirtazapine $1.5 \mathrm{mg}$, esmirtazapine $4.5 \mathrm{mg}$, zopiclone $7.5 \mathrm{mg}$ and placebo were 19.6 (3.6), 20.3 (3.4), 20.6 (3.3) and 18.3 (2.9), respectively. Mean (SD) SDLP after repeated doses of esmirtazapine $1.5 \mathrm{mg}$, esmirtazapine $4.5 \mathrm{mg}$ and placebo were 19.8 (3.6), 19.8 (3.8) and 19.5 (3.3), respectively.

Assay-sensitivity was clearly demonstrated as shown by the inferiority of zopiclone $7.5 \mathrm{mg}$ to placebo: i.e. the lower limit of the 95\% CI was above zero. Moreover, the estimated mean difference in SDLP between zopiclone and placebo was larger than the non-inferiority margin of $2.5 \mathrm{~cm}$, with an upper limit of the $95 \%$ CI of $3.6 \mathrm{~cm}$.

The primary endpoint, mean difference in SDLP after multiple dose 
treatment of esmirtazapine $4.5 \mathrm{mg}$ with placebo, clearly showed non-inferiority, i.e. the upper limit of the 95\% CI of the estimated mean difference in SDLP of multiple dose esmirtazapine $4.5 \mathrm{mg}$ vs. placebo was lower than the non-inferiority margin of $2.5 \mathrm{~cm}$. In agreement with this finding, the estimated mean difference in SDLP following single and multiple dose treatment of esmirtazapine 1.5 $\mathrm{mg}$ as compared to placebo, also showed non-inferiority. However, following single doses of esmirtzapine $4.5 \mathrm{mg}$, non-inferiority to placebo could not be demonstrated; the upper limit of the 95\% CI of SDLP $(3.2 \mathrm{~cm})$ exceeded the non-inferiority margin of $2.5 \mathrm{~cm}$. The mean $(95 \% \mathrm{CI})$ differences from placebo in SDLP values for all treatment conditions are shown in Figure 2.

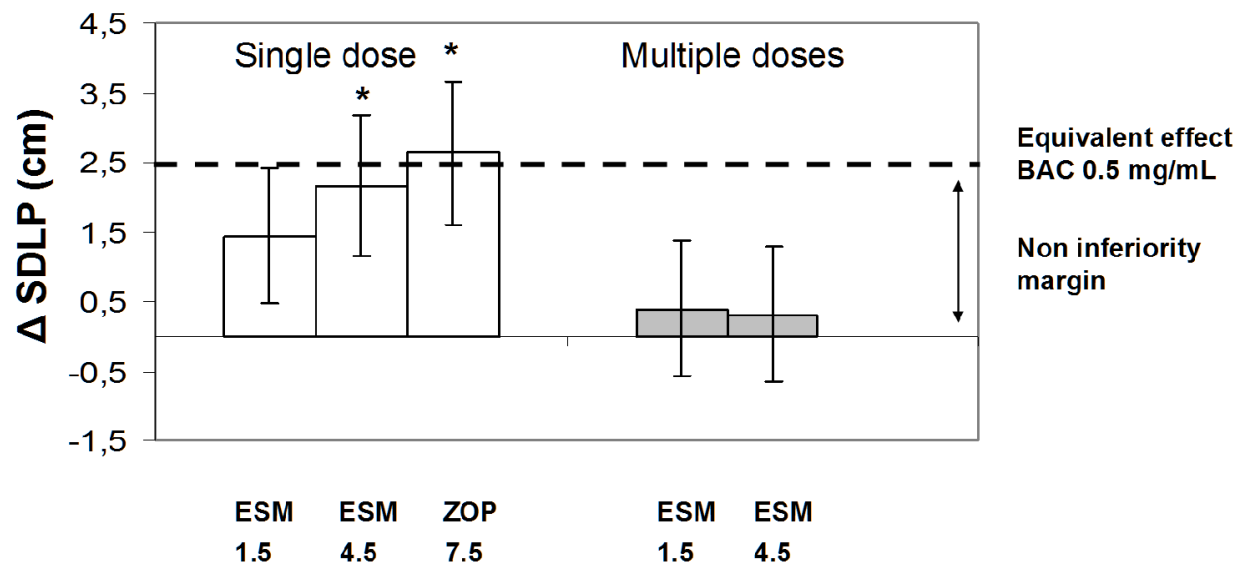

Figure 2 Mean (95\% CI) SDLP difference from placebo after single doses of esmirtazapine (ESM) and zopiclone (ZOP), and after multiple doses of ESM. * = non-inferiority not shown, upper bound of the $95 \% \mathrm{CI}$ is above the non-inferiority margin of $2.5 \mathrm{~cm}$.

In total, 7 (22\%) subjects were classified as poor metabolizers and 25 (78\%) subjects as extensive metabolizers. The explorative analysis on poor metabolizers $(\mathrm{N}=7)$ indicated inferiority compared to placebo following single dose administration of 1.5 and $4.5 \mathrm{mg}$ esmirtazapine, as the upper limits of the 95\% CI of SDLP difference vs. placebo exceeded the non-inferiority margin and the lower limits were above zero. After multiple doses, non-inferiority was demonstrated for the lower dose of esmirtazapine, but not for the higher dose.

The analysis of the data subset from extensive metabolizers $(\mathrm{N}=25)$ yielded results similar to those obtained from the data of the entire study population. In extensive metabolizers, non-inferiority was shown for the mean difference vs. placebo in SDLP after a single dose of esmirtazapine $1.5 \mathrm{mg}$ and after multiple doses of esmirtazapine 1.5 and $4.5 \mathrm{mg}$. Non-inferiority vs. placebo was not shown for SDLP after a single dose of esmirtazapine $4.5 \mathrm{mg}$. Mean (95\% CI) SDLP in poor and extensive metabolizers is shown in Figure 3. 


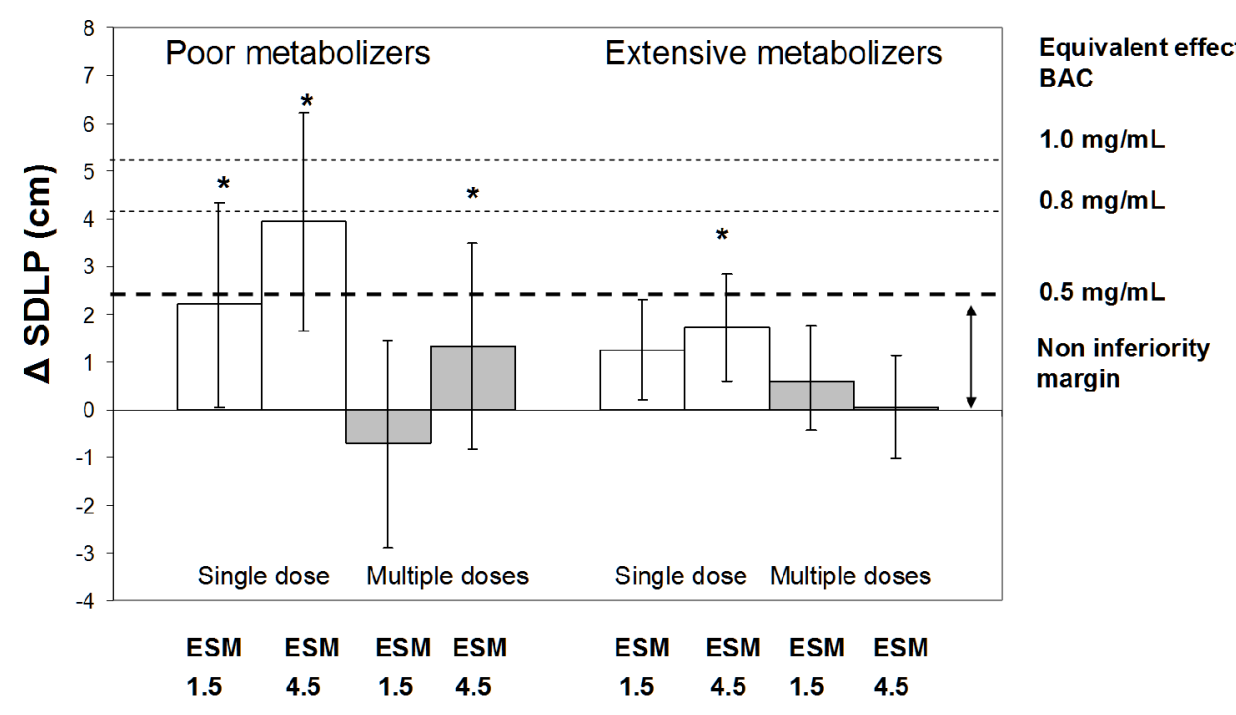

Figure 3 Mean (95\% CI) SDLP difference from placebo after single doses of esmirtazapine (ESM) and zopiclone (ZOP) and after multiple doses of ESM in poor $(\mathrm{N}=7)$ and extensive metabolizers $(\mathrm{N}=25) . *$ non-inferiority not shown, upper bound of the $95 \% \mathrm{CI}$ is above the non-inferiority margin of $2.5 \mathrm{~cm}$.

When comparing poor and extensive metabolizers, there were no statistically significant differences between the two metabolizer groups for any of the four treatment comparisons for interest (i.e. for the comparison of esmirtazapine single dose $1.5 \mathrm{mg}$ to placebo $(\mathrm{p}=0.43)$, single dose $4.5 \mathrm{mg}$ to placebo $(\mathrm{p}=0.09)$, multiple dose $1.5 \mathrm{mg}$ to placebo ( $\mathrm{p}=0.26$ ), and multiple dose $4.5 \mathrm{mg}$ to placebo $(\mathrm{p}=0.29))$. It should be noted that the study was not powered to draw conclusions on non-inferiority within or between subgroups.

Laboratory test demonstrated that the effects of zopiclone on cognition and psychomotor function were not shown to be statistically different from placebo. In general, the cognitive tests results for mirtazapine did not show a clear doseresponse relationship or major differences between the results following a single dose and multiple doses. Moreover, esmirtazapine did not show statistically differences from placebo for most laboratory measures, except for tracking error in the divided attention task. The performance on this task was statistically significantly worse than placebo after single and multiple doses of $1.5 \mathrm{mg}$ and single doses of $4.5 \mathrm{mg}$ esmirtazapine, but not after multiple dose of $4.5 \mathrm{mg}$ esmirtazapine. Following esmirtazapine $1.5 \mathrm{mg}$ single doses only, delayed recall in the word learning task and response time in the divided attention task also showed a statistically significant worsening compared with placebo. A summary of performance on cognitive and psychomotor measures is given in Table 1 . 
$\underline{\text { Residual effects of esmirtazapine on actual driving performance }}$

Table 1 Mean (SD) difference from placebo and 95\% confidence interval (CI) for cognitive and psychomotor measures in all treatments. $*=$ significant difference at $5 \%$ level; a $=$ least square mean differences and $95 \%$ CIs obtained from mixed model analyses.

\begin{tabular}{|c|c|c|c|c|c|c|}
\hline Parameter & Drug/dose & $\mathrm{N}$ & Mean (SD) & Difference a & $95 \% \mathrm{CI}$ a & Significance \\
\hline \multicolumn{7}{|c|}{ Word Learning Task } \\
\hline \multirow{7}{*}{$\begin{array}{l}\text { Immediate } \\
\text { Recall Score } \\
(\#)\end{array}$} & PLA (s) & 31 & $26.3(4.8)$ & & & \multirow{13}{*}{$*$} \\
\hline & ESM $1.5(\mathrm{~s})$ & 29 & $24.4(5.3)$ & -1.7 & {$[-3.8,0.4]$} & \\
\hline & ESM $4.5(\mathrm{~s})$ & 29 & $26.6(5.8)$ & 0.4 & {$[-1.2,2.1]$} & \\
\hline & $\mathrm{ZOP}(\mathrm{s})$ & 29 & $26.0(5.1)$ & -0.1 & {$[-2.0,1.8]$} & \\
\hline & $\operatorname{PLA}(\mathrm{m})$ & 28 & $27.0(5.7)$ & & & \\
\hline & ESM $1.5(\mathrm{~m})$ & 30 & $26.7(6.5)$ & 0.2 & {$[-2.3,2.6]$} & \\
\hline & ESM $4.5(\mathrm{~m})$ & 30 & $26.8(5.9)$ & -0.2 & {$[-2.7,2.3]$} & \\
\hline \multirow{6}{*}{$\begin{array}{l}\text { Delayed } \\
\text { Recall Score } \\
(\#)\end{array}$} & $\begin{array}{l}\text { PLA (s) } \\
\text { ESM } 1.5(\mathrm{~s})\end{array}$ & $\begin{array}{l}31 \\
29\end{array}$ & $\begin{array}{l}9.3(2.9) \\
7.8(3.3)\end{array}$ & -1.4 & {$[-2.5,-0.3]$} & \\
\hline & ESM 4.5 (s) & 29 & $8.6(3.6)$ & -0.7 & {$[-1.6,0.2]$} & \\
\hline & $\mathrm{ZOP}(\mathrm{s})$ & 28 & $8.7(3.0)$ & -0.6 & {$[-1.5,0.3]$} & \\
\hline & $\operatorname{PLA}(\mathrm{m})$ & 28 & $8.9(3.3)$ & & & \\
\hline & ESM $1.5(\mathrm{~m})$ & 30 & $9.4(3.5)$ & 0.7 & {$[-0.4,1.8]$} & \\
\hline & ESM $4.5(\mathrm{~m})$ & 29 & $9.3(3.1)$ & 0.6 & {$[-0.4,1.6]$} & \\
\hline \multicolumn{7}{|c|}{ Divided Attention Task } \\
\hline \multirow{4}{*}{$\begin{array}{l}\text { Tracking } \\
\text { Error }(\mathrm{mm})\end{array}$} & $\begin{array}{l}\text { PLA (s) } \\
\text { ESM } 1.5(\mathrm{~s})\end{array}$ & $\begin{array}{l}31 \\
29\end{array}$ & $\begin{array}{l}19.9(3.8) \\
21.3(4.2)\end{array}$ & 1.4 & {$[0.6,2.3]$} & $*$ \\
\hline & ESM 4.5 (s) & 31 & $21.8(4.3)$ & 2.0 & {$[0.9,3.1]$} & $*$ \\
\hline & $\begin{array}{l}\mathrm{ZOP}(\mathrm{s}) \\
\mathrm{PIA}(\mathrm{m})\end{array}$ & $\begin{array}{l}29 \\
30\end{array}$ & $20.1(4.6)$ & 0.2 & {$[-0.9,1.3]$} & \\
\hline & ESM $1.5(\mathrm{~m})$ & 30 & $21.4(4.1)$ & $\begin{array}{l}1.2 \\
0.9\end{array}$ & {$[0.1,2.2]$} & $*$ \\
\hline \multirow{6}{*}{$\begin{array}{l}\text { Respone Time } \\
\text { (msec) }\end{array}$} & PLA (s) & 31 & $1770(246)$ & & & \multirow{6}{*}{$*$} \\
\hline & ESM $1.5(\mathrm{~s})$ & 29 & $1899(261)$ & 139 & {$[33,246]$} & \\
\hline & ESM $4.5(\mathrm{~s})$ & 31 & 1859 (247) & 95 & {$[-3,192]$} & \\
\hline & $\mathrm{ZOP}(\mathrm{s})$ & 29 & $1833(205)$ & 62 & {$[-33,157]$} & \\
\hline & $\operatorname{ESM} 1.5(\mathrm{~m})$ & 30 & $\begin{array}{l}1 / 83(228) \\
1812(202)\end{array}$ & 27 & {$[-50,105]$} & \\
\hline & ESM $4.5(\mathrm{~m})$ & 30 & $1811(211)$ & 30 & {$[-49,109]$} & \\
\hline \multicolumn{7}{|c|}{ Critical Tracking Task } \\
\hline \multirow{7}{*}{$\begin{array}{l}\text { Critical Fre- } \\
\text { quency (rad/ } \\
\text { sec) }\end{array}$} & PLA (s) & 31 & $3.43(0.62)$ & & & \\
\hline & ESM 1.5 (s) & 30 & $3.36(0.61)$ & -0.10 & {$[-0.22,0.02]$} & \\
\hline & ESM 4.5 (s) & 32 & $3.29(0.68)$ & -0.15 & {$[-0.33,0.03]$} & \\
\hline & ZOP (s) & 30 & $3.38(0.79)$ & -0.05 & {$[-0.22,0.12]$} & \\
\hline & PLA (m) & 30 & $3.41(0.72)$ & & & \\
\hline & ESM $1.5(\mathrm{~m})$ & 30 & $3.44(0.62)$ & 0.02 & {$[-0.12,0.16]$} & \\
\hline & ESM $4.5(\mathrm{~m})$ & 30 & $3.34(0.70)$ & -0.07 & {$[-0.22,0.08]$} & \\
\hline \multicolumn{7}{|c|}{ Stop Signal Task } \\
\hline \multirow{6}{*}{$\begin{array}{l}\text { Stop Reaction } \\
\text { Time (msec) }\end{array}$} & PLA (s) & 31 & $288(48)$ & & & \\
\hline & ESM 1.5 (s) & 30 & $292(46)$ & 4 & {$[-15,23]$} & \\
\hline & ESM 4.5 (s) & 32 & $297(51)$ & 8 & {$[-13,30]$} & \\
\hline & ZOP (s) & 30 & $292(49)$ & 4 & {$[-15,23]$} & \\
\hline & $\begin{array}{l}\operatorname{PLA}(\mathrm{m}) \\
\operatorname{ESM} 1.5(\mathrm{~m})\end{array}$ & $\begin{array}{l}30 \\
30\end{array}$ & $\begin{array}{l}285(45) \\
297(57)\end{array}$ & 13 & {$[-11,36]$} & \\
\hline & ESM $4.5(\mathrm{~m})$ & 30 & $288(49)$ & 3 & {$[-18,24]$} & \\
\hline
\end{tabular}




\section{Pharmacokinetics}

A summary of mean (SD) and median esmirtazapine concentrations is given in Table 2. In general, mean and median esmirtazapine concentrations in poor metabolizers were about twice as high as those of extensive metabolizers.

Table 2 Mean (SD) and median esmirtazapine plasma concentrations $(\mathrm{ng} / \mathrm{mL})$ in poor and extensive metabolizers.

\begin{tabular}{|c|c|c|c|c|c|c|c|}
\hline & & \multicolumn{2}{|c|}{$\begin{array}{l}\text { Extensive metabolizers } \\
(\mathrm{N}=25)\end{array}$} & \multicolumn{2}{|c|}{$\begin{array}{l}\text { Poor Metabolizers } \\
(\mathrm{N}=7)\end{array}$} & \multicolumn{2}{|l|}{$\begin{array}{l}\text { Overall } \\
(\mathrm{N}=32)\end{array}$} \\
\hline \multicolumn{2}{|c|}{ Esmirtazapine } & Day 2 & Day 8 & Day 2 & Day 8 & Day 2 & Day 8 \\
\hline \multirow[t]{2}{*}{$1.5 \mathrm{mg}$} & $\begin{array}{l}\text { Mean } \\
\text { (SD) }\end{array}$ & $\begin{array}{l}0.53 \\
(1.02)\end{array}$ & $\begin{array}{l}0.54 \\
(0.42)\end{array}$ & $\begin{array}{l}0.67 \\
(0.27)\end{array}$ & $\begin{array}{l}0.97 \\
(0.70)\end{array}$ & $\begin{array}{l}0.56 \\
(0.91)\end{array}$ & $\begin{array}{l}0.63 \\
(0.51)\end{array}$ \\
\hline & Median & 0.34 & 0.47 & 0.66 & 0.81 & 0.35 & 0.48 \\
\hline \multirow[t]{2}{*}{$4.5 \mathrm{mg}$} & $\begin{array}{l}\text { Mean } \\
(\mathrm{SD})\end{array}$ & $\begin{array}{l}1.05 \\
(0.44)\end{array}$ & $\begin{array}{l}1.52 \\
(0.66)\end{array}$ & $\begin{array}{l}2.07 \\
(0.84)\end{array}$ & $\begin{array}{l}2.12 \\
(0.96)\end{array}$ & $\begin{array}{l}1.28 \\
(0.70)\end{array}$ & $\begin{array}{l}1.64 \\
(0.75)\end{array}$ \\
\hline & Median & 0.92 & 1.29 & 1.80 & 2.53 & 1.10 & 1.38 \\
\hline
\end{tabular}

\section{Adverse events}

Treatment of esmirtazapine for 7 days was generally safe and well tolerated. Overall, somnolence and fatigue were the most frequently reported adverse events. Somnolence was mainly experienced by subjects treated with esmirtazapine 1.5 or $4.5 \mathrm{mg}$. A summary of adverse events reported with incidence of at least $5 \%$ in any treatment during all treatments and during the first 24 hrs after first treatment dose is given in Table 3 and 4 respectively. 
Table 3 Summary of adverse events with an incidence of at least $5 \%$ in any treatment group.

\begin{tabular}{|c|c|c|c|c|}
\hline Adverse events & $\begin{array}{l}\text { Placebo } \\
(\mathrm{N}=31) \\
\mathrm{n}(\%)\end{array}$ & $\begin{array}{l}\text { Esmirtazapine } \\
1.5 \mathrm{mg} \\
(\mathrm{N}=30) \\
\mathrm{n}(\%)\end{array}$ & $\begin{array}{l}\text { Esmirtazapine } \\
4.5 \mathrm{mg} \\
(\mathrm{N}=32) \\
\mathrm{n}(\%)\end{array}$ & $\begin{array}{l}\text { Zopiclone } \\
7.5 \mathrm{mg} \\
(\mathrm{N}=30) \\
\mathrm{n}(\%)\end{array}$ \\
\hline Fatigue & $11(35.5)$ & $12(40.0)$ & $9(28.1)$ & $3(10.0)$ \\
\hline Somnolence & $1(3.2)$ & $9(30.0)$ & $10(31.3)$ & $1(3.3)$ \\
\hline Headache & $2(6.5)$ & $4(13.3)$ & $1(3.1)$ & $1(3.3)$ \\
\hline Poor quality sleep & $6(19.4)$ & $3(10.0)$ & $1(3.1)$ & $1(3.3)$ \\
\hline Dysgeusia & $4(12.9)$ & $2(6.7)$ & $1(3.1)$ & $1(3.3)$ \\
\hline Nasopharyngitis & $1(3.2)$ & $2(6.7)$ & $1(3.1)$ & $0(0.0)$ \\
\hline Dizziness & $1(3.2)$ & $2(6.7)$ & $2(6.3)$ & $1(3.1)$ \\
\hline Disturbance in attention & $1(3.2)$ & $2(6.7)$ & $1(3.1)$ & $0(0.0)$ \\
\hline Oral herpes & $0(0.0)$ & $2(6.7)$ & $0(0.0)$ & $0(0.0)$ \\
\hline Oropharyngeal pain & $0(0.0)$ & $2(6.7)$ & $0(0.0)$ & $0(0.0)$ \\
\hline Dry mouth & $1(3.2)$ & $1(3.3)$ & $2(6.3)$ & $0(0.0)$ \\
\hline Vomiting & $2(6.5)$ & $0(0.0)$ & $1(3.1)$ & $1(3.3)$ \\
\hline Irritability & $2(6.5)$ & $0(0.0)$ & $0(0.0)$ & $0(0.0)$ \\
\hline
\end{tabular}

Table 4 Summary of adverse events during the first $24 \mathrm{hr}$ after first drug intake only, with an incidence of at least $5 \%$ in any treatment group.

\begin{tabular}{lllll}
\hline & Placebo & $\begin{array}{l}\text { Esmirtazapine } \\
1.5 \mathrm{mg}\end{array}$ & $\begin{array}{l}\text { Esmirtazapine } \\
4.5 \mathrm{mg}\end{array}$ & $\begin{array}{l}\text { Zopiclone } \\
7.5 \mathrm{mg}\end{array}$ \\
& $(\mathrm{N}=31)$ & $(\mathrm{N}=30)$ & $(\mathrm{N}=32)$ & $(\mathrm{N}=30)$ \\
Adverse events & $\mathrm{n}(\%)$ & $\mathrm{n}(\%)$ & $\mathrm{n}(\%)$ & $\mathrm{n}(\%)$ \\
\hline Fatigue & $6(19.4)$ & $10(33.3)$ & $9(28.1)$ & $2(6.7)$ \\
Somnolence & $1(3.2)$ & $4(13.3)$ & $8(25.0)$ & $0(0.0)$ \\
Dysgeusia & $3(9.7)$ & $2(6.7)$ & $1(3.1)$ & $1(3.3)$ \\
Disturbance in attention $)$ & $0(0.0)$ & $2(6.7)$ & $1(3.1)$ & $0(0.0)$ \\
Headache & $1(3.2)$ & $2(6.7)$ & $0(0.0)$ & $1(3.3)$ \\
Poor quality sleep & $5(16.1)$ & $1(3.3)$ & $0(0.0)$ & $1(3.3)$ \\
Irritability & $2(6.5)$ & $0(0.0)$ & $0(0.0)$ & $0(0.0)$ \\
\hline
\end{tabular}


After single dose administration, somnolence and fatigue were also the most frequently reported adverse events. Note that adverse events summarized under placebo were reported on two single dose days (i.e combining the $1^{\text {st }}$ day of placebo in the zopiclone group and $1^{\text {st }}$ day of placebo in the placebo group). Furthermore, while the single dose safety evaluation of placebo and esmirtazapine refer to the $1^{\text {st }}$ day of treatment, the single dose zopiclone results refer to the $7^{\text {th }}$ day of treatment, where subjects are less likely to report AEs (including drug related AE) if these AE were already reported earlier during this treatment period while on placebo. As can be seen in Table 4, the overall frequency of adverse events as well as the frequencies of reported somnolence and fatigue while on zopiclone is lower than that reported while on placebo.

\section{Discussion}

Overall, non-inferiority vs. placebo was demonstrated for multiple doses of $1.5 \mathrm{mg}$ and multiple doses of $4.5 \mathrm{mg}$ esmirtazapine as compared to placebo. The results for these esmirtazapine doses indicated that the overall effects of esmirtazapine on car driving were mild and of no clinical relevance after one week of dosing. However, following a single dose of $4.5 \mathrm{mg}$ esmirtazapine, noninferiority could not be demonstrated as compared to placebo. While the mean SDLP difference vs. placebo was somewhat lower than the effect observed with $0.05 \mathrm{BAC}$, the upper limit of the 95\% CI exceeded the non-inferiority margin. Thus, a single dose of $4.5 \mathrm{mg}$ esmirtazapine produced a statistically and clinically significant driving impairment. After repeated administration for one week, both doses of esmirtazapine did not produce any residual impairment as is evident by the finding that the 95\% CI of mean difference in SDLP vs. placebo always contained zero and its upper limit was well below the non-inferiority margin. The finding of driving impairment after single dose of $4.5 \mathrm{mg}$ but not after single doses of $1.5 \mathrm{mg}$ esmirtazapine suggests that the acute effect of esmirtazapine on driving impairment is dose dependent. This effect rapidly resolves after repeated administration.

Previous studies ${ }^{8,31}$ on the effects of $\mathrm{H}_{1}$-antihistamines on actual driving performance have shown more pronounced effects on SDLP than those observed after esmirtazapine in the present study, however, the overall pattern was similar. Antidepressants with strong $\mathrm{H}_{1}$-antihistamine activity such as amitriptyline, imipramine and doxepin all produced significant driving impairment after single doses administered during the day. Difference in SDLP from placebo after single doses of these sedating antidepressants were comparable to those seen in drivers conducting the same test with a blood alcohol concentration (BAC) of $0.8 \mathrm{mg} / \mathrm{mL}$ or higher. The impairing effects of sedating antidepressants 
such as mirtazapine on next-day driving performance however were markedly lower when given in the evening. The impairing effects of antidepressants on driving were mostly present after single doses but disappeared after one week of repeated dosing due to tolerance ${ }^{8}$. Likewise, single doses of antihistamines have been demonstrated to significantly increase SDLP in a dose related manner ${ }^{31}$. However, the impairing effects of antihistamines on actual driving also resolved after 4-7 days after repeated dosing. In the present study, a single dose of esmirtazapine $4.5 \mathrm{mg}$ also produced significant driving impairment, but the impairing effects rapidly resolved after one week of repeated dosing. The implications will be twofold. First, next day driving need not be a priori contraindicated for esmirtazapine $1.5 \mathrm{mg}$ as overall it did not produce relevant driving impairment after single and repeated doses. Second, next day driving is not advised for patients taking a higher dose of esmirtazapine (i.e. $4.5 \mathrm{mg}$ ), but only during treatment initiation or initially after dose increase.

However, while the overall effect of esmirtazapine on driving performance is limited and transient, some subjects may be more susceptible to drug effects on driving impairment. In the case of esmirtazapine, which is a substrate for CYP2D6, patients who are poor metabolizers of CYP2D6 may experience greater impairment. In general CYP2D6 has high relevance in drug metabolism. CYP2D6 is involved in the metabolism of $20 \%-25 \%$ of clinically used drugs and exhibits a clinically relevant gene polymorphism that modifies the pharmacokinetics in patients that are either poor or extensive metabolizers ${ }^{32}$, 33. About 5-10\% of the Caucasian populations are poor metabolizers of CYP2D6 substrates which may cause elevated substrate concentrations in blood of these individuals. In the present study, 7 subjects (22\%) were phenotyped as poor metabolizers. Especially for $4.5 \mathrm{mg}$ esmirtazapine, mean and median plasma concentrations of esmirtazapine were about twice as high as the levels observed in extensive metabolizers. Poor metabolizers also appeared to be more sensitive to the impairing potential of esmirtazapine. Increments in SDLP were more pronounced compared with placebo after single doses of esmirtazapine 1.5 and $4.5 \mathrm{mg}$ in poor metabolizers. After a week of repeated dosing, the low dose of esmirtazapine no longer produced any relevant impairment in poor metabolizers. However, while the absolute effect on SDLP compared to placebo for poor metabolizers was still below the non-inferiority margin of $2.5 \mathrm{~cm}$, the highest dose still produced an increment in SDLP after one week of dosing, which may indicate that tolerance to impairing effects of esmirtazapine may not have been complete after 7 days of dosing. These findings support the notion that dose effects of esmirtazapine on driving are closely related to the drug's concentration in plasma.

For the extensive metabolizers, the results were similar to those obtained in the main analysis. No relevant impairment was observed after single and multiple 
doses of esmirtazapine $1.5 \mathrm{mg}$, whereas esmirtazapine $4.5 \mathrm{mg}$ produced a small, but clinically relevant increase in SDLP only after the initial dose.

A limitation of this explorative analysis on poor metabolizers is $(\mathrm{N}=7)$ is that the present study was not powered to demonstrate non-inferiority of esmirtazapine to placebo in this small number of subjects $(\mathrm{N}=7)$. Small numbers of subjects lead to wider confidence intervals which increase the chance that upper limits of $95 \%$ confidence intervals exceed a pre-specified limit, hampering their interpretation. For example, CIs in poor metabolizers $(\mathrm{N}=7)$ are about twice as wide as those in extensive metabolizers $(\mathrm{N}=25)$. Consequently one must be cautious when comparing the upper CI limit of the mean difference in SDLP with placebo in poor metabolizers to a pre-established alcohol equivalent, as the CI may actually become less wide with increasing subject numbers. Nonetheless, the results of the current analysis indicated more pronounced driving impairment in poor metabolizers after treatment with esmirtazapine. Although the exact magnitude of this driving impairment should be determined in a larger subject sample when comparing to alcohol criterion levels, these results are in line with the observation that esmirtazapine has a dose dependent effect on driving performance, with impairment observed after a single dose of $4.5 \mathrm{mg}$ or higher. In subjects with higher exposure, such as CYP2D6 poor metabolizers, the effect on driving performance is therefore likely to be more pronounced and impairment may be experienced even with a lower dose. It should be noted that the CYP2D6 phenotype only accounts for some of the inter-individual variability observed in the driving performance. While an effect on performance by gender and age, for example, was not observed, other factors may still exist that significantly influence the subject's susceptibility to drug effect on car driving performance. Thus, the general implications of these findings with regards to clinical practice may result in a recommendation to start treatment with the lowest available dose until therapeutic effect and tolerability are evaluated. Esmirtazapine is being evaluated for the treatment of insomnia in the dose range of $1.5-4.5 \mathrm{mg}$. Given the acute effect of esmirtazapine at $4.5 \mathrm{mg}$ on driving performance, a $1.5 \mathrm{mg} /$ day starting dose of esmirtazapine treatment may be recommended until therapeutic effect and tolerance is evaluated and the need to increase the dose is confirmed.

It should be noted here that factors that influence variability in drug response in general, and specifically CYP2D6 phenotype, do not just pertain to esmirtazapine. For example, CYP2D6 is the major route of metabolism for many sedative CNS drugs such as antidepressants, antipsychotics, opioids and antihistamines ${ }^{32}$. Previous studies on the effects of drugs on driving have never taken CYP2D6 genotype into account. These explorative results indicate that subjects with genetic CYP deviations (e.g. poor CYP2D6 metabolizers) may be at higher risk to be exposed to higher levels of drugs or metabolites which 
have the potential to impair car driving. A distinction in poor and extensive metabolizers may be of particular importance when overall driving impairment levels in the general study population are mild. Based on such an overall finding, the conclusion would be that driving is not contraindicated for a particular substance. However, factors which influence exposure to these drugs need to be taken into account. Especially if there is a dose-response relationship between car driving performance and dose of the drug, then factors which increase exposure (e.g. gender, race, age or P450 polymorphism) are likely to display more pronounced car driving impairment, which may reach levels of clinical relevance. Consequently, it should be recommended to always take factors likely to affect drug exposure and response, such as cytochrome $\mathrm{P} 450$ polymorphism, into account when designing future studies on drug effects on driving.

In the present study, single doses of zopiclone $7.5 \mathrm{mg}$ increased SDLP by 2.6 $\mathrm{cm}$ over placebo. Mean difference in SDLP with placebo and its 95\% CI upper limit exceeded the non-inferiority margin of $2.5 \mathrm{~cm}$ and the CI excluded zero. These data support findings from a number of previous studies that assessed the influence of zopiclone $7.5 \mathrm{mg}$ on SDLP as measured in the standardized highway driving test ${ }^{23,34,35}$. All of these studies demonstrated that evening doses of zopiclone produced residual driving impairment in the morning. In all studies, the impairing effects of zopiclone $7.5 \mathrm{mg}$ where comparable to a BAC between 0.5 and $0.8 \mathrm{mg} / \mathrm{mL}$. In the present study, impairment after zopiclone confirmed the sensitivity of the highway driving test for sedative drug effects and confirmed previous warnings concerning driving $23,34,35$.

Overall, low doses of esmirtazapine $(1.5 \mathrm{mg})$ did not produce any relevant driving impairment after single and repeated dosing. Driving impairment did occur after a higher single dose of emirtazapine $(4.5 \mathrm{mg})$ but resolved after repeated doses. The explorative results on the subgroup of poor metabolizers $(\mathrm{N}=7)$ indicated more pronounced car driving impairment after both doses of esmirtazapine, but not on the subgroup of extensive metabolizers $(\mathrm{N}=25)$. In these individuals, impairment appeared to persist after 7 days after administration of the highest dose.

\section{References}

1. De Boer, T. \& Ruigt, G. S. F. The selective effects of mirtazapine on central noradreniergic and serotonergic neurotransmission. Int Clin Psychopharmacol 10 19-23 (1995).

2. Pinder, R. M. \& Van Delft, A. M. The potential therapeutic role of the enantiomers and metabolites of mianserin. Br J Clin Pharmacol 15 Suppl 2, 269S-276S (1983).

3. de Boer, T. H. et al. Neurochemical and autonomic pharmacological profiles of the 6-azaanalogue of mianserin, Org 3770 and its enantiomers. Neuropharmacology 27, 399- 
408 (1988).

4. Kooyman, A. R., Zwart, R., Vanderheijden, P. M., Van Hooft, J. A. \& Vijverberg, H. P. Interaction between enantiomers of mianserin and ORG3770 at 5-HT3 receptors in cultured mouse neuroblastoma cells. Neuropharmacology 33, 501-507 (1994).

5. Biswas, P. N., Wilton, L. V. \& Shakir, S. A. The pharmacovigilance of mirtazapine: results of a prescription event monitoring study on 13554 patients in England. J Psychopharmacol 17, 121-126 (2003).

6. Curran, H. V., Shine, P. \& Lader, M. Effects of repeated doses of fluvoxamine, mianserin and placebo on memory and measures of sedation. Psychopharmacology (Berl) 89, 360-363 (1986).

7. Mattila, M., Mattila, M. J., Vrijmoed-de Vries, M. \& Kuitunen, T. Actions and interactions of psychotropic drugs on human performance and mood: single doses of ORG 3770, amitriptyline, and diazepam. Pharmacol Toxicol 65, 81-88 (1989).

8. Ramaekers, J. G. Antidepressants and driver impairment: empirical evidence from a standard on-the-road test. J Clin Psychiatry 64, 20-29 (2003).

9. Ramaekers, J. G., Muntjewerff, N. D., Van Veggel, L. M. A., Uiterwijk, M. M. C. \& O’Hanlon, J. F. Effects of Nocturnal Doses of Mirtazapine and Mianserin on Sleep and on Daytime Psychomotor and Driving Performance in Young, Healthy Volunteers. Hum Psychopharmacol 13, S87-S97 (1998).

10. Ramaekers, J. G., Swijgman, H. F. \& O’Hanlon, J. F. Effects of moclobemide and mianserin on highway driving, psychometric performance and subjective parameters, relative to placebo. Psychopharmacology (Berl) 106 Suppl, S62-S67 (1992).

11. Ridout, F., Meadows, R., Johnsen, S. \& Hindmarch, I. A placebo controlled investigation into the effects of paroxetine and mirtazapine on measures related to car driving performance. Hum Psychopharmacol 18, 261-269 (2003).

12. Wingen, M., Bothmer, J., Langer, S. \& Ramaekers, J. G. Actual driving performance and psychomotor function in healthy subjects after acute and subchronic treatment with escitalopram, mirtazapine, and placebo: a crossover trial. J Clin Psychiatry 66, 436443 (2005).

13. Wingen, M., Langer, S. \& Ramaekers, J. G. Verbal memory performance during subchronic challenge with a selective serotonergic and a mixed action antidepressant. Hum Psychopharmacol 21, 473-479 (2006).

14. Anttila, S. A. \& Leinonen, E. V. A review of the pharmacological and clinical profile of mirtazapine. CNS Drug Rev 7, 249-264 (2001).

15. Radhakishun, F. S., van den Bos, J., van der Heijden, B. C., Roes, K. C. \& O’Hanlon, J. F. Mirtazapine effects on alertness and sleep in patients as recorded by interactive telecommunication during treatment with different dosing regimens. J Clin Psychopharmacol 20, 531-537 (2000).

16. Ruigt, G. S., Kemp, B., Groenhout, C. M. \& Kamphuisen, H. A. Effect of the antidepressant Org 3770 on human sleep. Eur J Clin Pharmacol 38, 551-554 (1990).

17. Schmid, D. A. et al. Changes of sleep architecture, spectral composition of sleep EEG, the 
nocturnal secretion of cortisol, ACTH, GH, prolactin, melatonin, ghrelin, and leptin, and the DEX-CRH test in depressed patients during treatment with mirtazapine. Neuropsychopharmacology 31, 832-844 (2006).

18. Winokur, A. et al. Acute effects of mirtazapine on sleep continuity and sleep architecture in depressed patients: a pilot study. Biol Psychiatry 48, 75-78 (2000).

19. Mayers, A. G. \& Baldwin, D. S. Antidepressants and their effect on sleep. Hum Psychopharmacol 20, 533-559 (2005).

20. Stahl, S. M. Selective histamine H1 antagonism: novel hypnotic and pharmacologic actions challenge classical notions of antihistamines. CNS Spectr 13, 1027-1038 (2008).

21. van Laar, M., Volkerts, E. \& Verbaten, M. Subchronic effects of the GABA-agonist lorazepam and the 5-HT2A/2C antagonist ritanserin on driving performance, slow wave sleep and daytime sleepiness in healthy volunteers. Psychopharmacology (Berl) 154, 189197 (2001).

22. Brockmoller, J., Meineke, I. \& Kirchheiner, J. Pharmacokinetics of mirtazapine: enantioselective effects of the CYP2D6 ultra rapid metabolizer genotype and correlation with adverse effects. Clin Pharmacol Ther 81, 699-707 (2007).

23. Vermeeren, A. Residual effects of hypnotics: epidemiology and clinical implications. CNS Drugs 18, 297-328 (2004).

24. O'Hanlon, J. F. Driving performance under the influence of drugs: rationale for, and application of, a new test. Br J Clin Pharmacol 18 Suppl 1, 121S-129S (1984).

25. O’Hanlon, J. F., Haak, T. W., Blaauw, G. J. \& Riemersma, J. B. Diazepam impairs lateral position control in highway driving. Science 217, 79-81 (1982).

26. Louwerens, J. W., Gloerich, A. B. M., de Vries, G., Brookhuis, K. A. \& O’Hanlon, J. F. in International Congres on Alcohol, Drugs and Traffic Safety, T86 (eds. Noordzij, P. C. \& Roszbach, R.) 183-186 (Exerpta Medica, Amsterdam, 1987).

27. Rey, A. Léxamen clinique en psychologie (Presses Universitaires de France Paris, 1964).

28. Fillmore, M. T., Rush, C. R. \& Hays, L. Acute effects of oral cocaine on inhibitory control of behavior in humans. Drug Alcohol Depen 67, 157-167 (2002).

29. Ramaekers, J. G. et al. High-potency marijuana impairs executive function and inhibitory motor control. Neuropsychopharmacology 31, 2296-2303 (2006).

30. Ramaekers, J. G. \& Kuypers, K. P. Acute effects of 3,4-methylenedioxymethamphetamine (MDMA) on behavioral measures of impulsivity: alone and in combination with alcohol. Neuropsychopharmacology 31, 1048-1055 (2006).

31. O’Hanlon, J. F. \& Ramaekers, J. G. Antihistamine effects on actual driving performance in a standard test: a summary of Dutch experience, 1989-94. Allergy 50, 234-242 (1995).

32. Ingelman-Sundberg, M., Sim, S. C., Gomez, A. \& Rodriguez-Antona, C. Influence of cytochrome $\mathrm{P} 450$ polymorphisms on drug therapies: pharmacogenetic, pharmacoepigenetic and clinical aspects. Pharmacol Ther 116, 496-526 (2007).

33. Tomalik-Scharte, D., Lazar, A., Fuhr, U. \& Kirchheiner, J. The clinical role of genetic polymorphisms in drug-metabolizing enzymes. Pharmacogenomics 8, 4-15 (2008). 
34. Leufkens, T. R., Lund, J. S. \& Vermeeren, A. Highway driving performance and cognitive functioning the morning after bedtime and middle-of-the-night use of gaboxadol, zopiclone and zolpidem. J Sleep Res 18, 387-396 (2009).

35. Leufkens, T. R. \& Vermeeren, A. Highway driving in the elderly the morning after bedtime use of hypnotics: a comparison between temazepam $20 \mathrm{mg}$, zopiclone $7.5 \mathrm{mg}$, and placebo. J Clin Psychopharmacol 29, 432-438 (2009). 


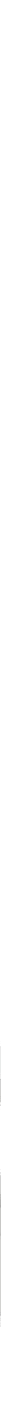




\section{Chapter 4}

\section{Affinity for the $P$-gp transporter determines CNS sedation of antihistamines}

Submitted as:

Conen S, Theunissen EL, Vermeeren A, Van Ruitenbeek P, Stiers P, Mehta MA, Ramaekers JG. Affinity for the P-gp transporter determines CNS sedation of antihistamines. 



\section{Abstract}

P-glycoprotein (P-gp) is a drug efflux pump expressed, amongst others, on the luminal surface of the cerebral endothelial cells forming the blood-brain barrier. Studies in rodents have demonstrated that antihistamines that are substrates of the P-gp transporter display no or minor central nervous system (CNS) effects as compared to antihistamines that are not P-gp transporter substrates. The present study explored whether P-gp contributes in similar ways to the occurrence of sedative effects of antihistamines in humans.

An fMRI study was conducted according to a double-blind, randomized, placebo-controlled, cross-over design in 13 healthy volunteers. Participants received cetirizine $15 \mathrm{mg}$ (an antihistamine); verapamil $120 \mathrm{mg}$ (a P-gp blocker); a combination of cetirizine + verapamil; and a placebo. Brain activity was assessed while conducting the attention network task (ANT) in a 3T magnetic resonance scanner. The ANT measures three independent attention domains: i.e. alerting, orienting and executive attention. It was expected that the combined treatment of cetirizine with verapamil would prevent efflux of cetirizine from the CNS, thus increasing attentional impairment, as compared to cetirizine administered alone.

The present study provides evidence that the P-gp transporter is involved in central antihistamine effects in humans. Participants were less alert during the combined treatment of cetirizine and verapamil as indicated by longer reaction times and decreased BOLD response in the right superior temporal gyrus. It is concluded that the affinity for the P-gp transporter may contribute to the lower incidence of CNS side effects of certain antihistamines.

\section{Introduction}

Sedation is a frequently occurring side effect of antihistamines (AHs) that can produce attentional impairments in day to day operations such as driving a car and working ${ }^{1-8}$. The magnitude of sedation varies between individual $\mathrm{AHs}$, but is more prominent in first generation AHs as compared to second generation AHs ${ }^{5,9-11}$. It is thought that the lipophilicity of first generation antihistamines enables them to cross the blood-brain barrier and bind to central histamine-1 
receptors (H1Rs) whereby they reduce the wake-promoting effects of centrally acting histamine. Second generation antihistamines are less lipophilic and therefore produce less sedation ${ }^{10}$.

Besides lipophilicity, the presence and/or magnitude of sedation may also be determined by the P-glycoprotein ( $\mathrm{P}$-gp) transporter ${ }^{12-16}$. P-gp is an efflux transporter that is expressed on the luminal surface of the cerebral endothelial cells forming the blood brain barrier. P-gp and other transporters actively pump substrates out of the brain, thereby limiting their effects in the central nervous system (CNS) ${ }^{12,13,17-19}$.

Studies in experimental animal models have demonstrated that the P-gp transporter may reduce CNS effects of $2^{\text {nd }}$ generation AHs. When comparing wild-type mice with P-gp knockout mice, the latter showed significantly higher brain distribution of non-sedative $2^{\text {nd }}$ generation AHs such as cetirizine, loratadine, and desloratadine. On the other hand, brain penetration of sedative $1^{\text {st }}$ generation AHs hydroxyzine, diphenhydramine, and triprolidine did not differ between wild-type and P-gp knockout mice 13, 20. This apparent difference between $2^{\text {nd }}$ and $1^{\text {st }}$ generation AHs is in keeping with the knowledge that only the former are P-gp substrates ${ }^{16}$. $\mathrm{P}$-gp is also expressed in the small intestine, liver and kidney, and studies in humans have revealed that $\mathrm{P}$-gp affects the pharmacokinetics of AHs. For example, P-gp inhibition has been shown to increase blood plasma concentrations of the second generation antihistamine fexofenadine ${ }^{21-}$ 23. However, to our knowledge, no human studies have been conducted to study the role of the P-gp transporter on pharmacodynamic effects caused by AHs, such as CNS sedation. Data from animal research may serve as a translational model for potential effects in humans, but these results need to be confirmed and validated in human subjects.

This project focused on the role of the P-gp transporter in the occurrence of CNS sedation after administration of cetirizine, a $2^{\text {nd }}$ generation antihistamine, in healthy volunteers. Blocking the P-gp transporter was expected to increase the distribution of cetirizine and to produce more CNS sedation due to enhanced H1R binding in the brain. It was hypothesized that sedation after cetirizine would be apparent in combination with a P-gp blocker, but not when administered alone.

Impairing effects of antihistamines have often been demonstrated in attention tasks ${ }^{9,24-26}$. In the present proposal we selected the Attention Network Test (ANT) to assess the sedative effects of cetirizine with and without P-gp blockade, in three independent attention domains: i.e. alerting, orienting and executive attention. The ANT task was conducted during functional MRI in order to assess drug induced changes in the neural networks underlying performance in the three attention domains. Previous research has shown that fMRI can be effectively used to examine drug induced changes in CNS functions ${ }^{27,28}$. 


\section{Methods}

\section{Subjects}

Eight healthy male and eight healthy female volunteers were recruited through poster advertisement. However, four participants could not complete all sessions. Hence, data will be reported on 13 participants for the behavioural data $(7$ male and 6 female; age range 19 to 33 years; mean \pm SD: $22.31 \pm 3.6$ years), and 12 participants for the imaging data ( 7 male, 5 female; age range 19 to 33 years; mean \pm SD: $22.42 \pm 3.8$ years). The 13 participants had a body mass index between 19.3 and $24.3 \mathrm{~kg} / \mathrm{m}^{2}$ (mean \pm SD: $21.25 \pm 1.5$ ). Participants were screened using a medical questionnaire and a physical examination. The latter included a 12-lead electrocardiogram evaluation, blood chemistry and haematology, urinalysis, and drug and pregnancy screening.

Volunteers with a history of medical or psychiatric illness, any major medical, endocrine and/or neurological condition, hypertension (diastolic $>100$; systolic $>170$ ); hypersensitivity to $\mathrm{H} 1$-antihistamines and/or seasonal allergic rhinitis or urticaria treated by antihistamines were excluded from the study. Additional exclusion criteria were alcohol consumption of more than 21 units per week; smoking; caffeine consumption of more than 6 cups per day; history of drug abuse or addiction; treatment with atropine or atropine-like drugs; and treatment with CNS depressants. Female volunteers could not participate when pregnant or breast feeding, and were allowed to use oral contraceptives.

The study was approved by the standing medical ethics committee of Maastricht University/University Hospital Maastricht and was carried out in compliance with the code of ethics on human experimentation established by the Declaration of Helsinki (1964), amended in Seoul (2008), and the principles of the International Conference on Harmonization guideline for Good Clinical Practice. Participants gave their written informed consent prior to study participation.

\section{Design and treatments}

The study was conducted according to a randomized, double blind, 4-way crossover design with treatments consisting of cetirizine $15 \mathrm{mg}$, verapamil $120 \mathrm{mg}$, cetirizine $15 \mathrm{mg}$ and verapamil $120 \mathrm{mg}$, and placebo. Cetirizine is a widely used $\mathrm{Hl}$-antihistamine for the treatment of seasonal and perennial allergic rhinitis, urticaria and pruritis ${ }^{5,20}$. It is a mildly-sedative $\mathrm{H} 1$-antihistamine, causing slight 
sedation at low doses ${ }^{29}$. Peak plasma concentrations are reached between 1 and 1.5 hours after oral ingestion. Its half-life varies on average between 7 and 11 hours ${ }^{30}$.

Verapamil is a calcium ion influx inhibitor and used in order to treat tachycardia, arterial fibrillation, and hypertensions. It is also known as a P-gp inhibitor ${ }^{31-33}$. Peak plasma concentrations are reached between 0.5 and 1.5 hours after oral ingestion. Its half-life varies from 7 and 15 hours ${ }^{31,34}$.

Participants visited the facility on two separate test days incorporating the four treatment conditions. More precisely, on each test day participants received two treatments and were scanned twice. The participants received either (i) placebo before the first scan session and verapamil $120 \mathrm{mg}$ before the second scan session; or (ii) cetirizine $15 \mathrm{mg}$ before the first scan session and verapamil $120 \mathrm{mg}$ before the second scan session. Because of the relative long half-life of cetirizine ( $7-11$ hours), during the second scan session on day (ii) the combination of cetirizine with verapamil $120 \mathrm{mg}$ was measured instead of only verapamil $120 \mathrm{mg}$. Test days were separated by a washout period of at least 7 days. All treatments were administered as identical encapsulated tablets to ensure blinding, and test day order was randomized and counterbalanced across participants.

\section{Procedure}

Participants received a training of the tests and a habituation session before the first test day. Drug screens and pregnancy tests were conducted upon arrival on the study site. Participants had a light breakfast two hours prior to medication intake. Approximately one and a half hour after medication intake, blood samples were taken and questionnaires were filled out after which participants performed the Attention Network Tes (ANT) while being scanned in an event-related fMRI experiment. The second medication intake was at the end of the first scan session, after filling out another questionnaire. Approximately one and a half hours after the second treatment blood samples were taken, questionnaires were filled out and the second scan session, which was identical to the first scan session, started. A detailed flowchart of the test days is given in Figure 1.

\begin{tabular}{|l|l|l|l|l|l|l|l|}
$\mathbf{9 : 3 0}$ & $10: 15$ & $11: 30$ & $11: 45$ & $13: 00$ & $14: 15$ & $\mathbf{1 4 : 3 0}$ & $16: 10$ \\
\hline $\begin{array}{l}\text { Arrival } \\
\text { Drug screen } \\
\text { Pregnancy test } \\
\text { Questionnaires }\end{array}$ & Intake Pla/Cet & Blood sample & $\begin{array}{l}\text { Tmax Cet } \\
\text { Test session 1 }\end{array}$ & Intake Ver & Blood sample & $\begin{array}{l}\text { Tmax Ver* } \\
\text { Test session 2 }\end{array}$ & End of Testday \\
\hline
\end{tabular}

Figure 1 Flowchart of the test days. Pla = placebo; Cet = cetirizine; Ver = verapamil. $*=$ Because of the relative long half-life ( $7-11$ hours) of cetirizine, during the second scan session the combination of cetirizine $15 \mathrm{mg}$ with verapamil $120 \mathrm{mg}$ was measured on the day that cetirizine was administered before test session 1. 


\section{Assessments}

\section{Pharmacokinetic assessment}

Blood samples $(10 \mathrm{ml})$ for drug monitoring were collected before each scan session, i.e. 65 minutes post drug. The blood samples were centrifuged to separate plasma and frozen at $-20^{\circ} \mathrm{C}$. Plasma samples were analyzed after liquidliquid extraction using a triple quadrupole LC/MS system in MRM mode. The lower limits of quantification were $0.002 \mathrm{mg} / \mathrm{l}$ for verapamil and $0.003 \mathrm{mg} / \mathrm{l}$ for cetirizine.

\section{Subjective evaluations}

The Groningen Subjective Quality of Sleep Questionnaire (GSQS) was filled out at the beginning of a test day in order to assess the participants' sleep quality and sleep duration of the previous night (Mulder-Hajonides, 1981). This questionnaire scores sleep complaints, ranging from 0 (good sleep) to 14 (bad sleep).

Before the scan sessions, subjective evaluations of alertness, contentedness and calmness were rated with the Bond and Lader questionnaire using visual analogue scales (Bond \& Lader, 1974). Subjective feelings of daytime sleepiness were rated with the Karolinska Sleepiness Scale (KSS) which provides scores ranging from 1 ('extremely alert') to 9 ('very sleepy', 'fighting sleep') (Akerstedt and Gillberg, 1990).

The Rating Scale Mental Effort (Zijlstra, 1993) was used in order to rate the degree of effort it took the participants to perform the scan session. The scale is a visual analogue scale $(150 \mathrm{~mm})$ with labels ranging from 'extremely demanding' to 'not demanding at all'.

\section{Attention Network Test (ANT)}

The Attention Network Task measures three independent attention networks: i.e. the alerting network, the orienting network and the executive control network ${ }^{35,36}$. Alerting is defined as response readiness to a warning cue (phasic alertness) as well as cognitive control of wakefulness and arousal (tonic alertness). Orienting is the allocation of attentional focus to a potentially relevant area, and executive control is the more complex mental operation of resolving conflict amongst responses 37,38 .

During the ANT, participants are asked to determine whether a central arrow (the target display) points to the left or to the right. The arrow appears above or below a fixation point and is accompanied by four arrows that either point in the same direction (congruent flankers) or in the opposite direction (incongruent flankers). Each trial begins with the presentation of a fixation cross and before the display of the arrows, a warning cue may appear in the center 
(center cue condition), above or below the fixation cross (spatial cue condition), or not at all (no cue condition) for $200 \mathrm{~ms}$. After a variable duration (300 $11800 \mathrm{~ms}$ ) the arrows appear and remain visible on the screen until a response is made (pressing a key indicating the direction of the target arrow) ${ }^{39}$. The time between the onset of the target and the start of the next trial varies between $3000-15000 \mathrm{~ms}$. There are 6 runs with 38 trials (216 trials in total) in which combinations of the flankers and cues are randomly presented. Each run lasted approximately 6 minutes. Participants performed 3 runs consecutively after which they had a break for approximately 9 minutes. After the break, the second half (i.e. 3 runs) of the test was conducted.

Previous research conducted b Fan et al. (2005) has demonstrated strong modulations of the BOLD signal associated with the ANT contrasts for alerting, orienting and executive network in the thalamus, the parietal cortex, and the anterior cingulate cortex, respectively ${ }^{35}$. In the present study, we used the same event-related design and the same timing parameters to study the change in activations of the attention networks after medication intake. In order to separate brain activity to the cues and targets, time intervals between cue and target and between target and the next trial were jittered, similarly to the Fan et al. (2005) study.

Also in line with the study conducted by Fan et al. (2005), efficiency of the alerting network was defined as the difference in brain activity and reaction time (RT) between center-cue (the warning cue) and no-cue conditions;.efficiency of the orienting network was defined as the difference in brain activity and RT between center- and spatial-cue conditions; and efficiency of the executive network was defined as the difference in brain activity and RT between incongruent and congruent flankers ${ }^{39}$.

\section{Image acquisition}

MRI data were acquired using a Siemens MAGNETOM Allegra 3T head Scanner with a single channel quadrature transceiver head coil. All participants completed 4 experimental runs. A total of 32 axial slices covering the whole brain were obtained using a $\mathrm{T} 2{ }^{*}$-weighted gradient echo planner pulse sequence $(\mathrm{TR}=2000 \mathrm{~ms}, \mathrm{TE}=30 \mathrm{~ms}, \mathrm{FoV}=224$, slice thickness $=3.5 \mathrm{~mm}$, matrix size $=64 \times 64$, flip angle $=90^{\circ}$ ). Voxel size was $3.5 \mathrm{~mm}^{3}$. Slice scanning order was interleaved. A high-resolution T1-weighted sequence was used to collect structural scans $(\mathrm{TR}=2250 \mathrm{~ms}, \mathrm{TE}=2.6 \mathrm{~ms}, \mathrm{FoV}=256$, slice thickness $=1$ mm, matrix size $=256 \times 256$, flip angle $=90^{\circ}$, number of slices $=192$ ).

\section{Image pre-processing}

Image preprocessing was conducted using SPM8 (Statistical Parametric Mapping, Wellcome Department of Imaging Neuroscience, Institute of Neurology, 
London, UK) running in Matlab R2010a (MathWorks, Natick, Massachusetts). The first two volumes were discarded because of the T1 saturation effect and images were corrected for slice scan time differences. The functional data from all treatment sessions were aligned to the anatomical data from the first session, using unwrapped fieldmaps. When translational movement of more than $3.5 \mathrm{~mm}$ from the first volume and/or rotational movement of more than 2.3 degrees were apparent in more than three runs, those runs were removed from the dataset together with all other data from that participant. When movement of more than $3.5 \mathrm{~mm}$ from the first volume was apparent in fewer than three runs, movement parameters across treatment conditions were compared in order to evaluate whether there were significant differences in movement between treatment conditions. In case of significant differences, the data from that participant was also removed. Each participant's anatomical image was linearly co-registered to a standard template from the Montreal Neurological Institute (MNI), and its functional data was co-registered with this (co-registered) anatomical data. Next, the anatomical data was segmented into CSF, white matter and grey matter, and in the same procedure the non-linear normalization parameters were estimated. These parameters were used to non-linearly normalize the anatomical and functional data to the MNI template. Finally, functional data were spatially smoothed using a Gaussian filter (8 mm FWHM).

\section{Statistical Analyses}

All subjective parameters and behavioral data were analyzed in two steps. First, it was determined whether performance in both $1^{\text {st }}$ scan sessions and in both $2^{\text {nd }}$ scan sessions separately differed significantly, using paired samples $t$-tests. More precisely, comparison between the $1^{\text {st }}$ scan sessions were conducted to reveal differences between placebo and cetirizine $15 \mathrm{mg}$. Comparison between the $2^{\text {nd }}$ scan sessions were conducted to reveal differences between verapamil $120 \mathrm{mg}$ and verapamil + cetirizine.

Secondly, to determine whether verapamil modulates cetirizine effects, change scores were calculated for the first scan sessions (cetirizine $15 \mathrm{mg}$ minus placebo), and the second scan sessions (verapamil $120 \mathrm{mg}$ and cetirizine combined minus verapamil $120 \mathrm{mg}$ ) separately, and than compared by testing for significance using paired samples $t$-tests.

\section{Imaging analysis}

Statistical analysis using general linear modeling (GLM) was conducted in order to analyze the imaging data. At the first level data in the four treatment conditions were analyzed separately. For each participant and treatment 
conditions regressors were created that represented the separate trial events, i.e.: fixation with no cue, central cue, spatial cue (the appearance of the fixation slide indicated the onset of these trials), and targets with congruent flankers, targets with incongruent flankers (the appearance of the targets was used as onset time). Six realignment parameters were used as covariates. Contrast images consisting of t-maps (center cue minus no cue for alerting, spatial cue minus center cue for orienting, and incongruent minus congruent for conflict) from each subject were calculated. In short, GLM with (i) alerting, orienting, and conflict attention, (ii) the six movement parameters as independent variables, and (iii) the BOLD response as dependent variable was calculated.

At a second level of analysis, the contrast images were used in order to analyze the effects of treatment (cetirizine vs. placebo and verapamil vs. cetirizine + verapamil) on alerting, orienting and conflict with voxel-wise paired samples t-tests. The regions activated for alerting, orienting, and executive attention that were observed by Fan et al. (2005) were used as anatomical regions of interest (ROI) and defined a priori in the WFU Pickatlas (Wake Forest University, Winston-Salem, North Carolina). For the alerting network these regions were: the superior temporal gyrus; superior colliculus; thalamus, inferior parietal lobe; fusiform gyrus; inferior frontal gyrus, and the superior parietal lobe. For the orienting network: the fusiform gyrus; precentral gyrus; superior parietal lobe; superior frontal gyrus; postcentral en precentral gyrus. For the executive attention network the regions included: the thalamus; superior frontal gyrus; inferior frontal gyrus; fusiform gyrus; middle frontal gyrus; and the anterior cingulated gyrus. Comparisons were thresholded at $\mathrm{p}<.05$, and familywise error (FWE) rate was corrected with a minimum cluster of 30 voxels. If no significant results were found, a less conservative threshold of false discovery rate (FDR), p $<.05$ was applied.

\section{Results}

A total of 16 right-handed participants entered the study. However, only 13 participants ( 7 male and 6 female) were included in the analyses of the behavioral data, because 2 participants experienced the scanning session as uncomfortable resulting in an early termination of the session, and one subject missed the sessions due to personal matters.

\section{Pharmacokinetic assessment}

Mean $( \pm$ SE) cetirizine and verapamil concentrations in the 4 treatment conditions are presented in Table 1. T-tests revealed that mean cetirizine concentrations, 
when given alone, did not significantly differ from concentrations when given in combination with verapamil. Likewise, verapamil concentrations did not significantly differ when given alone as compared to when given in combination with cetirizine.

Table 1 Mean \pm SE plasma concentrations ( $\mathrm{mg} / \mathrm{l}$ ) of cetirizine (CET) and verapamil (VER) in every treatment condition.

\begin{tabular}{lllll}
\hline & $\begin{array}{l}\text { No P-gp blockade } \\
\text { (without verapamil) }\end{array}$ & \multicolumn{2}{l}{$\begin{array}{l}\text { P-gp blockade } \\
\text { (with verapamil) }\end{array}$} & \\
Treatment & CET $(\mathrm{mg} / \mathrm{l})$ & VER $(\mathrm{mg} / \mathrm{l})$ & CET $(\mathrm{mg} / \mathrm{l})$ & VER $(\mathrm{mg} / \mathrm{l})$ \\
\hline CET & $0.15 \pm 0.03$ & N/A & $0.21 \pm 0.01$ & $0.08 \pm 0.02$ \\
PLA & N/A & N/A & N/A & $0.06 \pm 0.02$ \\
\hline
\end{tabular}

\section{Subjective measurements}

Sleep quality and sleep duration as assessed with the GSQS did not differ between nights preceding both test days. Treatments did not affect subjective mood, calmness, and/or contentedness as measured with the visual analogue scales, KSS and mental effort ratings (see Table 2).

\section{Attention Network Test (ANT)}

The combination of cetirizine and verapamil increased the difference in RT between center-cue and no-cue (alerting) as compared to verapamil alone (see Figure 2a) $\left(t_{12}=3.11, p=0.009\right)$. Alerting, orienting and executive attention was not affected by cetirizine alone as compared to placebo. Comparison of change scores from scan session 1 (cetirizine $15 \mathrm{mg}$ minus placebo) and scan session 2 (verapamil $120 \mathrm{mg}+$ cetirizine minus verapamil $120 \mathrm{mg}$ ) further confirmed a significant difference in the effect of cetirizine on alerting with and without P-gp blockade $\left(\mathrm{t}_{12}=-2.88, \mathrm{p}=0.014\right)$.

Additional analyses were conducted to identify the effect of cetirizine in two separate cue conditions that contribute to the alerting effect (i.e. center-cue and no-cue). This analysis revealed that the significant difference between placebo and cetirizine after P-gp blockade was caused by an increased reaction time in the no-cue condition $\left(\mathrm{t}_{12}=3.54, \mathrm{p}=0.004\right)$, and not in the (alerting) center-cue condition $\left(\mathrm{t}_{12}=0.87, \mathrm{p}=0.466\right)$ (Figure $\left.2 \mathrm{~b}\right)$. Mean $( \pm \mathrm{SE})$ RT during the alerting, 
orienting, and executive trials are shown in Table 2.

Taken together, the combination of verapamil and cetirizine increased the difference in RT between center-cue and no-cue. Further analyses revealed that blocking P-gp affected responsiveness (i.e. increased RT) when no warning cue was apparent, whereas it did not affect responsiveness when a prior cue indicated that a target would appear.

Table 2 Summary of the results from the Attention Network Test and the Subjective measurements, divided into placebo (PLA) and cetirizine (CET) with and without P-gp blockade. Results indicate that alerting (reaction times no-cue minus reaction times center-cue) between placebo and cetirizine after P-gp blockade differed significantly from each other. $\mathrm{df}=$ degrees of freedom, VAS $=$ Visual Analogue Scales (Bond \& Lader), KSS = Karolinska Sleepiness Scale, SME = rating Scale of Mental Effort, msec $=$ milliseconds, $\mathrm{mm}=$ millimeter .

No P-gp blockade (without verapamil)

\begin{tabular}{|c|c|c|c|c|c|}
\hline \multirow{2}{*}{$\begin{array}{l}\text { Attention Network Test } \\
\text { (Change in Reaction Times, msec) }\end{array}$} & \multicolumn{2}{|c|}{ Mean change \pm SE per treatment } & \multicolumn{3}{|c|}{ Paired samples t-test } \\
\hline & PLA & CET & $\mathrm{t}$ & $\mathrm{df}$ & $p$ \\
\hline Alerting & $50.17 \pm 12.95$ & $38.02 \pm 7.73$ & -0.89 & 12 & 0.39 \\
\hline Orienting & $49.54 \pm 9.11$ & $53.67 \pm 7.60$ & 0.35 & 12 & 0.73 \\
\hline Executive control & $82.08 \pm 13.83$ & $79.38 \pm 9.05$ & -0.17 & 12 & 0.87 \\
\hline \multirow{2}{*}{ Subjective measurements } & \multicolumn{2}{|c|}{ Mean change \pm SE per treatment } & \multicolumn{3}{|c|}{ Paired samples t-test } \\
\hline & PLA & CET & $\mathrm{t}$ & $\mathrm{df}$ & $p$ \\
\hline VAS Alertness (mm) & $68.27 \pm 5.00$ & $69.13 \pm 3.73$ & -2.90 & 12 & 0.78 \\
\hline VAS Contentedness (mm) & $82.23 \pm 4.09$ & $81.12 \pm 3.60$ & 0.41 & 12 & 0.69 \\
\hline VAS Calmness (mm) & $79.95 \pm 3.61$ & $80.95 \pm 2.87$ & -0.61 & 12 & 0.55 \\
\hline KSS (range $1-9$ ) & $4.15 \pm 0.48$ & $4.31 \pm 0.47$ & 0.31 & 12 & 0.92 \\
\hline SME (mm) & $55.77 \pm 8.08$ & $62.69 \pm 7.39$ & 0.97 & 12 & 0.35 \\
\hline
\end{tabular}

\section{P-gp blockade (with verapamil)}

\begin{tabular}{|c|c|c|c|c|c|}
\hline \multirow{2}{*}{$\begin{array}{l}\text { Attention Network Test } \\
\text { (Change in Reaction Times, msec) }\end{array}$} & \multicolumn{2}{|c|}{ Mean change \pm SE per treatment } & \multicolumn{3}{|c|}{ Paired samples t-test } \\
\hline & PLA & CET & $\mathrm{t}$ & $\mathrm{df}$ & $p$ \\
\hline Alerting & $28.55 \pm 9.50$ & $66.55 \pm 10.07$ & 3.71 & 12 & $0.009 *$ \\
\hline Orienting & $52.63 \pm 12.23$ & $33.85 \pm 11.67$ & -1.13 & 12 & 0.28 \\
\hline Conflict & $89.14 \pm 11.16$ & $95.09 \pm 11.69$ & 0.68 & 12 & 0.51 \\
\hline \multirow{2}{*}{ Subjective measurements } & \multicolumn{2}{|c|}{ Mean change \pm SE per treatment } & \multicolumn{3}{|c|}{ Paired samples t-test } \\
\hline & PLA & CET & $\mathrm{t}$ & $\mathrm{df}$ & $p$ \\
\hline VAS Alertness (mm) & $70.02 \pm 4.66$ & $67.81 \pm 3.55$ & 0.67 & 12 & 0.52 \\
\hline VAS Contentedness (mm) & $78.69 \pm 5.28$ & $76.65 \pm 4.91$ & 0.62 & 12 & 0.55 \\
\hline VAS Calmness (mm) & $80.65 \pm 3.60$ & $80.77 \pm 2.89$ & -0.11 & 12 & 0.91 \\
\hline KSS (range 1 - 9) & $4.38 \pm 0.45$ & $4.92 \pm 0.49$ & 1.10 & 12 & 0.29 \\
\hline SME (mm) & $57.54 \pm 7.52$ & $56.39 \pm 6.0$ & -0.26 & 12 & 0.35 \\
\hline
\end{tabular}




\section{Attention Network Test (ANT)}

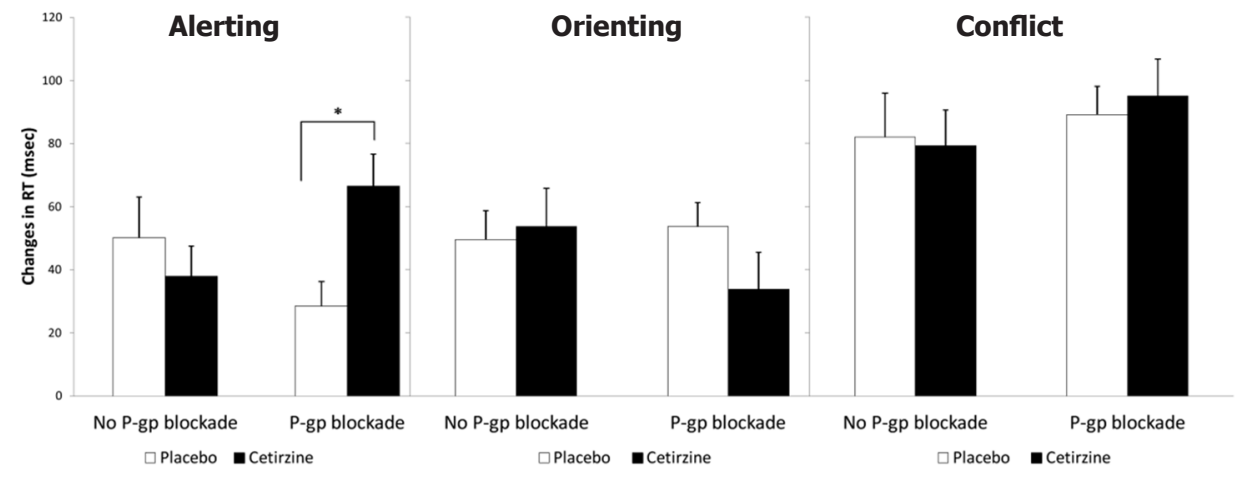

Figure $2 \mathrm{a}$

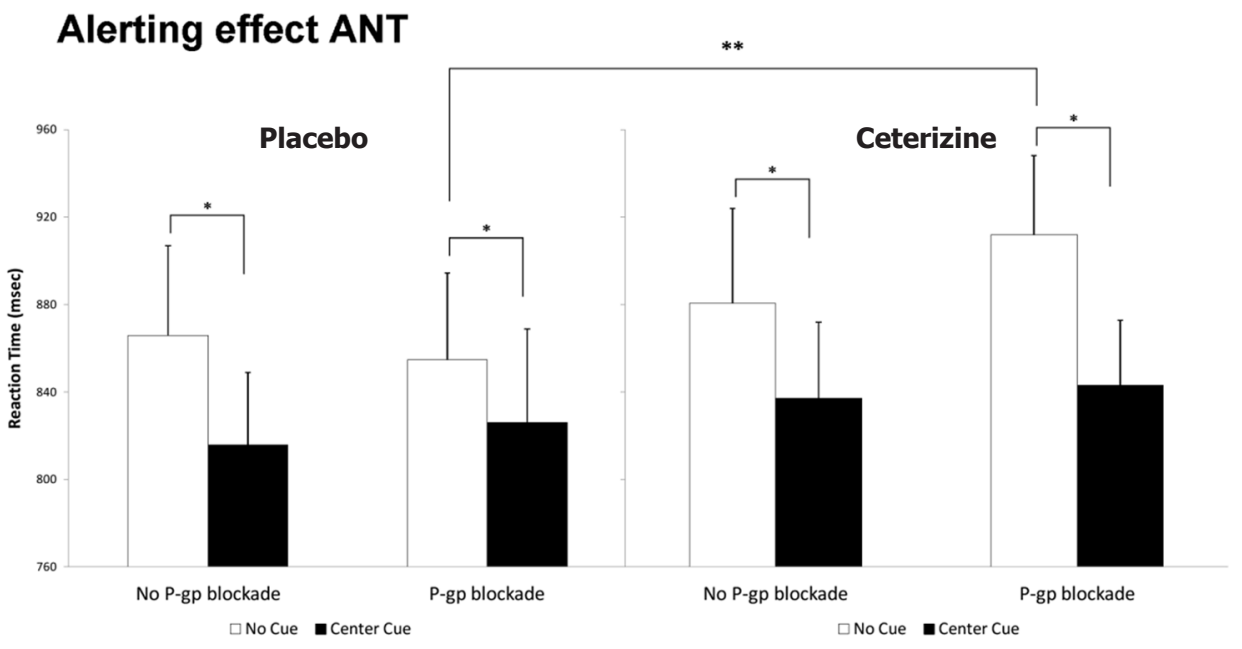

Figure $2 b$

Figure 2a Mean (+ SE) changes in reaction time (RT) in the Attention Network Test, divided into placebo and cetirizine with and without P-gp blockade. $*=$ significant difference from placebo, indicating an increased difference in RT between no-cue and center-cue conditions (i.e. alerting), $\mathrm{p}<0.05$.

Figure 2b Mean (+ SE) RT between no-cue and center-cue conditions (i.e. alerting) of the Attention Network Test. * = significant differences between no-cue and center-cue conditions, indicating that in all conditions the task manipulation was as expected, $p<0.01$. ** = significant difference between placebo and cetirizine after P-gp blockade in the no-cue condition, indicating that the significant result in Figure $2 \mathrm{a}$ is mostly caused by the no-cue and not the center-cue (i.e. warning cue) condition, $\mathrm{p}<0.005$. 


\section{Imaging data}

Data from one participant was removed from the dataset due to excessive head movement. Therefore 12 participants ( 7 male and 5 female) were included in the analyses of the imaging data.

\section{Task activation}

The afore-mentioned regions associated with the alerting network (center-cue minus no-cue), the orienting network (spatial-cue minus center-cue), and the executive attention network (incongruent minus congruent) were used as regions of interest $(\mathrm{ROI})^{35}$. Within these areas, we detected significant task activation of the alerting network in the left inferior parietal lobe $\left(t_{47}=4.97, p=0.009\right.$, FWE corrected), left inferior frontal gyrus $\left(\mathrm{t}_{47}=6.35, \mathrm{p}=0.002\right.$, FWE corrected), and right superior temporal gyrus $\left(\mathrm{t}_{47}=6.35, \mathrm{p}=0.002\right.$, uncorrected $)$. See table 3 for details. No significant task activation was detected for orienting and executive attention; therefore effects of treatments on orienting and executive attention were not further analyzed.

\section{Treatment effects}

The combination of cetirizine and verapamil increased the difference in BOLD activation associated with alerting in the right superior temporal gyrus as compared to verapamil alone. More precise, the difference in brain activity between center-cue and no-cue (i.e. the alerting effect) was larger in the cetirizine/P-gp blockade combination as compared with the placebo/Pgp blockade combination $\left(\mathrm{t}_{11}=8.39, \mathrm{p}=0.05\right.$, FWE corrected $)$. No significant differences between cetirizine alone and placebo were detected.

\section{Treatment effects in center-cue and no-cue conditions}

As the behavioral data revealed that the difference between placebo and cetirizine after P-gp blockade was primarily located in the no-cue condition, BOLD effects in center-cue and no-cue conditions were analyzed separately to determine if a similar pattern occurs at the neural level. These analyses also revealed that the effect of cetirizine was prominent in the no-cue condition, but not in de center-cue condition. Cetirizine + verapamil decreased the BOLD response relative to verapamil only in the no-cue condition, which approached significance in the right superior temporal gyrus $\left(t_{11}=7.68, p=0.06\right.$, FWE corrected). The comparison between verapamil and cetirizine + verapamil is depicted in Fig 3b and shows a positive difference of verapamil over cetirizine + verapamil. 
Table 3 Regions activated during the attention network test, divided into task activation, treatment effects, and treatment effects in the no cue condition. Results indicate that 3 regions are activated during alerting, and that the right superior temporal gyrus is affected by cetirizine after P-gp blockade as compared to P-gp blockade alone. BA $=$ Brodmann area, Voxel size $=2 \times 2 \times 2 \mathrm{~mm}$. ${ }^{*}=p$-value peak voxel uncorrected.

\section{Task activation}

Brain area

BA

$\mathrm{x}$

y

z

$\mathrm{t}$

$p$

Voxel

\section{Alerting}

$\mathrm{R}$ superior temporal gyrus

$\begin{array}{rrrrrrr}42 & 52 & -38 & 14 & 4.55 & 0.074 & 75 \\ 7 & -28 & -52 & 46 & 4.97 & 0.009 & 163 \\ 44 & -46 & 4 & 32 & 6.35 & 0.002 * & 231\end{array}$

$\mathrm{L}$ inferior parietal lobe

$44-2-46$

42

6.35

\section{Orienting}

\section{Executive attention}

\section{Treatment effects Alerting}

\begin{tabular}{lllllllll} 
Brain area & BA & $\mathrm{x}$ & $\mathrm{y}$ & $\mathrm{z}$ & $\mathrm{t}$ & $p$ & Voxel \\
\hline
\end{tabular}

\section{Alerting}

Cetirizine vs placebo after P-gp blockade

$\begin{array}{llllllll}\text { R superior temporal gyrus } & 48 & 48 & -8 & -2 & 8.39 & 0.050 & 60\end{array}$

Treatment effects No cue condition

Brain area

BA

$x$

y

z

$\mathrm{t}$

$p$

Voxel

Placebo vs cetirizine after P-gp blockade

Treatment effects Center cue condition 


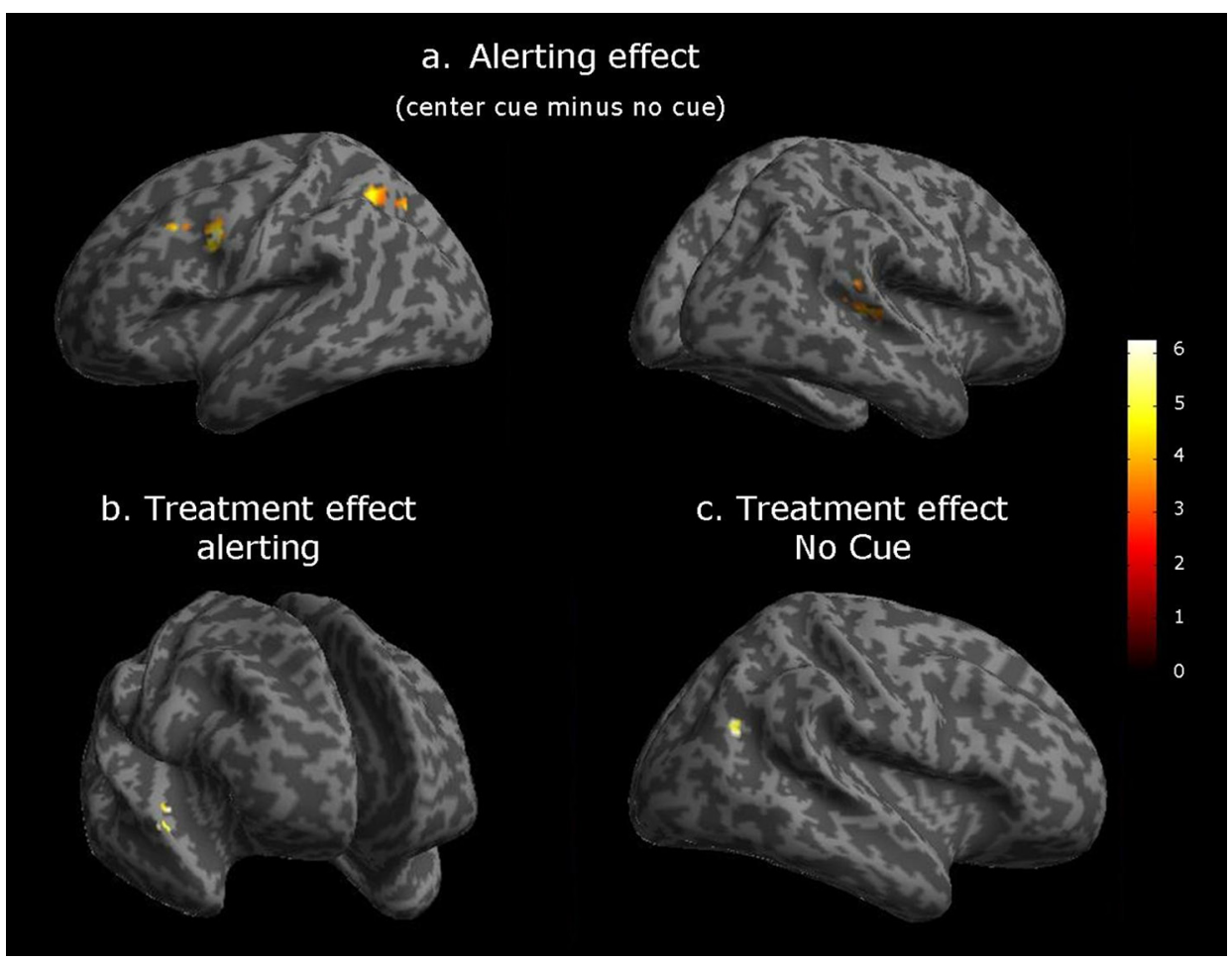

Figure 3a fMRI results for the alerting network of the Attention Network Test, showing significant activation in the left inferior parietal lobe, left inferior frontal gyrus and right superior temporal gyrus. Figure 3b Significant treatment effects in the alerting network, showing activation in the right superior temporal gyrus when comparing cetirizine after P-gp blockade as compared to P-gp blockade alone.

Figure 3c Treatment effect in the no-cue condition, showing activation in the right superior temporal gyrus when comparing cetirizine after P-gp blockade as compared to P-gp blockade alone.

\section{Discussion}

The present study was conducted in order to investigate the effect of the P-gp transporter on the central effects of AHs in healthy volunteers. It was expected that blocking P-gp with verapamil would increase the distribution of the second generation $\mathrm{AH}$ cetirizine in the CNS, which would result in increased H1R binding, and consequently would promote CNS sedation. The present study supports this hypothesis both at the behavioral and the neural level.

At the behavioral level, cetirizine combined with verapamil reduced alertness in the ANT task, when compared to verapamil alone and when compared to 
cetirizine alone. This impairing effect of cetirizine was apparent in the alerting network, but not in the orienting and executive attention network. Moreover, the influence of cetirizine was most apparent in the no-cue condition, rather than in the central-cue condition. This implies that participants were still able to profit from the alerting cue in the central-cue condition in every treatment, but were slow in their response during cetirizine in the absence of an alerting cue, indicating reduced sustained attention / top-down control ${ }^{40}$. The locus of the cetirizine effect contrasts with previous work showing that drug or sleep induced changes in alertness are mostly reflected in the center-cue condition. For example, caffeine decreased RT in the center-cue condition while leaving RT in the no-cue condition unaffected ${ }^{41}$. Likewise, sleep deprivation increased RT in the center-cue conditions, but not in the no-cue condition ${ }^{38}$. The present data seem to indicate that central cetirizine affected intrinsic alertness (i.e. vigilance) more than readiness to a target / bottom-up activation of alertness ${ }^{42}$. Neural effects of cetirizine on alerting were apparent in the right superior temporal gyrus. Bold activations in this area were more pronounced after cetirizine and verapamil combined in comparison to verapamil alone. Further analyses of treatment effects in the center-cue and no-cue condition separately revealed that brain activations were less in the no-cue condition after the combination of cetirizine and verapamil. This decrement in brain activation coincides with the increment in RT that was measured at the behavioral level during combined treatment in the no-cue condition. The neural data in the present study support the conclusion from behavioral data showing that cetirizine decreases alertness when given in combination with verapamil.

Both behavioral and neural data support the hypothesis that P-gp affinity plays an important role in the occurrence of CNS sedation associated with antihistamines. Cetirizine is a $2^{\text {nd }}$ generation antihistamine that is known to produce no or only mild sedation and has often been portrayed as a 'non-sedating' antihistamine ${ }^{10}$. In the present study, cetirizine did not affect performance or brain activation in the ANT task when given alone. However, when given in combination with a P-gp blocker, CNS sedation became apparent. This finding demonstrates that CNS effects of antihistamines depend on the affinity of these drugs for the P-gp transporter. In case of high affinities, as in $2^{\text {nd }}$ generation antihistamines, CNS side effects can be low. In case of no affinity, as in $1^{\text {st }}$ generation antihistamines, CNS side effects can be high.

The current finding may also have implications for other CNS drugs that have affinity for the P-gp transporter. P-gp plays a role in the distribution of many drugs besides antihistamines, such as antipsychotics, antidepressants and anti-cancer treatments ${ }^{12,43-45}$. Concerning those treatments, P-glycoprotein may play a role in treatment resistance. Research has shown that, for instance, antipsychotics appear to be P-gp substrates, which makes them less effective in 
the treatment of schizophrenia as P-gp reduces their distribution in the CNS and consequently their effectiveness ${ }^{46,47}$. In that case the combined use of a P-gp blocker with an antipsychotic may promote or prolong therapeutic efficacy of certain medicinal drugs. Also, it has been shown that genetic variations in $\mathrm{P}$-gp activity can change responsiveness to antipsychotic treatment ${ }^{48}$. More knowledge about these genetic variations in P-gp activity might be of importance, as these can explain inter-individual variations in treatment response and may support the development and improvement of tailor-made treatment procedures. Task activations in the present study partly confirmed previous definitions of brain networks involved in ANT performance ${ }^{35}$. Alerting effects were prominent in a number of predefined ROIs such as the left inferior parietal lobe, the left inferior frontal gyrus, and the right superior temporal gyrus, but not in the other predefined ROIs that have also been associated with the alerting network. Cue and target conditions priming the orienting and the executive attention network respectively, did not produce any significant fMRI task activation. The lack of task activation during orienting and executive attention may have been caused by the lower number of volunteers in the present study, relative to the study by Fan et al. (2005).

Several other studies confirm the involvement of parietal and frontal sites in alerting ${ }^{49}, 50$. In addition, research has shown that activation of the left hemisphere can be associated with phasic alertness, and right hemisphere activation with intrinsic (or tonic) alertness ${ }^{49,51,52}$. As the no-cue condition is associated with intrinsic alertness, the finding of no-cue related activation in the superior temporal gyrus in the right hemisphere is therefore in line with these findings.

In general, the finding that decrements in alertness occur after central actions of an antihistamine is in line with previous work demonstrating that blockade of H1R decreases wakefulness ${ }^{10,53-55}$. However, the impact of sedative actions on attention networks may actually differ between antihistamines. Our group demonstrated in a previous study that the sedative actions of hydroxyzine as measured with the ANT caused impairment in the executive network, but not in the alerting and orienting network ${ }^{24}$. Differential effects of antihistamines on attention networks may be caused by differences in binding affinities for H1R or may be due to differences in drug pharmacology. Cetirizine is the major metabolite of hydroxyzine, and displays selective binding affinity for H1Rs. Hydroxyzine in addition also binds to cholinergic and dopaminergic receptors that are known to produce sedation when blocked ${ }^{56}$. Dopamine plays an important modulating role in the control of executive attention ${ }^{35,37,57}$ which may explain why antihistamines with dopaminergic action affect executive attention. Cetirizine blood plasma concentrations with and without verapamil did not significantly differ from each other. Yet, mean cetirizine levels still increased by 
40\% after P-gp inhibition. As P-gp is also expressed in the small intestine, liver and kidney ${ }^{58}$, this may cause P-gp inhibition to alter plasma concentrations of P-gp substrates. Blood samples were taken at Tmax (i.e. $1 \mathrm{hr}$ after drug administration) after cetirizine administration and also 4 hrs after cetirizine administration, at the Tmax of verapamil. Cetirizine has a relatively long halflife of 7-11 hours, but nonetheless a decline in cetirizine plasma levels would be expected at 4 hours after administration. That this decline was not present can be interpreted as indicative of P-gp inhibition by verapamil. Indeed, increments in drug plasma concentration have previously been reported after combined administration of fexofenadine, a $2^{\text {nd }}$ generation antihistamine, and a P-gp inhibitor ${ }^{21-23}$.

Cetirizine did not affect subjective rating of alertness, sleepiness or mental effort, before or after P-gp blockade. This suggests that participants did not subjectively experience the sedative effect of combined cetirizine and verapamil use that was apparent in objective measures of CNS sedation. Such discrepancy between subjective and objective measures of CNS effects of antihistamines has been reported before in studies assessing antihistamine effects on cognition and driving ${ }^{59,60}$. It underscores the notion that users of sedating antihistamines should receive explicit warnings that these drugs may cause deleterious effects on cognition that may go unnoticed.

In conclusion, alertness was sensitive to the combined treatment of cetirizine with a P-gp blocker, and both plasma levels and brain activation underpinned this finding. These results suggest that P-gp blockade may exacerbate the effects of $2^{\text {nd }}$ generation antihistamines. The affinity for the P-gp transporter may therefore contribute to the lower incidence of CNS side effects of certain antihistamines.

\section{References}

1. Montoro, J. et al. Effect of $\mathrm{H} 1$ antihistamines upon the central nervous system. J Invest Allergol Clin Immunol 16 Suppl 1, 24-28 (2006).

2. Tashiro, M. et al. Brain histamine H1 receptor occupancy of orally administered antihistamines, bepotastine and diphenhydramine, measured by PET with 11C-doxepin. Br J Clin Pharmacol 65, 811-821 (2008).

3. Van Ruitenbeek, P., Vermeeren, A. \& Riedel, W. J. Histamine H1-receptor blockade in humans affects psychomotor performance but not memory. J Psychopharmacol 22, 663-672 (2008).

4. Abbas, M. N., Abdel Fattah, A. A. \& Zahran, E. A novel membrane sensor for histamine H1receptor antagonist "fexofenadine". Anal Sci 20, 1137-1142 (2004).

5. Theunissen, E. L., Vermeeren, A. \& Ramaekers, J. G. Repeated-dose effects of mequitazine, 
cetirizine and dexchlorpheniramine on driving and psychomotor performance. $\mathrm{Br} J$ Clin Pharmacol 61, 79-86 (2006).

6. Verster, J. C. \& Volkerts, E. R. Antihistamines and driving ability: evidence from on-the-road driving studies during normal traffic. Ann Allerg Asthma Immunol 92, 294-303; quiz 303-305, 355 (2004).

7. Jauregui, I. et al. H1 antihistamines: psychomotor performance and driving. J Investig Allergol Clin Immunol 16 Suppl 1, 37-44 (2006).

8. Ramaekers, J. G. \& O'Hanlon, J. F. Acrivastine, terfenadine and diphenhydramine effects on driving performance as a function of dose and time after dosing. Eur J Clin Pharmacol 47, 261-266 (1994).

9. Vuurman, E. F., Rikken, G. H., Muntjewerff, N. D., de Halleux, F. \& Ramaekers, J. G. Effects of desloratadine, diphenhydramine, and placebo on driving performance and psychomotor performance measurements. Eur J Clin Pharmacol 60, 307-313 (2004).

10. Kay, G. G. The effects of antihistamines on cognition and performance. J Allerg Cl Immunol 105, S622-S627 (2000).

11. Tashiro, M. et al. Effects of fexofenadine and hydroxyzine on brake reaction time during car-driving with cellular phone use. Hum Psychopharmacol 20, 501-509 (2005).

12. Bartra, J. et al. Interactions of the $\mathrm{H} 1$ antihistamines. J Investig Allergol Clin Immunol 16 Suppl 1, 29-36 (2006).

13. Chen, C., Hanson, E., Watson, J. W. \& Lee, J. S. P-glycoprotein limits the brain penetration of nonsedating but not sedating H1-antagonists. Drug Metab Dispos 31, 312-318 (2003).

14. Mahar Doan, K. M. et al. Steady-state brain concentrations of antihistamines in rats: interplay of membrane permeability, P-glycoprotein efflux and plasma protein binding. Pharmacology 72, 92-98 (2004).

15. Mimura, N., Nagata, Y., Kuwabara, T., Kubo, N. \& Fuse, E. P-glycoprotein limits the brain penetration of olopatadine hydrochloride, H1-receptor antagonist. Drug Metab Pharmacokinet 23, 106-114 (2008).

16. Obradovic, T., Dobson, G. G., Shingaki, T., Kungu, T. \& Hidalgo, I. J. Assessment of the first and second generation antihistamines brain penetration and role of P-glycoprotein. Pharm Res 24, 318-327 (2007).

17. Schinkel, A. H. P-Glycoprotein, a gatekeeper in the blood-brain barrier. Adv Drug Deliv Rev 36, 179-194 (1999).

18. Sun, H., Dai, H., Shaik, N. \& Elmquist, W. F. Drug efflux transporters in the CNS. Adv Drug Deliv Rev 55, 83-105 (2003).

19. Zhou, S. F., Liu, J. P. \& Chowbay, B. Polymorphism of human cytochrome P450 enzymes and its clinical impact. Drug Metab Rev 41, 89-295 (2009).

20. Polli, J. W. et al. P-glycoprotein influences the brain concentrations of cetirizine (Zyrtec), a second-generation non-sedating antihistamine. J Pharm Sci 92, 2082-2089 (2003).

21. Kim, K. A., Park, P. W. \& Park, J. Y. Short-term effect of quercetin on the pharmacokinetics 
of fexofenadine, a substrate of P-glycoprotein, in healthy volunteers. Eur J Clin Pharmacol 65, 609-614 (2009).

22. Sakugawa, T. et al. Enantioselective disposition of fexofenadine with the P-glycoprotein inhibitor verapamil. Br J Clin Pharmacol 67, 535-540 (2009).

23. Yasui-Furukori, N., Uno, T., Sugawara, K. \& Tateishi, T. Different effects of three transporting inhibitors, verapamil, cimetidine, and probenecid, on fexofenadine pharmacokinetics. Clin Pharmacol Ther 77, 17-23 (2005).

24. Conen, S., Theunissen, E. L., Vermeeren, A. \& Ramaekers, J. G. Short-term effects of morning versus evening dose of hydroxyzine $50 \mathrm{mg}$ on cognition in healthy volunteers. J Clin Psychopharmacol 31, 294-301 (2011).

25. Theunissen, E. L., Vermeeren, A., van Oers, A. C., van Maris, I. \& Ramaekers, J. G. A doseranging study of the effects of mequitazine on actual driving, memory and psychomotor performance as compared to dexchlorpheniramine, cetirizine and placebo. Clin Exp Allergy 34, 250-258 (2004).

26. Verster, J. C. et al. Acute and subchronic effects of levocetirizine and diphenhydramine on memory functioning, psychomotor performance, and mood. J Allergy Clin Immunol 111, 623-627 (2003).

27. Jenkins, B. G., Chen, Y.-C. I. \& Mandeville, J. B. in Biomedical imaging in experimental neuroscience (eds. van Bruggen, N. \& Roberts, T.) 155-209 (CRC Press, New York, 2003).

28. Leslie, R. A. \& James, M. F. Pharmacological magnetic resonance imaging: a new application for functional MRI. Trends Pharmacol Sci 21, 314-318 (2000).

29. Tashiro, M. et al. Dose dependency of brain histamine H(1) receptor occupancy following oral administration of cetirizine hydrochloride measured using PET with [11C] doxepin. Hum Psychopharmacol 24, 540-548 (2009).

30. del Cuvillo, A. et al. Comparative pharmacology of the H1 antihistamines. J Investig Allergol Clin Immunol 16 Suppl 1, 3-12 (2006).

31. Dadashzadeh, S., Javadian, B. \& Sadeghian, S. The effect of gender on the pharmacokinetics of verapamil and norverapamil in human. Biopharm Drug Dispos 27, 329-334 (2006).

32. Gupta, S. K., Atkinson, L., Tu, T. \& Longstreth, J. A. Age and gender related changes in stereoselective pharmacokinetics and pharmacodynamics of verapamil and norverapamil. Br J Clin Pharmacol 40, 325-331 (1995).

33. John, D. N., Fort, S., Lewis, M. J. \& Luscombe, D. K. Pharmacokinetics and pharmacodynamics of verapamil following sublingual and oral administration to healthy volunteers. Br J Clin Pharmacol 33, 623-62 7 (1992).

34. Choi, D. H., Chung, J. H. \& Choi, J. S. Pharmacokinetic interaction between oral lovastatin and verapamil in healthy subjects: role of P-glycoprotein inhibition by lovastatin. Eur J Clin Pharmacol 66, 285-290 (2010).

35. Fan, J., McCandliss, B. D., Fossella, J., Flombaum, J. I. \& Posner, M. I. The activation of attentional networks. Neuroimage 26, 471-479 (2005). 
36. Fan, J., McCandliss, B. D., Sommer, T., Raz, A. \& Posner, M. I. Testing the efficiency and independence of attentional networks. J Cogn Neurosci 14, 340-347 (2002).

37. Fan, J. \& Posner, M. Human attentional networks. Psychiatr Prax 31 Suppl 2, S210-S14 (2004).

38. Martella, D., Casagrande, M. \& Lupianez, J. Alerting, orienting and executive control: the effects of sleep deprivation on attentional networks. Exp Brain Res 210, 81-89 (2011).

39. Fan, J. et al. The relation of brain oscillations to attentional networks. J Neurosci 27, 61976206 (2007).

40. Sturm, W. \& Willmes, K. On the functional neuroanatomy of intrinsic and phasic alertness. Neuroimage 14, S76-S84 (2001).

41. Brunye, T. T., Mahoney, C. R., Lieberman, H. R. \& Taylor, H. A. Caffeine modulates attention network function. Brain Cogn 72, 181-188 (2010).

42. Mottaghy, F. M. et al. Systems level modeling of a neuronal network subserving intrinsic alertness. Neuroimage 29, 225-233 (2006).

43. Boulton, D. W., DeVane, C. L., Liston, H. L. \& Markowitz, J. S. In vitro P-glycoprotein affinity for atypical and conventional antipsychotics. Life Sci 71, 163-169 (2002).

44. de Klerk, O. L. et al. Locally increased P-glycoprotein function in major depression: a PET study with [11C]verapamil as a probe for P-glycoprotein function in the blood-brain barrier. Int J Neuropsychopharmacol 12, 895-904 (2009).

45. Schinkel, A. H. Pharmacological insights from P-glycoprotein knockout mice. Int J Clin Pharmacol Ther 36, 9-13 (1998).

46. El Ela, A. A. et al. Identification of P-glycoprotein substrates and inhibitors among psychoactive compounds--implications for pharmacokinetics of selected substrates. $J$ Pharm Pharmacol 56, 967-975 (2004).

47. Wang, L. J., Ree, S. C. \& Chen, C. K. Courses of aripiprazole-associated tardive dyskinesia: report of two cases. Prog Neuropsychopharmacol Biol Psychiatry 33, 743-744 (2009).

48. Xing, Q. et al. Polymorphisms of the ABCB1 gene are associated with the therapeutic response to risperidone in Chinese schizophrenia patients. Pharmacogenomics 7, 987-993 (2006).

49. Raz, A. \& Buhle, J. Typologies of attentional networks. Nat Rev Neurosci 7, 367-379 (2006).

50. Xu, G. Q. et al. Visuospatial attention deficit in patients with local brain lesions. Brain Res 1322, 153-159 (2010).

51. Coull, J. T., Nobre, A. C. \& Frith, C. D. The noradrenergic alpha 2 agonist clonidine modulates behavioural and neuroanatomical correlates of human attentional orienting and alerting. Cereb Cortex 11, 73-84 (2001).

52. Sturm, W. et al. Spatial attention: more than intrinsic alerting? Exp Brain Res 171, 16-25 (2006).

53. Conen, S., Theunissen, E. L., Van Oers, A. C., Valiente, R. \& Ramaekers, J. G. Acute and subchronic effects of bilastine (20 and $40 \mathrm{mg}$ ) and hydroxyzine (50 mg) on actual 
driving performance in healthy volunteers. J Psychopharmacol 25, 1517-1523 (2011).

54. Passani, M. B., Giannoni, P., Bucherelli, C., Baldi, E. \& Blandina, P. Histamine in the brain: Beyond sleep and memory. Biochem Pharmacol 73, 1113-1122 (2007).

55. Schwartz, J. C., Arrang, J. M. in Neuropsychopharmacology: The fifth generation of progress (ed. Davis, K. L., Charney, D., Coyle, J. T., Nemeroff, C.) 179-190 (Lippincott Williams \& Wilkins, Philadelphia, 2002).

56. Snowman, A. M. \& Snyder, S. H. Cetirizine: actions on neurotransmitter receptors. J Allergy Clin Immunol 86, 1025-1028 (1990).

57. Posner, M. I. \& Rothbart, M. K. Research on attention networks as a model for the integration of psychological science. Annu Rev Psychol 58, 1-23 (2007).

58. Fromm, M. F. Importance of P-glycoprotein at blood-tissue barriers. Trends Pharmacol Sci 25, 423-429 (2004).

59. Theunissen, E. L., Jonkman, L. M., Kuypers, K. P. \& Ramaekers, J. G. A combined neurophysiological and behavioural study into the stimulating effects of fexofenadine on performance. J Psychopharmacol 20, 496-505 (2006).

60. Vermeeren, A., Ramaekers, J. G. \& O’Hanlon, J. F. Effects of emedastine and cetirizine, alone and with alcohol, on actual driving of males and females. J Psychopharmacol 16, 57-64 (2002). 


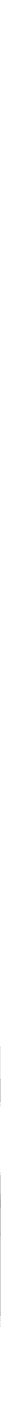




\section{Chapter 5}

\section{Short-term effects of morning versus evening dose of hydroxyzine on cognition}

Published as:

Conen S, Theunissen EL, Vermeeren A, Ramaekers JG. (2011). Short-term effects of morning versus evening dose of hydroxyzine $50 \mathrm{mg}$ on cognition in healthy volunteers. Journal of Clinical Psychopharmacology, 31, 294-301. 



\section{Abstract}

It is well known that sedative properties of antihistamines can differ considerably between individual drugs. Several factors have been suggested to determine the presence, absence and/or magnitude of sedation by antihistamines. Research has suggested that the sedative effects caused by central $\mathrm{H} 1$ blockade partly depend on the availability of histamine competing for the same receptor, and that this competition is affected by a mechanism related to sleep. Consequently, the present study was designed to compare the effects of evening and morning doses of the $1^{\text {st }}$ generation antihistamine hydroxyzine on cognition. It was expected that the sedative effect of hydroxyzine would be apparent in the evening after an evening dose, but would be smaller in the morning after a morning dose due to the greater release of histamine shortly after awakening. Eighteen participants (9 femalesand 9 males) participated in a placebo-controlled, randomized, double-blind, 3-way cross-over design. Performance was assessed using several psychomotor tests: i.e. the divided attention task, the critical tracking task, the stop signal task, the attention network test and the experimental attention switch task. Results demonstrated that evening doses of hydroxyzine impaired performance on the divided attention task and the attention network test. Impairment after morning doses was generally larger in magnitude and affected performance measures in all tasks. It is concluded that hydroxyzine induced impairment at $t_{\max }$ is more prominent after morning doses as compared to evening doses and that the present study could not present direct evidence to substantiate the hypothesis that histamine availability inversely affects the magnitude of antihistamine impairment.

\section{Introduction}

It is well known that antihistamines produce sedation and that the magnitude of sedation varies between individual drugs ${ }^{1-4}$. First generation antihistamines, such as hydroxyzine, induce sedation by blocking the histamine 1 receptor $(\mathrm{H} 1 \mathrm{R})$ in the central nervous system. This sedation can impair cognitive functions such as psychomotor speed and attention ${ }^{5-7}$. Also, this sedation can cause impairments 
in real life performance such as driving ${ }^{1,8-11}$. Understanding the mechanism of sedation caused by antihistamines is therefore of importance.

It was long assumed that the difference in sedation between antihistamines could be explained by their capacity to enter the brain, and their selectivity for the H1R ${ }^{12}$. First generation antihistamines are lipophilic. Therefore, they can easily cross the blood-brain barrier and block H1Rs in the central nervous system ${ }^{5}$, which causes the sedation. Because $2^{\text {nd }}$ generation antihistamines are more lipophobic, they cause less sedation ${ }^{3}$. However, other factors may also determine the presence, absence and/or magnitude of sedation.

In 1993, Rhoers, Clairborue, Knox, and Roth ${ }^{13}$ demonstrated that a 60-minutes nap selectively neutralized the sedative effects of an $\mathrm{H} 1$-antihistamine but not the sedative effects of a benzodiazepine. Other studies have also suggested that sleep may affect the magnitude of impairment caused by H1antihistamines. It was demonstrated that performance impairments produced by mianserin (an antidepressant with strong $\mathrm{Hl}$ binding potential) were much larger after daytime doses as compared to doses given the night before, even though blood concentrations of mianserin were comparable at time of testing ${ }^{14,}$ 15. Likewise, it has been shown that residual impairments after evening doses of sedative $\mathrm{H1}$-antihistamine with long elimination half lives, such as mirtazapine and dexchlorpheniramine, are mild or negligible when tested in the morning ${ }^{14,}$ 16,17 . Together, these results suggest that the sedative effects caused by central H1 blockade may be reduced by a mechanism related to sleep.

The histaminergic neurons in the tubero-mammillary nucleus (TMN) fire spontaneously ${ }^{18,19}$ with a variation of firing across the sleep-wake cycle ${ }^{20,21}$. The firing of these neurons is highest during the waking state ${ }^{22,23}$, slowing during light slow-wave sleep, and stops during deep slow wave sleep and REM sleep 22,24 . A study conducted in freely moving cats demonstrated that the waking selective histaminergic neurons resumed their activity on, or a few seconds before, awakening ${ }^{24}$. Furthermore, data suggest that H1Rs are involved in the transition from non-rapid eye movement sleep to wakefulness ${ }^{25}$, and that the histaminergic TMN neurons play an important role in initiating wakefulness ${ }^{26}$. Variations in histamine release throughout the sleep wake cycle may also explain some of the variations in performance impairments observed after nocturnal and daytime doses of $\mathrm{H} 1$-antihistamines. It has been hypothesized that the mechanism responsible for the reversal of sedative effects might be mediated by restoring the balance between histamine release and synthesis ${ }^{14,16}$. If histamine is released during waking state and histamine synthesis continues during sleep, then histamine availability will be largest shortly after awakening. Consequently, it could be expected that $\mathrm{H1}$-antihistamines are less likely to bind to H1Rs in times when histamine availability is highest, due to extensive competition between histamine and antihistamine for binding at the H1R. In the present 
study, it was hypothesized that the behavioral effect of a sedative antihistamine (in this case hydroxyzine) would be apparent in the evening after an evening dose, but would be smaller in the morning after a morning dose due to the greater release of histamine shortly after awakening.

The impairing effects of antihistamines are often demonstrated by perceptual motor tasks (e.g. critical tracking) and attention tasks (e.g. divided attention) 2, 27-29. The present study therefore used a critical tracking task and two attention tasks in order to assess the impairing effects of antihistamines in the evening versus morning. Also, this study was used to assess whether antihistamines would affect impulse control. Therefore, a stop signal test and an attention switch test were conducted as well. Consequently, the present study was designed to compare the time of dosing (morning versus evening) dependent effects of the $1^{\text {st }}$ generation antihistamine hydroxyzine on a perceptual motor task, two attention tasks and two impulsivity tasks in healthy volunteers.

\section{Methods}

\section{Subjects}

Nine healthy male and 9 healthy female volunteers (age range 21 to 28 years; mean \pm SD: $23.4 \pm 2.0$ years) were recruited through poster advertisement. Participants were screened by means of a medical questionnaire and a physical examination. The latter included a 12-lead electrocardiogram evaluation, blood chemistry and haematology, urinalysis, and drug and pregnancy screening. Participants had a body mass index of 19 to $30 \mathrm{~kg} / \mathrm{m}^{2}$. Furthermore, the volunteers were selected for being neither extreme morning types nor extreme evening types, by using a Dutch questionnaire for the selection of morning and evening type individuals ${ }^{30}$.

Volunteers with a history of medical or psychiatric illness, hypersensitivity to $\mathrm{H} 1$-antihistamines, and/or seasonal allergic rhinitis or urticaria treated by antihistamines were excluded from the study. Additional exclusion criteria were alcohol consumption of more than 21 units per week; smoking; caffeine consumption of more than 6 cups per day; treatment by atropine or atropine like drugs; treatment by a drug depressant of the central nervous system, and regular use of sedatives. Female volunteers could not participate when pregnant or breast feeding, and were allowed to use oral contraceptives. The menstrual cycle was not taken into account during the treatment periods.

The study was approved by the standing medical ethics committee of Maastricht University and was carried out in compliance with the code of ethics on human experimentation established by the Declaration of Helsinki (1964) and 
amended in Seoul (2008), and the principles of the International Conference on Harmonization guideline for Good Clinical Practice. Participants gave their written informed consent prior to study participation.

\section{Design and treatments}

The study was conducted according to a randomized, double-blind, 3 period cross-over design with hydroxyzine $50 \mathrm{mg}$, and a placebo control. Hydroxyzine is a $1^{\text {st }}$ generation antihistamine, with plasma peak concentrations reached between 1.7 and 2.5 hours after oral ingestion. Its half-life varies on average between 15.9 and 24.1 hours ${ }^{31,32}$. Treatment conditions were hydroxyzine 50 $\mathrm{mg}$ in the evening and placebo in the morning (HYE), placebo in the evening and hydroxyzine $50 \mathrm{mg}$ in the morning (HYM), and placebo in the evening and placebo in the morning conditions (PBO). As earlier studies show strong significant performance impairments within $1-2$ hours after hydroxyzine intake ${ }^{33,34}$, tests were performed one hour following drug or placebo intake in the evening, and 1 hour following drug or placebo intake in the morning (labelled hereafter as $\mathrm{HYE}_{\mathrm{PM}}$, $\mathrm{HYE}_{\mathrm{AM}}, \mathrm{HYMp}_{\mathrm{M}}, \mathrm{HYM}_{\mathrm{AM}}, \mathrm{PBOp}_{\mathrm{M}}$ and $\mathrm{PBO}_{\mathrm{AM}}$, respectively). Treatment periods were separated by a washout period of at least 7 days. All treatments were administered as identical encapsulated tablets to ensure blinding.

\section{Procedure}

Participants received a training of the tests and a sleep habituation session before the first treatment period. Each test session consisted of an evening, night and morning. In test sessions, drug screens and pregnancy tests were conducted upon arrival on the study site. In the evening of the test session, approximately one hour after intake of the medication, at $8.30 \mathrm{pm}$., participants conducted the laboratory tests until $10.00 \mathrm{pm}$. Participants were instructed to go to bed at $11.00 \mathrm{pm}$. They were woken up at $07.00 \mathrm{am}$, after which the medication was administered. One hour later the laboratory tests were conducted for the second time.

\section{Assessments}

\section{Critical Tracking Task}

The critical tracking task measures the subject's ability to control a moving signal on a computer screen using a joystick. The signal deviates horizontally 
from a midpoint and the subject has to compensate for this deviation by moving a joystick in the opposite direction. Over time, the signal deviations increase, causing the subject to compensate more frequently. The frequency at which the subject loses control is the critical frequency $(\lambda c)$. The test includes five trials of which the lowest and the highest score are removed; the average of the remaining scores is taken as the final score ${ }^{35}$.

\section{Divided Attention Task}

The divided attention task ${ }^{36}$ measures the ability to divide attention between two tasks performed simultaneously. In one, the subject performs the above described critical tracking task at a constant level of difficulty, set at $50 \%$ of the subject's maximum capacity. In the other task, the subject monitors a central display upon which single digits are presented for 17 milliseconds with a variable inter stimulus interval between 1.03 and 1.23 seconds ${ }^{37}$. The occurrence of the digit " 2 " is a signal for the subject to remove the foot from a pedal as rapidly as possible. Mean Absolute Tracking Error ( $\mathrm{mm}$ ), Average Reaction Time (ms), and the amount of control losses and hits are the respective performance measures 36 .

\section{Attention Network Test}

The attention network test combines warning cues and flanker displays in order to study the alerting network, the orienting network and the executive control network ${ }^{38,39}$. The subject is asked to determine whether a central arrow points to the left or to the right. The arrow appears above or below a fixation point and is accompanied by four arrows that either point in the same direction (congruent flankers) or in the opposite direction (incongruent flankers). Before the display of the arrows, a cue may appear in the center (center cue condition), above or below a fixation cross (spatial cue condition), or not at all (no cue condition). Each trial begins with the presentation of a fixation cross and at some variable interval a cue is presented for $200 \mathrm{~ms}$. Four hundred ms after the offset of the cue, a target display appears and remains visible on the screen until a response is made (pressing a key indicating the direction of the target arrow) ${ }^{40}$. A shortened version of the attention network test was used in which 114 trials, consisting of combinations of the flankers and cues, were randomly presented. Efficiency of the alerting network is examined by changes in reaction time (RT) and accuracy (ACC) between center-cue conditions and no-cue conditions. The orienting network is studied by changes in RT and ACC between center- and spatial-cue conditions. Efficiency of the executive network is examined by changes in RT and ACC between incongruent flankers and congruent flankers ${ }^{40}$. 


\section{Stop Signal Task}

The stop signal task requires the subject to respond to visually presented go signals, and to inhibit any response when a visual stop signal is suddenly presented. The stop signal task is adapted ${ }^{41}$ from an earlier version of Fillmore, Rush, \& Hays (2002) and has been shown to be sensitive to sedative as well as to stimulant drugs. The go signals are the letters A, B, C and D, which are presented one at a time in the center of a computer screen. The subject is asked to respond to each letter as quickly as possible by pressing on of two response buttons. One button is pressed to indicate that "A" or "C" appeared, and the other to indicate "B" or "D". Letters are displayed for $500 \mathrm{~ms}$ and the subject has in total 2 seconds to respond.

The test consists of 176 trials in which each of the 4 letters is presented equally often. A stop signal occurs in 48 trials during a test. The stop signal consists of an asterisk that appears in one of the four corners of the screen. Subjects are required to withhold any response when a stop-signal is presented. Stop signals are presented 48 times randomly at the following delays after the onset of a letter: 50, 150, 250 and $350 \mathrm{msec}$. Each delay of onset of a letter occurred 12 times. Trials always begin with a $500 \mathrm{msec}$ preparation interval in which a fixation point appears on the center of the screen ${ }^{42}$. Dependent variables are stop signal reaction time (SSRT), number of hits in Go-trials, number of failed inhibitions at stop trials (commission errors or misses), RT (Go-RT), and number of incorrect responses (omission errors or false alarms) at Go trials.

\section{Experimental Attention switch task (AST)}

The experimental attention switch task (AST) is used to measure the subject's ability to frequently switch attention between different task instructions 43. This task is an adjusted version of the task reported by Cepeda, Cepeda, et al. 44 . The attention switch task consists of three separate blocks; two non-switch and one switch block. During the task, four stimulus types are randomly presented on the screen $(1,3,111$, or 333). During the first block, the subject is asked to respond to the question "what number?" by pressing a left button when the cue ' 1 ' or ' 111 ' appears, and a right button when ' 3 ' or ' 333 ' appears. In the second block, the question "how many?" has to be answered by pressing the left button when the cue ' 1 ' or ' 3 ' appears, and the right button when the cue '111' or ' 333 ' appears. In the switch block, both afore-mentioned blocks are randomly mixed.

The non-switch blocks include 40 randomly presented trials each, consisting of 10 stimuli of each stimulus type. The switch block includes 80 randomly presented trials, with 20 stimuli of each stimulus type. The questions are presented for $400 \mathrm{~ms}$ after which a stimulus is presented for $800 \mathrm{~ms}$. After this, a 2000 ms response interval occurs before the next instruction appears. Dependent variables are mean non-switch RT and number of errors (computed 
by averaging the non-switch blocks) and mean switch RT and number of errors ${ }^{43}$.

\section{Subjective measurements}

The Groningen Subjective Quality of Sleep Questionnaire (GSQS) ${ }^{45}$ was filled out at the beginning, and in the morning of a test session in order to asses the subject's sleep quality and sleep duration of the previous night. This questionnaire scores sleep complaints, ranging from 0 (good sleep) to 14 (bad sleep). Before the laboratory tests, subjective evaluations of alertness and mood were assessed by using a series of 16 visual analogue scales $(100 \mathrm{~mm})$, which provide scores for 'alertness', 'contentedness', and 'calmness' ${ }^{46}$.

\section{Statistics}

As the main focus of this study was to detect the differences between morning dosing of hydroxyzine and evening dosing of hydroxyzine, it was of importance to exclude the possibility of carry-over effects from evening to morning sessions. Consequently, data were analyzed in two steps. First, it was determined whether the effects of hydroxyzine were significantly different from placebo by comparing performance following hydroxyzine with performance following placebo within evening and morning sessions separately, using paired samples $t$-tests. More precisely, $\mathrm{HYE}_{\mathrm{PM}}$ was compared with $\mathrm{PBO}_{\mathrm{PM}}$, and $\mathrm{HYM}_{\mathrm{AM}}$ was compared with $\mathrm{PBO}_{\mathrm{Am}}$. This way, no carry-over effects that might occur in the other morning placebo $\left(\mathrm{HYE}_{\mathrm{AM}}\right)$ condition were measured. Secondly, to determine whether the effects of hydroxyzine differed between times of the day, change scores were calculated between hydroxyzine and placebo in the evening $\left(\mathrm{HYE}_{\mathrm{PM}}\right.$ minus $\left.\mathrm{PBO}_{\mathrm{PM}}\right)$ and in the morning $\left(\mathrm{HYM}_{\mathrm{AM}}\right.$ minus $\left.\mathrm{PBO}_{\mathrm{AM}}\right)$ using a paired samples $t$-test.

Performance in the switch task was analyzed using two two-way ANOVAs for evening and morning sessions separately, with Treatment (hydroxyzine and placebo) and Switch (non-switch and switch) as factors. In case of extreme values and non-normality, winsorization was applied ${ }^{47}$. The Statistical Package for the Social Sciences (SPSS) version 15.0 was used for the achievement of all listings, tables and analyses.

\section{Results}

A total of 18 participants entered the study. However, only 17 participants (8 male and 9 female) were included in the analyses, because one subject missed two treatment periods due to personal matters. 


\section{Effects of hydroxyzine compared to placebo}

\section{Critical Tracking Task}

There was no significant difference in the evening between hydroxyzine and placebo on the mean tracking $(\mathrm{mm})$ of the critical tracking task. In the morning, the difference between hydroxyzine (mean \pm SE: $3.33 \pm 0.2$ ) and placebo (mean \pm SE: $3.88 \pm 0.2)$ was significant $\left(\mathrm{t}_{16}=-4.61, \mathrm{p}<0.001\right)$, indicating impairing effects of hydroxyzine.

\section{Divided Attention Task}

Mean $(+\mathrm{SE})$ scores in the divided attention task of hydroxyzine and placebo in the morning and evening are presented in Figure la. The control losses in the divided attention task were significantly increased by hydroxyzine compared to placebo in both the evening $\left(\mathrm{t}_{16}=3.14, \mathrm{p}<0.01\right)$ and morning $\left(\mathrm{t}_{16}=3.33, \mathrm{p}<0.01\right)$. In the morning, but not in the evening, hydroxyzine significantly increased tracking error $\left(\mathrm{t}_{16}=4.69, \mathrm{p}<0.001\right)$ and slowed average RT $\left(\mathrm{t}_{16}=4.21, \mathrm{p}<0.01\right)$ compared with placebo. No differences in the number of hits were detected.

\section{Attention Network Test}

Analyses of accuracy scores in the attention network test showed that there was a significant difference between hydroxyzine and placebo in both the evening $\left(\mathrm{t}_{16}=-2.25, \mathrm{p}<0.05\right)$ and morning $\left(\mathrm{t}_{16}=-2.70, \mathrm{p}<0.05\right)$ in efficiency of executive attention (congruent - incongruent flankers), indicating that hydroxyzine impaired executive attention. There were no significant effects on orienting and alerting attention. Also, no significant effects were found on RTs. The mean $(+\mathrm{SE})$ effects on accuracy of the alerting, orienting, and executive control network are shown in Figure 1b.

\section{Stop Signal Task}

There were no significant differences in the evening between hydroxyzine and placebo in the stop signal task. In the morning, hydroxyzine significantly reduced the number of hits in the Go-trials $\left(\mathrm{t}_{16}=-2.60, \mathrm{p}<0.05\right)$ and slowed GoRT $\left(\mathrm{t}_{16}=2.23, \mathrm{p}<0.05\right)$ as compared to placebo (see Figure 2). No differences were detected in the morning for the SSRT and the number of not inhibited responses on stop trials. 
$1 \mathrm{a}$

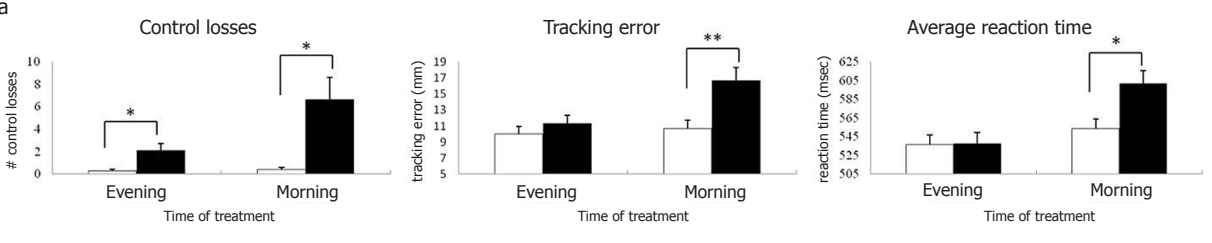

$\square$ Placebo Hydroxyzine

$\square$ Placebo Hydroxyzine

$\square$ Placebo Hydroxyzine

$1 \mathrm{~b}$

Alerting effect

Orienting effect
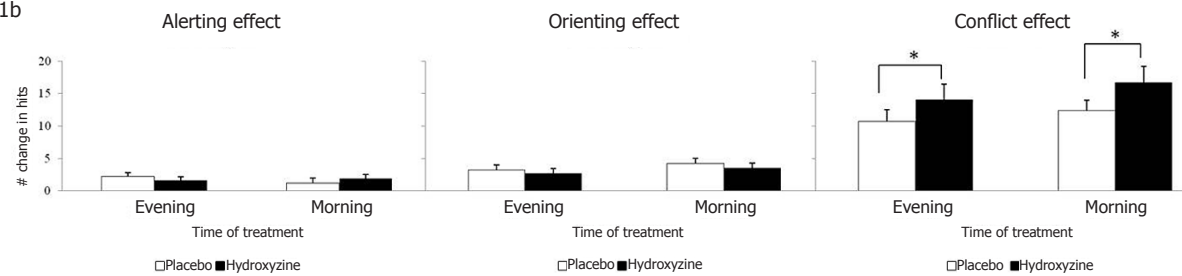

Figure 1a Mean (+ SE) results of the Divided Attention Task, divided into amount of control losses, tracking error $(\mathrm{mm})$, and average reaction time $(\mathrm{msec})$ of hydroxyzine and placebo in the morning and evening. $*$ significant differences from placebo per time of treatment, indicating performance impairment in the hydroxyzine condition, $\mathrm{p}<0.01 .{ }^{*} *$ significant differences from placebo per time of treatment, indicating performance impairment in the hydroxyzine condition, $\mathrm{p}<0.001$.

Figure 1b Mean (+ SE) amount of hits of hydroxyzine and placebo in the morning and evening for the alerting, orienting, and conflict effect of the Attentional Network Test. * = significant differences from placebo per time of treatment indicating performance impairment in the hydroxyzine condition, $\mathrm{p}<0.05$.
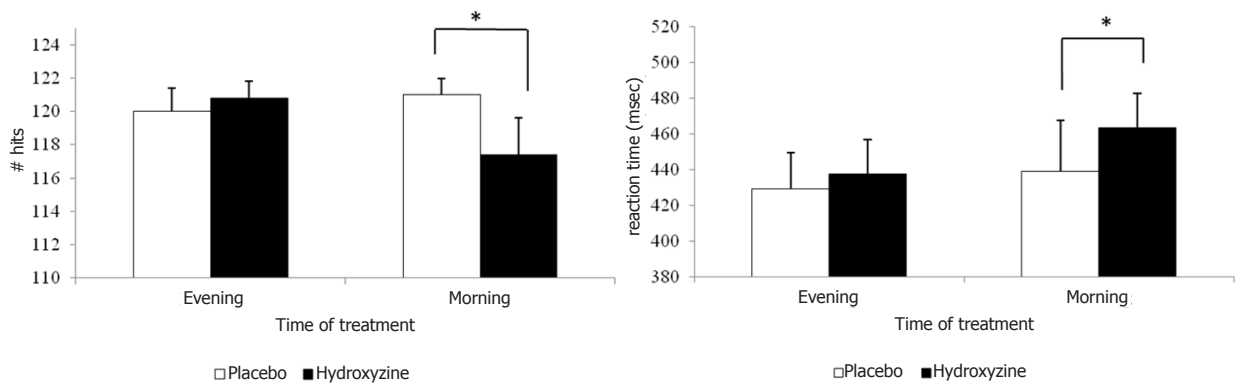

Figure 2 Mean (+ SE) results of the Stop Signal Task divided into amount of hits on Go-trials and Go-reaction time (msec) of hydroxyzine and placebo in the morning and evening. ${ }^{*}=$ significant differences from placebo per time of treatment indicating performance impairment in the hydroxyzine condition, $\mathrm{p}<0.05$. 


\section{Experimental Attention switch task}

A main effect of Switch on the number of errors was detected in the evening $\left(\mathrm{F}_{1,16}=6.48 ; \mathrm{p}<0.05\right)$ as well as in the morning $\left(\mathrm{F}_{1,16}=12.44 ; \mathrm{p}<0.01\right)$; the number of errors was significantly increased in the switch block. In addition, a main effect of Treatment on the number of errors was detected in the morning $\left(\mathrm{F}_{1,16}\right.$ $=9.16 ; \mathrm{p}<0.01)$; the number of errors was significantly increased after treatment with hydroxyzine. There was no significant interaction between Treatment and Switch.

Comparably, a main effect of Switch on the RT was detected in the evening $\left(\mathrm{F}_{1,16}=21.92 ; \mathrm{p}<0.001\right)$ as well as in the morning $\left(\mathrm{F}_{1,16}=23.29 ; \mathrm{p}<0.001\right)$; the RT was significantly increased in the switch block. An effect on RT was detected in the morning for Treatment $\left(\mathrm{F}_{1,16}=14.39 ; \mathrm{p}<0.01\right)$. Additionally, a Treatment by Switch interaction $\left(\mathrm{F}_{1,16}=7.22 ; \mathrm{p}<0.05\right)$ on RT was detected in the morning, showing a larger switch effect after treatment with hydroxyzine.

\section{Subjective measurements}

There were no significant differences neither between, hydroxyzine and placebo, nor between the night before the test session and the morning after the test night on the Groningen subjective quality of sleep questionnaire (GSQS). In the Bond \& Lader VAS $(\mathrm{mm})$, there was a significant difference between hydroxyzine (mean \pm SE: $74.28 \pm 2.7$ ) and placebo (mean \pm SE: $79.12 \pm 2.93$ ) in the morning $\left(\mathrm{t}_{16}=-2.58, \mathrm{p}<0.05\right)$, but not in the evening, on contentedness. No significant differences on alertness and calmness were detected.

\section{Change scores in the evening versus change scores in the morning}

Comparison of hydroxyzine's effects in the evening and in the morning as measured by changes from placebo $\left(\mathrm{HYE}_{\mathrm{PM}}-\mathrm{PBO}_{\mathrm{PM}}\right.$ versus $\mathrm{HYM}_{\mathrm{AM}}-\mathrm{PBO}_{\mathrm{AM}}$ ) revealed significant differences in the critical tracking task, as well as for the divided attention task except for the amount of hits. Overall, performance was (more) impaired by hydroxyzine in the morning than in the evening dose condition. In the stop signal task the difference between evening and morning was significant for the hits in the Go-trials, and a significant effect could also be seen for contentedness in the Bond \& Lader VAS. No significant differences between evening and morning effects were detected in the attention network test. A summary of the results of the afore-mentioned assessments are presented in Table 1. Also, no significant evening versus morning effect was detected in the experimental attention switch task. 
Table 1 Summary of the results from the differences between change scores in the morning $\left(\mathrm{HYM}_{\mathrm{AM}}\right.$ $\left.\mathrm{PBO}_{\mathrm{AM}}\right)$ and change scores in the evening $\left(\mathrm{HYE}_{\mathrm{PM}}-\mathrm{PBO}_{\mathrm{PM}}\right)$. Overall, performance was (more) impaired in the morning than in the evening dose condition. Reaction time is in $\mathrm{msec}$; NS = not significant; df $=$ degrees of freedom.

\begin{tabular}{|c|c|c|c|c|}
\hline & \multirow{2}{*}{$\begin{array}{l}\text { Morning effect } \\
\text { minus } \\
\text { evening effect } \\
\text { Mean } \pm \text { SE }\end{array}$} & \multicolumn{3}{|c|}{ Time of dosing effect } \\
\hline & & $\mathrm{t}$ & $\mathrm{df}$ & $p$ \\
\hline \multicolumn{5}{|l|}{ Critical Tracking Task } \\
\hline Mean & $0.48 \pm 0.11$ & 3.69 & 16 & $<0.01$ \\
\hline \multicolumn{5}{|l|}{ Divided Attention Task } \\
\hline Control losses & $4.53 \pm 1.89$ & 2.40 & 16 & $<0.05$ \\
\hline Tracking error (mm) & $4.70 \pm 1.27$ & 3.70 & 16 & $<0.01$ \\
\hline Hits & $0.13 \pm 1.36$ & 0.10 & 16 & NS \\
\hline Reaction time & $47.15 \pm 9.93$ & 4.75 & 16 & $<0.001$ \\
\hline \multicolumn{5}{|l|}{ Attentional Network Task } \\
\hline \multicolumn{5}{|l|}{ Accuracy } \\
\hline Alerting & $1.35 \pm 1.04$ & 1.29 & 16 & NS \\
\hline Orienting & $0.19 \pm 1.07$ & 0.18 & 16 & NS \\
\hline Conflict & $1.12 \pm 1.75$ & 0.64 & 16 & NS \\
\hline \multicolumn{5}{|l|}{ Reaction Time } \\
\hline Alerting & $-3.21 \pm 7.28$ & -0.44 & 16 & NS \\
\hline Orienting & $3.59 \pm 9.43$ & 0.38 & 16 & NS \\
\hline Conflict & $-16.60 \pm-1.42$ & -1.34 & 16 & NS \\
\hline \multicolumn{5}{|l|}{ Stop Signal Task } \\
\hline Hits Go trial & $8.19 \pm 3.61$ & 2.27 & 16 & $<0.05$ \\
\hline Go reaction time & $11.90 \pm 22.39$ & 0.53 & 16 & NS \\
\hline Stop Signal Reaction Time & $3.55 \pm 16.57$ & 0.21 & 16 & NS \\
\hline Failed inhibitions at stop trials & $1.24 \pm 1.85$ & 0.67 & 16 & NS \\
\hline Misses & $0.31 \pm 0.41$ & 0.77 & 16 & NS \\
\hline \multicolumn{5}{|l|}{ Bond \& Lader VAS } \\
\hline Alertness & $6.35 \pm 4.19$ & 1.52 & 16 & NS \\
\hline Contentedness & $5.93 \pm 2.16$ & 2.75 & 16 & $<0.05$ \\
\hline Calmness & $0.91 \pm 3.29$ & 0.28 & 16 & NS \\
\hline
\end{tabular}




\section{Discussion}

The present study has been conducted in order to compare hydroxyzine induced impairment at $\mathrm{t}_{\max }$ after morning dose and evening dose administration. It was expected that the sedative effect of hydroxyzine would be apparent in the evening after an evening dose condition, but would be smaller in the morning after a morning dose condition due to the larger release of histamine shortly after awakening and an increased competition between histamine and hydroxyzine in the CNS. Interestingly, the results of this study were exactly opposite to our hypothesis. In the evening, the sedative effects were only apparent in parts of the attention tasks (i.e. increased control losses in the divided attention task and the conflict effect of the attention network test), whereas in the morning hydroxyzine impairment was very prevalent in most of the performance outcomes. Moreover, performance impairments observed after a morning dose were significantly larger than those observed after an evening dose of hydroxyzine for several tasks (see table 1). As there were no differences in sleep quality between conditions on the night before and during treatment, it can be stated that performance was not affected by quality.

A possible explanation for the lack of reduced performance impairment in the morning can be that hydroxyzine was given too late in order to compete with the hypothesized larger histamine release. It is not known for how long this larger histamine release continues during onset of awakening. In the present study hydroxyzine was administered in the morning immediately after the participants were awakened. Also, because the $t_{\max }$ of hydroxyzine appears after approximately 1.5 hours, the possibility exists that before hydroxyzine had an effect on the participants' performance, the histamine release was stabilized and could therefore not reduce the sedative side effects.

Alternatively, a larger impairment in the morning dose condition compared with the evening dose condition could also be explained by sleep inertia. Sleep inertia is the decreased performance and / or disorientation that can occur immediately after awakening ${ }^{48}$, and is together with the amount of sleepiness and the time of being awake a predictor of alertness according to the threeprocess model of alertness regulation ${ }^{49}$. Research has shown that cognitive performance can be impaired for more than two hours after awakening ${ }^{50}$, and that performance can be worse than after 26 hours of sleep deprivation ${ }^{51}$. Sleep inertia may interact with the sedative effects of hydroxyzine to increase impairing effects on performance.

Also, daytime variations in pharmacokinetics may have contributed to the 
hydroxyzine effect on performance. It has been reported that a morning dose of a lipophilic drug is absorbed faster in the morning compared with an evening dose ${ }^{52}$. As hydroxyzine is a lipophilic antihistamine, a morning dose might be absorbed faster which can lead to a higher Cmax. This difference in absorption could, partially, explain the difference in the behavioral data. Unfortunately, as no plasma concentrations were analyzed for this study, it is not known whether there actually were differences in the pharmacokinetics of evening and morning dosing.

The unexpected results may also be related to the lack of knowledge concerning the actual histamine levels in the brain during evening and morning test sessions. It has been shown that brainstem histamine neurons fire rapidly during waking and much more slowly during NREM sleep. Likewise, groups of (sub) cortical neurons containing histamine have decreased activity during REM sleep, but are active during waking ${ }^{24,26,53}$. However, the relationship between firing rate of histamine neurons and general histamine availability in the brain remains obscure. Our hypothesis assumed that histamine levels would be considerably higher right after awakening because of a high firing rate of histamine neurons. Alternatively, one could also argue that histamine levels progressively deplete during sleep because of a low firing rate of histamine neurons, and that histamine levels only gradually restore to normal after waking when histamine neurons become active again. In the latter scenario, histamine levels would temporarily be lower right after awakening when compared to 'regular' histamine levels in the evening, even though histamine neurons are equally, or more active at both times. Low levels of histamine in the morning would imply less competition for $\mathrm{H} 1$-antihistamines to occupy $\mathrm{H} 1 \mathrm{Rs}$, leading to more pronounced impairments as observed in the present study.

Hydroxyzine effects were most prominent in psychomotor and attention tasks such as the critical tracking task, the divided attention task as well as the attention network test. The attention network test indicated that hydroxyzine affected the executive network of attention, but not the alerting and orienting network. It has been argued by Fan et al. (2007) ${ }^{40}$ that the executive network is primarily under control of the anterior cingulate cortex. Neuroimaging studies have shown that H1Rs are widely available at the anterior cingulate ${ }^{54}$ and that hydroxyzine $(30 \mathrm{mg}$ ) occupied about $70 \%$ of the H1Rs in the anterior cingulate after single dose administration ${ }^{55}$. The pronounced effect of hydroxyzine on the executive network may thus be related to the strong H1R occupancy in the anterior cingulate.

Hydroxyzine also affected performance in two impulsivity tasks (i.e. stop signal task and attention switch task). However, the impairing effects of hydroxyzine on stop signal task performance do not automatically indicate that hydroxyzine had a direct effect on impulse control. In the stop signal task, the 
primary measure of impulsivity is the ability to inhibit a response when a stopsignal is presented. This measure is represented by the stop reaction time ${ }^{56}$, and the number of failed inhibitions (i.e. commission errors or misses) during stop trials. These parameters, though, were not significantly impaired after hydroxyzine. Hydroxyzine did increase RT to Go-trials and decreased the number of correct responses (hits Go trial) during Go-trials. However, these effects can be explained by a general decrease in attention as well. On the other hand, performance outcomes of the attention switch task show that hydroxyzine in the morning did impair overall performance on the switch task. The significant interaction of switch RT and treatment in the morning indicate that in the hydroxyzine morning condition the participants need more time to inhibit the previous task set.

Finally, it is of interest to notice that using the Bond \& Lader VAS, only the feeling of contentedness was decreased by hydroxyzine in the morning. This decrease is in line with the cognitive impairments assessed in the morning. The finding that alertness was not affected by hydroxyzine indicates that, although the performance after hydroxyzine was worse, the volunteers were unaware of the decrease in alertness. Similar findings have been reported before ${ }^{1,33,57}$. It underscores the notion that users of hydroxyzine should receive explicit warnings about these drugs' deleterious effects on cognitive performance regardless of time of dosing.

To our knowledge, this is the first study to assess the sedative effects of hydroxyzine in relation to time of dosing in healthy participants. In summary, it can be concluded that hydroxyzine induced impairment at $t_{\max }$ is more prominent after morning doses as compared to evening doses and that the present study could not present direct evidence to substantiate the hypothesis that histamine availability inversely affects magnitude of antihistamine impairment.

\section{References}

1. Theunissen, E. L., Vermeeren, A. \& Ramaekers, J. G. Repeated-dose effects of mequitazine, cetirizine and dexchlorpheniramine on driving and psychomotor performance. $\mathrm{Br} J$ Clin Pharmacol 61, 79-86 (2006).

2. Vuurman, E. F., Rikken, G. H., Muntjewerff, N. D., de Halleux, F. \& Ramaekers, J. G. Effects of desloratadine, diphenhydramine, and placebo on driving performance and psychomotor performance measurements. Eur J Clin Pharmacol 60, 307-313 (2004).

3. Kay, G. G. The effects of antihistamines on cognition and performance. J Allergy Clin Immunol 105, S622-S627 (2000).

4. Tashiro, M. et al. Effects of fexofenadine and hydroxyzine on brake reaction time during car- 
driving with cellular phone use. Hum Psychopharmacol 20, 501-509 (2005).

5. Montoro, J. et al. Effect of $\mathrm{H} 1$ antihistamines upon the central nervous system. J Investig Allergol Clin Immunol 16 Suppl 1, 24-28 (2006).

6. Tashiro, M. et al. Brain histamine H1 receptor occupancy of orally administered antihistamines, bepotastine and diphenhydramine, measured by PET with 11C-doxepin. Br J Clin Pharmacol 65, 811-821 (2008).

7. Van Ruitenbeek, P., Vermeeren, A. \& Riedel, W. J. Histamine H1-receptor blockade in humans affects psychomotor performance but not memory. J Psychopharmacol 22, 663-672 (2008).

8. Jauregui, I. et al. H1 antihistamines: psychomotor performance and driving. J Investig Allergol Clin Immunol 16 Suppl 1, 37-44 (2006).

9. Ramaekers, J. G. \& O'Hanlon, J. F. Acrivastine, terfenadine and diphenhydramine effects on driving performance as a function of dose and time after dosing. Eur J Clin Pharmacol 47, 261-266 (1994).

10. Vermeeren, A., Ramaekers, J. G. \& O'Hanlon, J. F. Effects of emedastine and cetirizine, alone and with alcohol, on actual driving of males and females. J Psychopharmacol 16, 57-64 (2002).

11. Verster, J. C. \& Volkerts, E. R. Antihistamines and driving ability: evidence from on-theroad driving studies during normal traffic. Ann Allergy Asthma Immunol 92, 294303; quiz 303-5, 355 (2004).

12. Quach, T. T., Duchemin, A. M., Rose, C. \& Schwartz, J. C. In vivo occupation of cerebral histamine H1-receptors evaluated with 3H-mepyramine may predict sedative properties of psychotropic drugs. Eur J Pharmacol 60, 391-392 (1979).

13. Roehrs, T., Claiborue, D., Knox, M. \& Roth, T. Effects of ethanol, diphenhydramine, and triazolam after a nap. Neuropsychopharmacology 9, 239-245 (1993).

14. Ramaekers, J. G., Muntjewerff, N. D., Van Veggel, L. M. A., Uiterwijk, M. M. C. \& O'Hanlon, J. F. Effects of Nocturnal Doses of Mirtazapine and Mianserin on Sleep and on Daytime Psychomotor and Driving Performance in Young, Healthy Volunteers. Hum Psychopharmacol 13, S87-S97 (1998).

15. Ramaekers, J. G., Swijgman, H. F. \& O’Hanlon, J. F. Effects of moclobemide and mianserin on highway driving, psychometric performance and subjective parameters, relative to placebo. Psychopharmacol (Berl) 106 Suppl, S62-S6 7 (1992).

16. Vermeeren, A., Ramaekers, G., Van Leeuwen, C. J. \& O’ Hanlon, J. F. Residual effects on Actual Car Driving of Evening Dosing of Chlorpheniramine 8 and $12 \mathrm{mg}$ When Used with Terfenadine in the Morning. Hum Psychopharmacol 13, S79-S86 (1998).

17. Wingen, M., Bothmer, J., Langer, S. \& Ramaekers, J. G. Actual driving performance and psychomotor function in healthy subjects after acute and subchronic treatment with escitalopram, mirtazapine, and placebo: a crossover trial. J Clin Psychiatry 66, 436443 (2005).

18. Haas, H. L. \& Reiner, P. B. Membrane properties of histaminergic tuberomammillary neurones of the rat hypothalamus in vitro. J Physiology 399, 633-646 (1988). 
19. Reiner, P. B., Heimrich, B., Keller, F. \& Haas, H. L. Organotypic culture of central histamine neurons. Brain Res 442, 166-170 (1988).

20. Brown, R. E., Stevens, D. R. \& Haas, H. L. The physiology of brain histamine. Prog Neurobiol 63, 637-672.(2001).

21. Tuomisto, L., Lozeva, V., Valjakka, A. \& Lecklin, A. Modifying effects of histamine on circadian rhythms and neuronal excitability. Behav Brain Sci 124, 129-135 (2001).

22. Sakai, K., Mansari, M., Lin, J. S., Zhang, J. G. \& Vanni-Mercier, G. in The diencephalon and sleep (eds. Mancia, M. \& Marini, M.) (Raven, New York, 1990).

23. Schwartz, J. C., Arrang, J. M., Garbarg, M. \& Traiffort, E. in Psychopharmacology: the Fourth Generation of Progress (eds. Blomm, F. E. \& Kupfer, D. J.) 397-405 (Raven, New York, 1994).

24. Vanni-Mercier, G., Gigout, S., Debilly, G. \& Lin, J. S. Waking selective neurons in the posterior hypothalamus and their response to histamine H3-receptor ligands: an electrophysiological study in freely moving cats. Behav Brain Res 144, 227-241 (2003).

25. Huang, Z. L. et al. Altered sleep-wake characteristics and lack of arousal response to H3 receptor antagonist in histamine $\mathrm{H} 1$ receptor knockout mice. Proc Natl Acad Sci USA 103, 4687-4692 (2006).

26. Ko, E. M., Estabrooke, I. V., McCarthy, M. \& Scammell, T. E. Wake-related activity of tuberomammillary neurons in rats. Brain Res 992, 220-226 (2003).

27. Seidel, W. F., Cohen, S., Bliwise, N. G. \& Dement, W. C. Direct measurement of daytime sleepiness after administration of cetirizine and hydroxyzine with a standardized electroencephalographic assessment. J Allergy Clin Immunol 86, 1029-1033 (1990).

28. Theunissen, E. L., Vermeeren, A., van Oers, A. C., van Maris, I. \& Ramaekers, J. G. A doseranging study of the effects of mequitazine on actual driving, memory and psychomotor performance as compared to dexchlorpheniramine, cetirizine and placebo. Clin Exp Allergy 34, 250-258 (2004).

29. Verster, J. C. et al. Acute and subchronic effects of levocetirizine and diphenhydramine on memory functioning, psychomotor performance, and mood. J Allergy Clin Immunol 111, 623-627 (2003).

30. Kerkhof, G. A. Een Nederlandse vragenlijst voor de selectie van ochtend-en avondmensen. (A Dutch questionnaire for the selection of morning and evening type individuals). Ned tijdschr psychol 39, 281-294 (1984).

31. del Cuvillo, A. et al. Comparative pharmacology of the H1 antihistamines. J Investig Allergol Clin Immunol 16 Suppl 1, 3-12 (2006).

32. Simons, F. E., Simons, K. J. \& Frith, E. M. The pharmacokinetics and antihistaminic of the H1 receptor antagonist hydroxyzine. J Allergy Clin Immunol 73, 69-75 (1984).

33. Conen, S., Theunissen, E. L., Van Oers, A. C., Valiente, R. \& Ramaekers, J. G. Acute and subchronic effects of bilastine (20 and $40 \mathrm{mg}$ ) and hydroxyzine (50 mg) on actual driving performance in healthy volunteers. J Psychopharmacol 25, 1517-1523 (2011). 
34. Vuurman, E., Theunissen, E., van Oers, A., van Leeuwen, C. \& Jolles, J. Lack of effects between rupatadine $10 \mathrm{mg}$ and placebo on actual driving performance of healthy volunteers. Hum Psychopharmacol 22, 289-97 (2007).

35. Jex, H. R., McDonnell, J. D. \& Phatak, A. V. A “critical” tracking task for man-machine research related to the operator's effective delay time. I. Theory and experiments with a first- order divergent controlled element. NASA CR-616. NASA Contractor Report NASA CR, 1-105 (1966).

36. Moskowitz, H. Laboratory studies of the effects of alcohol on some variables related to driving. J Safety Res 5, 185-192 (1973).

37. Theunissen, E. L., Jonkman, L. M., Kuypers, K. P. C. \& Ramaekers, J. G. Stimulating effects of fexofenadine under high workload conditions. A combined neurophysiological and behavioral approach. J Psychopharmacol, 485-495 (2006).

38. Fan, J., McCandliss, B. D., Fossella, J., Flombaum, J. I. \& Posner, M. I. The activation of attentional networks. Neuroimage 26, 471-9 (2005).

39. Fan, J., McCandliss, B. D., Sommer, T., Raz, A. \& Posner, M. I. Testing the efficiency and independence of attentional networks. J Cogn Neurosci 14, 340-347 (2002).

40. Fan, J. et al. The relation of brain oscillations to attentional networks. J Neurosci 27, 6197206 (2007).

41. Ramaekers, J. G. \& Kuypers, K. P. Acute effects of 3,4-methylenedioxymethamphetamine (MDMA) on behavioral measures of impulsivity: alone and in combination with alcohol. Neuropsychopharmacology 31, 1048-1055 (2006).

42. Theunissen, E. L., van Kroonenburgh, M. J., van Deursen, J. A., Blom-Coenjaerts, C. \& Ramaekers, J. G. Stimulating effects of fexofenadine: testing the dopamine transporter hypothesis. Psychopharmacology 187, 95-102 (2006).

43. Markus, C. R. \& Jonkman, L. M. Attention switching after dietary brain 5-HT challenge in high impulsive subjects. J Psychopharmacol 21, 700-708 (2007).

44. Cepeda, N. J., M. L. Cepeda, et al. Task switching and attention deficit hyperactivity disorder. J Abnorm Child Psychol 28, 213-226 (2000).

45. Mulder-Hajonides van der Meulen, W. R. E. H. in Proceedings of International European Sleep Congress (Elsevier, Amsterdam, 1981).

46. Bond, A. \& Lader, M. The use of analogue scales in rating subjective feelings. $\mathrm{Br}$ J Med Psychol 47, 211-218 (1974).

47. Shete, S. et al. Effect of winsorization on power and type 1 error of variance components and related methods of QTL detection. Behav Gen 34, 153-159 (2004).

48. Tassi, P. \& Muzet, A. Sleep inertia. Sleep Med Rev 4, 341-353 (2000).

49. Akerstedt, T. Work hours, sleepiness and the underlying mechanisms. J Sleep Res 4, 15 22 (1995).

50. Jewett, M. E. et al. Time course of sleep inertia dissipation in human performance and alertness. J Sleep Res 8, 1-8 (1999).

51. Wertz, A. T., Ronda, J. M., Czeisler, C. A. \& Wright, K. P., Jr. Effects of sleep inertia on 
cognition. JAMA 295, 163-164 (2006).

52. Baraldo, M. The influence of circadian rhythms on the kinetics of drugs in humans. Expert Opin Drug Metab Toxicol 4, 175-192 (2008).

53. Siegel, J. M. Clues to the functions of mammalian sleep. Nature 437, 1264-1271 (2005).

54. Tagawa, M. et al. Neuroimaging of histamine H1-receptor occupancy in human brain by positron emission tomography (PET): a comparative study of ebastine, a secondgeneration antihistamine, and (+)-chlorpheniramine, a classical antihistamine. $\mathrm{Br} \mathrm{J}$ Clin Pharmacol 52, 501-509 (2001).

55. Tashiro, M. et al. Dose dependency of brain histamine H(1) receptor occupancy following oral administration of cetirizine hydrochloride measured using PET with [11C] doxepin. Hum Psychopharmacol 24, 540-548 (2009).

56. Eagle, D. M. et al. Stop-signal reaction-time task performance: role of prefrontal cortex and subthalamic nucleus. Cereb Cortex 18, 178-1788 (2008).

57. Ramaekers, J.G. et al. A comparative study of the effects of carbamazepine and the NMDA receptor antagonist remacemide on road tracking and car-following performance in actual traffic. Psychopharmacology (Berl) 159, 203-210 (2002). 



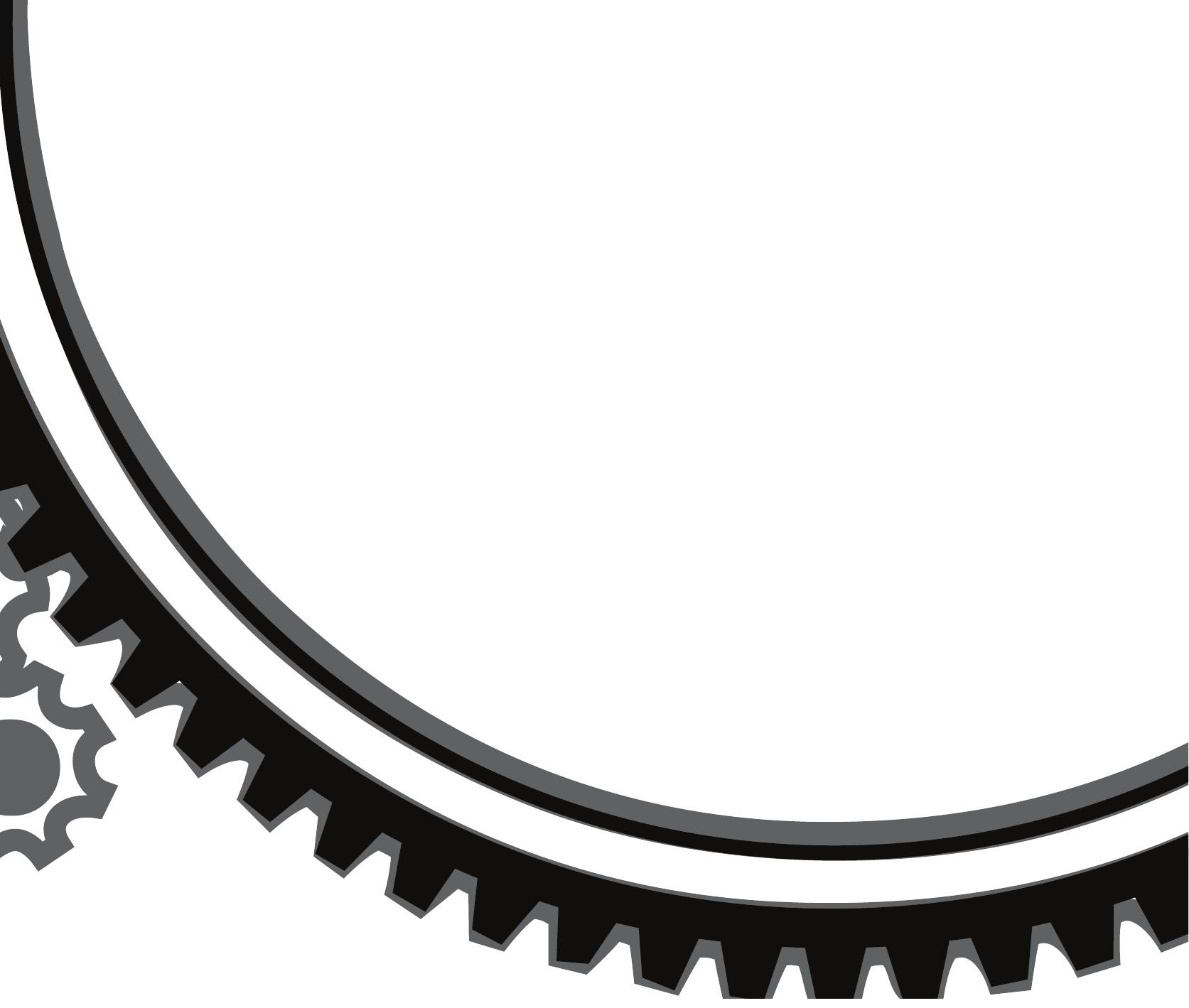




\section{Chapter 6}

\section{CNS impairing effects of hydroxyzine as a function of histamine availability}

Accepted for publication as:

Conen S, Theunissen EL, Sambeth A, Vermeeren A, Ramaekers JG. CNS impairing effects of hydroxyzine as a function of histamine availability. Journal of Clinical Psychopharmacology. 



\section{Abstract}

Research has suggested that the sedative effects caused by central H1 blockade may partly depend on the availability of histamine in the CNS, and that this histamine availability fluctuates during day and night. The aim therefore was to assess the role of time of dosing on the magnitude of sedation caused by H1-antihistamines. This was done by measuring the effect of hydroxyzine on electrocortical activity (event related potentials) after an evening dose, when histamine levels are relatively low, and after a morning dose, when histamine levels are higher. Event related potential (ERP) effects were compared to those of placebo using a within-subjects design in healthy volunteers. It was expected that the sedative effect of hydroxyzine would be prominent in the evening after an evening dose (i.e. increased peak latency and decreased peak amplitude), but would be smaller in the morning after a morning dose due to greater release of histamine shortly after awakening. Results demonstrated that treatment effects were more apparent in the morning after a morning dose, than in the evening after an evening dose for the divided attention task. Hydroxyzine effects on ERPs in the Attention Network test were in line with our hypotheses, but limited in number. It is concluded that, in general, the ERP data indicate that hydroxyzine induced impairment is more prominent after morning doses as compared to evening doses. Therefore, the present study could not completely establish direct evidence to confirm the hypothesis that histamine availability inversely affects magnitude of antihistamine impairment.

\section{Introduction}

In the previous chapter it was hypothesized that the sedative antihistaminergic effects of $1^{\text {st }}$ generation antihistamine hydroxyzine would be maximal in the evening when histamine levels are low, and less in the morning when histamine levels are high, as a result of increased competition between histamine and hydroxyzine in the CNS in the morning. However, the results of the behavioral data were opposite to the hypothesis. In the evening, the sedative effects were only apparent in parts of two attention tasks, whereas in the morning hydroxyzine impairment was very prevalent in most of the performance outcomes. Moreover, performance impairments observed after a morning dose were significantly larger than those observed after an evening dose of hydroxyzine for several tasks. 
The present chapter focuses on the results from event-related potentials (ERPs) measured in the same study.

It has previously been demonstrated that event related potential (ERP) measures may show drug effects that go undetected in behavioral tasks ${ }^{1}$. In a study assessing the stimulating effects of fexofenadine, the behavioral results of the divided attention task (DAT) showed no stimulating effects, whereas the stimulating effects did appear in the generated potentials ${ }^{2}$. Additionally, it has been demonstrated that ERPs can serve as markers of specific stages of cognitive information processing in order to distinguish less noticeable effects ${ }^{3,4}$. Additionally, ERP measurements are useful in detecting sedation caused by antihistamines. For instance, research has shown that the sedative antihistamines chlorpheniramine impaired performance of an Odd-ball task and increased P300 latency ${ }^{5,6}$.

In the present chapter the effects were compared of the sedative antihistamine hydroxyzine on electrocortical activity (ERPs) during performance of the DAT and the Attention Network Test (ANT) after evening and morning dose administration. Effects were compared to those of placebo using a withinsubjects design in healthy volunteers. Using former studies as reference ${ }^{7-9}$, it was expected that the peak latencies of the ERPs would be increased, and the peak amplitude would be decreased after hydroxyzine compared with placebo. Because in the morning hydroxyzine is less likely to bind at H1Rs due to more competition between hydroxyzine and histamine, a morning dose of hydroxyzine was expected to cause less sedation than an evening dose. Therefore, it was hypothesized that in the morning, 1 hour after treatment with the sedative hydroxyzine, the peak latencies would be less increased and the peak amplitude would be less decreased compared with the ERP effects in the evening, 1 hour after treatment with hydroxyzine.

\section{Methods}

\section{Subjects}

Eighteen healthy volunteers ( 9 male and 9 female; age range 21 to 28 years; mean \pm SD: $23.4 \pm 2.0$ years) were recruited through poster advertisement. Volunteers were selected for being neither extreme morning types nor extreme evening types, by using a Dutch questionnaire for the selection of morning and evening type individuals 10. Participants were screened using a medical questionnaire and a physical examination. The latter included a 12-lead electrocardiogram evaluation, blood chemistry and haematology, urinalysis, and drug and pregnancy screening. Participants had a body mass index of 19 to $30 \mathrm{~kg} / \mathrm{m}^{2}$. 
Exclusion criteria were a history of medical or psychiatric illness, hypersensitivity to $\mathrm{H1}$-antihistamines, and/or seasonal allergic rhinitis or urticaria treated by antihistamines. Additionally, healthy volunteers with an alcohol consumption of more than 21 units per week; caffeine consumption of more than 6 cups per day; treatment by atropine or atropine like drugs; treatment by a drug depressant of the central nervous system, and regular use of sedatives were excluded from the study. Females could not participate when pregnant or breast feeding. Participants gave their written informed consent prior to study participation.

The study was approved by the standing medical ethics committee of University hospital Maastricht and Maastricht University, and was carried out in compliance with the code of ethics on human experimentation established by the Declaration of Helsinki (1964) and amended in Seoul (2008), and the principles of the International Conference on Harmonization guideline for Good Clinical Practice.

\section{Design and treatments}

The study was conducted according to a double blind, within-subjects design with hydroxyzine $50 \mathrm{mg}$ and a placebo control. Hydroxyzine is a $1^{\text {st }}$ generation antihistamine, with plasma peak concentrations between 1.7 and 2.5 hours after oral ingestion. Its half-life varies on average between 15.9 and 24.1 hours ${ }^{11,12}$. Treatment periods consisted of (i) hydroxyzine in the evening and placebo in the morning, (ii) placebo in the evening and hydroxyzine in the morning and (iii) placebo in the evening and placebo in the morning conditions. Earlier studies have shown that hydroxyzine causes performance impairments within 1-2 hours after intake ${ }^{13,14}$. Therefore, tests were conducted and ERP measurements were obtained one hour after drug intake in the evening, and one hour after drug intake in the morning. Treatment periods were separated by a washout period of at least 7 days and treatment order was randomized and counterbalanced across participants. All treatments were administered as identical encapsulated tablets to ensure blinding. The test battery included a number of performance tasks and 2 ERP paradigms that are described below. Performance data have been described elsewhere ${ }^{15}$. The present report focuses on ERP data only.

\section{Procedure}

Before the first treatment period, participants received a training of the tests and a sleep habituation session. Each test session lasted from evening until morning. Participants were asked to have a light meal not less than 1 hour before arriving 
on study site. Upon arrival on the study site, drug screens and pregnancy tests were conducted, and vital signs were measured. In the evening of the test session approximately one hour after medication intake, at 8:30 pm, the measurements were performed until 10:00 pm. Participants were instructed to go to bed at 11:00 pm. Immediately after being woken up at 07:00 am, the medication was administered. One hour later the measurements were conducted for the second time. A detailed overview of the test sessions is presented in Figure 1.

\begin{tabular}{|c|c|c|c|c|}
\hline $19: 00$ & $19: 15$ & $19: 30$ & $20: 30-22: 00$ & 23:00 \\
\hline $\begin{array}{c}\text { Start } \\
\text { testday }\end{array}$ & $\begin{array}{l}\text { Drug test } \\
\text { Vital signs }\end{array}$ & $\begin{array}{l}\text { Medication } \\
\text { intake }\end{array}$ & Test battery & Bedtime \\
\hline 07:00 & 07:01 & 07:05 & $08: 00-09: 30$ & 10:00 \\
\hline & $\begin{array}{l}\text { Medication } \\
\text { intake }\end{array}$ & Vital signs & $\begin{array}{c}\text { Test } \\
\text { battery }\end{array}$ & $\begin{array}{l}\text { End of } \\
\text { testday }\end{array}$ \\
\hline
\end{tabular}

Figure 1 Overview of test sessions.

\section{Assessments}

\section{Attention tests}

The divided attention task (DAT) ${ }^{16}$ measures the ability to divide attention between two tasks performed simultaneously. One task measures the subject's ability to control a moving signal on a computer screen using a joystick ${ }^{17}$. In the other task, the subject monitors a central display upon which single digits are presented for 17 milliseconds with a variable inter stimulus interval between 1.03 and 1.23 seconds. The subject has to remove his foot from a pedal as rapidly as possible when the digit "2" (target) occurs in the center of the screen. When other digits (distracters) are presented in the center of the screen the subject is asked not to respond. In total, 75 targets and 375 distracters were presented. The task takes about 10 minutes, depending on the competence of the participant. ERPs were measured in relation to the secondary task, and ERP averages were calculated for targets and distracters ${ }^{18}$.

The attention network test (ANT) combines warning cues and flanker displays in order to study the alerting network, the orienting network and the 
executive control network ${ }^{19,20}$. The subject is asked to determine whether a central arrow points to the left or to the right by pressing a key. The arrow appears above or below a fixation point and is accompanied by four arrows that either point in the same direction (congruent flankers) or in the opposite direction (incongruent flankers). Before the display of the arrows, a cue may appear in the center (center cue condition), above or below a fixation cross (spatial cue condition), or not at all (no cue condition). Each trial begins with the presentation of a fixation cross and at some variable interval a cue is presented for $200 \mathrm{~ms}$. Four hundred ms after the offset of the cue, a target display appears and remains visible on the screen until a response is made (pressing a key indicating the direction of the target arrow) ${ }^{3}$. A shortened version of the attention network test was used in which 114 trials, consisting of combinations of the flankers and cues were randomly presented ${ }^{15}$. Performing this version takes about 25 minutes. Efficiency of the alerting network is examined by changes in latency and amplitude between center-cue and no-cue conditions. The orienting network is studied by changes in latency and amplitude between center- and spatialcue conditions. Efficiency of the executive network is examined by changes in latency and amplitude between incongruent flankers and congruent flankers ${ }^{3}$.

\section{Event Related Potentials}

Recording - EEG activity was recorded from 32 electrodes according to the international 10-20 system ${ }^{21}$, using Neuroscan software. All electrodes were filled with electrode-gel and were referenced to the left and right mastoid electrodes. The Fpz electrode was used as ground electrode. Eye movements were detected by horizontal and vertical electro-oculogram (EOG) recordings. All electrode impedances were kept below $5 \Omega$. All signals were sampled at a $500 \mathrm{~Hz}$ frequency and filtered online using a $250 \mathrm{~Hz}$ low-pass filter and a 0.05 high-pass filter.

Signal analysis - All sampled EEG and EOG epochs were filtered offline using a $30 \mathrm{~Hz}$ filter. EEGs were corrected for vertical and horizontal eye movements according the Gratton and Coles method ${ }^{22}$. The EEG fragments within an epoch of $100 \mathrm{~ms}$ before target stimulus onset and $1000 \mathrm{~ms}$ after onset were averaged, using the pre-stimulus interval as baseline. The EEG fragments were averaged for each condition separately.

ERP-components - The ERP-components of interest in the used tasks were P100, N100, N200 and P3b (from now on referred to as P300). Both N100 and P100 are early sensory evoked components that are larger in response to attended than unattended stimuli ${ }^{23-27}$. The occipital P100 is a positive peak which appears approximately between $80-130 \mathrm{~ms}$ after stimulus presentation 24. In a former study conducted by Theunissen et al. (2006), P100 latency demonstrated significant effects for treatment by workload during the DAT, 
testing the antihistamine fexofenadine. N100 is a negative component with latency around 140 and $200 \mathrm{~ms}^{24}$ and is studied in experiments to examine selective or divided attention processes. Furthermore, research has demonstrated that target N100 significantly increases during alerting and orienting in the ANT ${ }^{4}$.

The afore-mentioned higher-level components N200 and P300 were also measured. The N200 reflects attention switching processes ${ }^{28}$ and is affected by conflict trials ${ }^{29}$. The N200 occurs between 200 and 300 ms after stimulusonset. It has been demonstrated that during the ANT the N200 component can be seen from cue- and target-locked responses. Furthermore, there were small differences detected between congruent and incongruent target conditions in the $\mathrm{ANT}^{3}$. The parietal P300 is a positive wave between 300 and $800 \mathrm{~ms}$ mostly demonstrated in discrimination tasks ${ }^{30}$, and is a sensitive measure for sustained attention ${ }^{31}$. However, as the P300 is detected in any task that requires stimulus discrimination, it is difficult to determine the functional implication of this component. More recently, it is hypothesized that P300 reveals neural inhibition of current activity in order to facilitate transmission of stimulus/task information, and is therefore related to processing of incoming information ${ }^{32}$. Furthermore, research demonstrated that hydroxyzine increased P300 latency significantly compared with placebo and the non-sedative antihistamine cetirizine ${ }^{8}$. Significant treatment effects of the antihistamine fexofenadine on P100 and P300 latency were also found during the DAT in former studies ${ }^{18}$.

For both tasks ERPs were analyzed at Fz, FCz, Cz, Pz, P3 and P4. The P100 component was established as the highest amplitude within a time window of 50-160 ms after stimulus onset, and N100 as the lowest amplitude within 80-180 ms. N200 was determined as the lowest amplitude within a time window of $180-300 \mathrm{~ms}$, and the P300 component as the highest amplitude within 220-320 ms after stimulus onset. All the time windows were defined after inspection of the grand averages. Additionally, the latencies of these four peaks were included in the analysis.

\section{Statistics}

The ERP data, that were normally distributed, were analyzed by means of paired samples $t$-test. The main focus of this study was to identify the differences between morning dosing of hydroxyzine and evening dosing of hydroxyzine. Therefore, it was of importance to exclude the possibility of carry-over effects from evening to morning sessions. For that reason, the effects of hydroxyzine (i.e. increased latency and decreased amplitude of ERPs) in the evening were compared with the effects of placebo in the evening, and the effects of hydroxyzine in the morning were compared with the effects of placebo in the 
morning. This way, no carry-over effects that might occur in the other morning placebo condition were measured.

In case of extreme values and non-normality, winsorization was applied ${ }^{33}$. The Statistical Package for the Social Sciences (SPSS) version 15.0 was used for the achievement of all listings, tables and analyses.

\section{Results}

A total of 18 volunteers participated in the present experiment. However, because one subject missed two treatment periods due to personal matters, only 17 participants ( 8 male and 9 female) were included in the analysis. All 17 participants completed all three testing periods.

\section{Divided Attention Task (DAT)}

The results of the ERPs in the DAT showed that overall, more impairing effects of hydroxyzine were apparent in the morning, as N100 latency was increased at $\mathrm{Cz}$ $\left(\mathrm{t}_{15}=2.5, \mathrm{p}=0.03\right)$, and P300 amplitude was decreased at $\mathrm{Cz}\left(\mathrm{t}_{15}=-2.8, \mathrm{p}=0.015\right)$, $\mathrm{Pz}\left(\mathrm{t}_{15}=-2.1, \mathrm{p}=0.05\right), \mathrm{P} 3\left(\mathrm{t}_{15}=2.6, \mathrm{p}=0.018\right)$ and $\mathrm{P} 4\left(\mathrm{t}_{15}=-2.2, \mathrm{p}=0.042\right)$. In the evening, less impairing effects were apparent as P100 amplitude was significantly decreased after hydroxyzine at $\mathrm{Fz}\left(\mathrm{t}_{15}=2.6, \mathrm{p}=0.013\right)$ while $\mathrm{N} 200$ and P300 latency were increased at respectively $\mathrm{Cz}\left(\mathrm{t}_{15}=2.6, \mathrm{p}=0.021\right)$ and $\mathrm{Pz}\left(\mathrm{t}_{15}=2.6\right.$, $\mathrm{p}=0.02$ ). To summarize, the relationship between hydroxyzine treatment and P300 at $\mathrm{Cz}$ is plotted in Figure 2.

\section{ANT}

The results of the ERPs in the ANT showed that in the morning, a decreased alerting effect in N200 amplitude was apparent at $\mathrm{Cz}$ after hydroxyzine $\left(\mathrm{t}_{15}=-\right.$ 2.37, $\mathrm{p}<0.03)$. For the other attention networks no significant treatment effects were present for ERP latency or amplitude in the ANT. In the evening, significant differences in alerting effects (no cue minus center cue conditions) were present as indicated by an increase in P300 latency at P3 $\left(t_{15}=3.25\right.$, $\mathrm{p}=0.005$ ) after hydroxyzine. Significant orienting effects (center cue minus spatial cue) were present in the evening as indicated by an increase in P300 latency at $\mathrm{Cz}\left(\mathrm{t}_{15}=3.89, \mathrm{p}=0.001\right)$, and a decrease in $\mathrm{P} 300$ amplitude at $\mathrm{P} 3\left(\mathrm{t}_{15}=-\right.$ $2.46, \mathrm{p}=0.027)$ after hydroxyzine treatment. No treatment effects were present for the conflict effect (incongruent minus congruent flankers). To summarize, the relationship between hydroxyzine treatment and amplitude and latency of the P3 peak is plotted in Figure 3. 

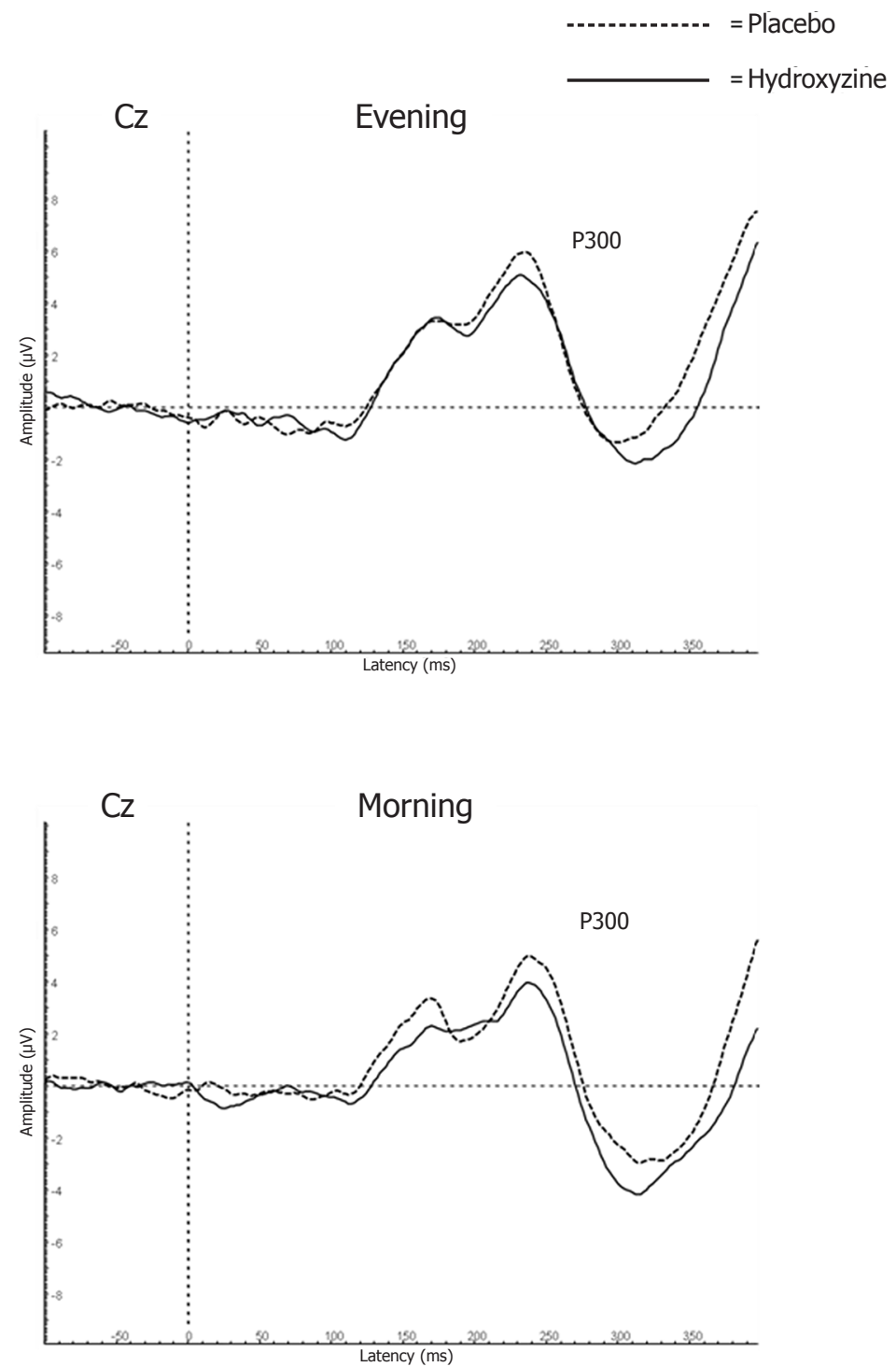

Figure 2 Grand average ERPs at Cz of the DAT. P300 latencies are shown on the x-axis in milliseconds and amplitudes are presented on the $y$-axis in microvolts. In the morning, target amplitude was significantly decreased after hydroxyzine treatment. 


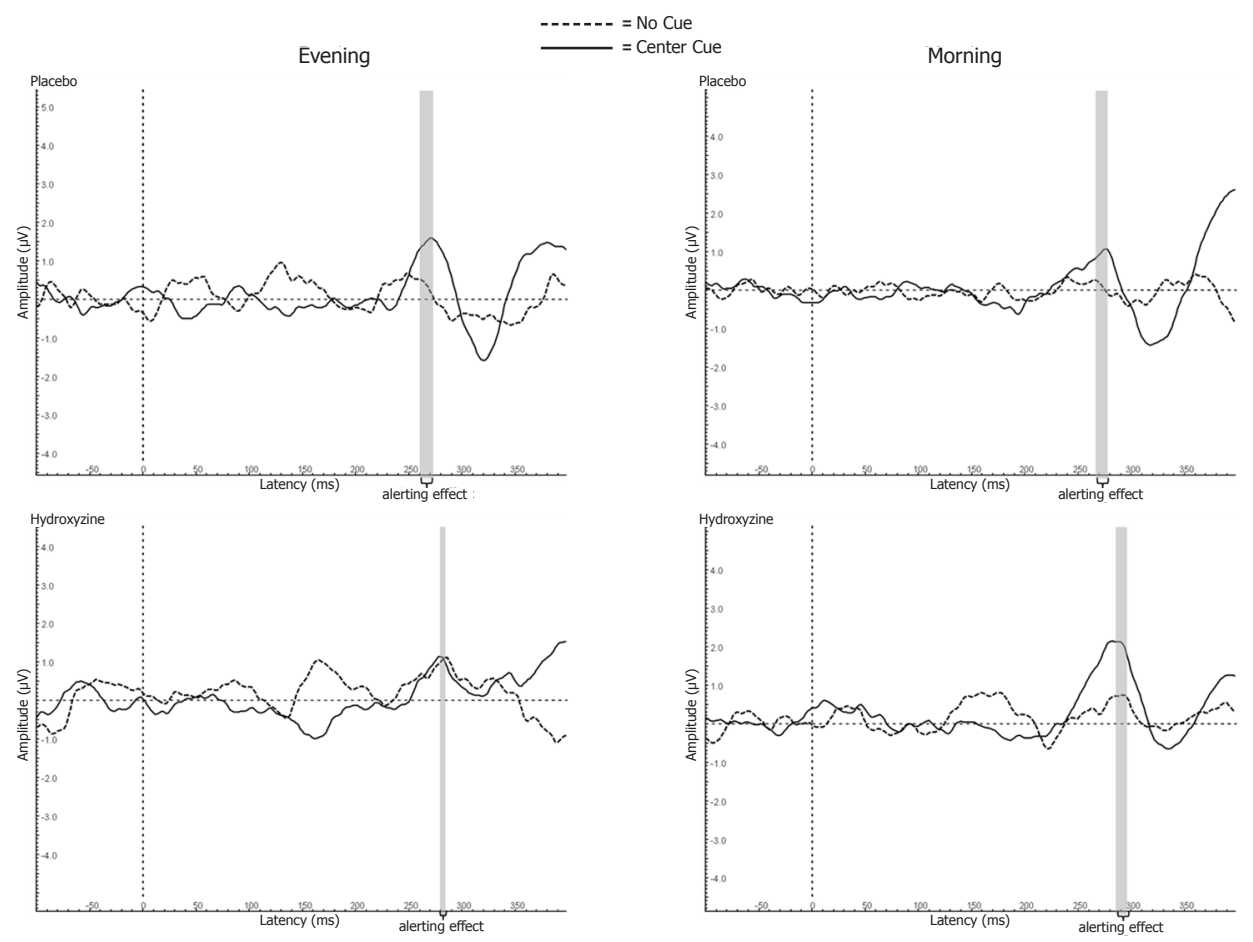

Figure 3 Grand average ERPs at P3 in the center-cue and no-cue conditions of the ANT. P3 peak latencies are shown on the $x$-axis in milliseconds and amplitudes are presented on the $y$-axis in microvolt. The shaded bars indicate the magnitude of the alerting effect (center-cue minus no-cue) on P3 latency.

\section{Discussion}

The aim of the present experiment was to compare hydroxyzine induced impairment after morning dose and evening dose administration. It was expected that the peak latency of the ERPs would increase and that the peak amplitude would decrease after hydroxyzine treatment compared with placebo, and that this effect would be less apparent in the morning due to the larger release of histamine shortly after awakening, and an increased competition between histamine and hydroxyzine in the CNS. The data does confirm that most ERP latencies increased and amplitudes decreased by hydroxyzine on several electrode positions. The results of the DAT did not confirm the second hypothesis as they did show that sedation was more apparent in the morning. However, in the ANT sedative effects of hydroxyzine were mostly apparent in the evening. 
ERP data of the DAT confirmed previous behavioral data ${ }^{15}$ which demonstrated that hydroxyzine effects on divided attention task performance were worse in the morning as compared to the evening. Hydroxyzine did affect ERPs a-specifically, but the effects were mostly apparent at the P300 component. Latencies increased and amplitudes decreased after hydroxyzine on several electrode positions, showing that sedation was more apparent in the morning instead of the evening for the targets. As the P300 component has been linked to facilitating the transmission of stimulus / task information ${ }^{32}$, it can be concluded that this facilitation was inhibited after hydroxyzine treatment, with more effects in the morning condition.

The ERP data of the ANT demonstrated that both the alerting and orienting network were significantly affected by hydroxyzine. During hydroxyzine treatment participants were less alert (i.e. had less benefit from a warning cue) both in the evening and in the morning. P300 amplitude during orienting tasks was mostly affected in the evening, indicating that participants had less benefit from a spatial cue after hydroxyzine. P300 latency at Cz was also affected by hydroxyzine during orienting, but here participants apparently had more benefit from a spatial cue in the hydroxyzine condition. As the effects were more prominent in the evening, the ERP data from the ANT appears to confirm our original hypothesis. However, the ERP data were not in line with the behavioral data of the ANT that we have presented before. These performance data showed that hydroxyzine impairment was apparent both in the evening and morning, and only during conflict tasks. The apparent conflicts between behavioral data and ERP data in the ANT tasks and between ERP latency and amplitude during orienting therefore indicate that the present ERP results of the ANT should be interpreted with caution.

A number of reasons may have accounted for the finding that hydroxyzine effects were generally worse after morning doses as compared to evening doses. First, the actual brain histamine levels during testing in the evening or morning are unknown and, as a consequence, the timing of hydroxyzine may have been incorrect. If hydroxyzine was given too late, excessive histamine release might already have stabilized or degraded, and therefore no longer be available to compete with histamine. Hydroxyzine may also have been given to early if histamine levels did not increase excessively after awakening but only gradually restored at re-activation of histamine neurons in morning. This would mean that histamine levels would temporarily be lower right after awakening when compared to 'regular' histamine levels in the evening, even though histamine neurons are equally, or more active at both times. This would also cause less competition for hydroxyzine to occupy H1Rs, which would explain more pronounced impairments in the morning as observed in this study. Secondly, a larger impairment in the morning dose condition compared with the evening 
dose condition could also be explained by sleep inertia. As sleep inertia is the decreased performance immediately after awakening ${ }^{34}$, it may interact with the sedative effects of hydroxyzine to increase impairing effects on performance. Thirdly, variations in pharmacokinetics during the day may have affected the pharmacodynamics of hydroxyzine ${ }^{35}$. It is possible that hydroxyzine might be absorbed faster in the morning which can lead to a higher Cmax, which could, partially, contribute to differences in hydroxyzine effects observed in the present study.

In summary, although the ANT data are in line with our hypotheses, these data should be interpreted with caution because the number of effects were limited and in contrast with hydroxyzine effects on behavioral parameters of the ANT. ERP data of the DAT indicate that hydroxyzine induced impairment was more prominent after morning doses as compared to evening doses. Taken together, the present study could not provide unambiguous evidence to confirm the hypothesis that histamine availability inversely affects magnitude of antihistamine impairment.

\section{References}

1. Theunissen, E. L., Jonkman, L. M., Kuypers, K. P. \& Ramaekers, J. G. A combined neurophysiological and behavioural study into the stimulating effects of fexofenadine on performance. J Psychopharmacol 20, 496-505 (2006).

2. Theunissen, E. L., Vermeeren, A., Vuurman, E. F. \& Ramaekers, J. G. Stimulating effects of H1-antagonists. Curr Pharm Des 12, 2501-2509 (2006).

3. Fan, J. et al. The relation of brain oscillations to attentional networks. J Neurosci 27, 61976206 (2007).

4. Neuhaus, A. H. et al. Event-related potentials associated with Attention Network Test. Int J Psychophysiol 76, 72-79 (2010).

5. Loring, D. W. \& Meador, K. J. Central nervous system effects of antihistamines on evoked potentials. Ann Allergy 63, 604-608 (1989).

6. Simons, F. E., Reggin, J. D., Roberts, J. R. \& Simons, K. J. Benefit/risk ratio of the antihistamines (H1-receptor antagonists) terfenadine and chlorpheniramine in children. J Pediatr 124, 979-983 (1994).

7. Lucchesi, L. M. et al. Flunitrazepam-induced changes in neurophysiological, behavioural, and subjective measures used to assess sedation. Prog Neuropsychopharmacol Biol Psychiatry 27, 525-533 (2003).

8. Simons, F. E., Fraser, T. G., Reggin, J. D. \& Simons, K. J. Individual differences in central nervous system response to antihistamines (H1-receptor antagonists). Ann Allergy Asthma Immunol 75, 507-514. (1995).

9. Simons, F. E., Fraser, T. G., Reggin, J. D. \& Simons, K. J. Comparison of the central nervous 
system effects produced by six H1-receptor antagonists. Clin Exp Allergy 26, 10921097 (1996).

10. Kerkhof, G. A. Een Nederlandse vragenlijst voor de selectie van ochtend-en avondmensen. (A Dutch questionnaire for the selection of morning and evening type individuals). Ned tijdschr psychol 39, 281-294 (1984).

11. del Cuvillo, A. et al. Comparative pharmacology of the H1 antihistamines. J Investig Allergol Clin Immunol 16 Suppl 1, 3-12 (2006).

12. Simons, F. E., Simons, K. J. \& Frith, E. M. The pharmacokinetics and antihistaminic of the $\mathrm{H} 1$ receptor antagonist hydroxyzine. J Allergy Clin Immunol 73, 69-75 (1984).

13. Abbas, M. N., Abdel Fattah, A. A. \& Zahran, E. A novel membrane sensor for histamine H1receptor antagonist "fexofenadine". Anal Sci 20, 1137-1142 (2004).

14. Vuurman, E., Theunissen, E., van Oers, A., van Leeuwen, C. \& Jolles, J. Lack of effects between rupatadine $10 \mathrm{mg}$ and placebo on actual driving performance of healthy volunteers. Hum Psychopharmacol 22, 289-297 (2007).

15. Conen, S., Theunissen, E. L., Vermeeren, A. \& Ramaekers, J. G. Short-term effects of morning versus evening dose of hydroxyzine $50 \mathrm{mg}$ on cognition in healthy volunteers. J Clin Psychopharmacol 31, 294-301 (2011).

16. Moskowitz, H. Laboratory studies of the effects of alcohol on some variables related to driving. J Safety Res 5, 185-192 (1973).

17. Jex, H. R., McDonnell, J. D. \& Phatak, A. V. A “critical” tracking task for man-machine research related to the operator's effective delay time. I. Theory and experiments with a first- order divergent controlled element. NASA CR-616. NASA Contractor Report NASA CR, 1-105 (1966).

18. Theunissen, E. L., Jonkman, L. M., Kuypers, K. P. C. \& Ramaekers, J. G. Stimulating effects of fexofenadine under high workload conditions. A combined neurophysiological and behavioral approach. J psychopharmacol 20, 485-495 (2006).

19. Fan, J., McCandliss, B. D., Fossella, J., Flombaum, J. I. \& Posner, M. I. The activation of attentional networks. Neuroimage 26, 471-479 (2005).

20. Fan, J., McCandliss, B. D., Sommer, T., Raz, A. \& Posner, M. I. Testing the efficiency and independence of attentional networks. J Cogn Neurosci 14, 340-347 (2002).

21. Jasper, H. H. The ten-twenty electrode system of the international federation. Electroencephalogr Clin Neurophysiol 10, 371-375 (1958).

22. Gratton, G., Coles, M. G. \& Donchin, E. A new method for off-line removal of ocular artifact. Electroencephalogr Clin Neurophysiol 55, 468-484 (1983).

23. Golob, E. J., Pratt, H. \& Starr, A. Preparatory slow potentials and event-related potentials in an auditory cued attention task. Clin Neurophysiol 113, 1544-1557 (2002).

24. Hillyard, S. A. \& Anllo-Vento, L. Event-related brain potentials in the study of visual selective attention. Proc Natl Acad Sci USA 95, $781-787$ (1998).

25. Hillyard, S. A., Vogel, E. K. \& Luck, S. J. Sensory gain control (amplification) as a mechanism of selective attention: electrophysiological and neuroimaging evidence. Philos Trans $R$ Soc Lond B Biol Sci 353, 1257-1270 (1998). 
26. Mangun, G. R. Neural mechanisms of visual selective attention. Psychophysiology 32, 4-18 (1995).

27. Watter, S., Geffen, G. M. \& Geffen, L. B. The n-back as a dual-task: P300 morphology under divided attention. Psychophysiology 38, 998-1003 (2001).

28. Kasai, K. et al. Psychophysiological index during auditory selective attention correlates with visual continuous performance test sensitivity in normal adults. Int $J$ Psychophysiol 45, 211-225 (2002).

29. van Veen, V. \& Carter, C. S. The anterior cingulate as a conflict monitor: fMRI and ERP studies. Physiol Behav 77, 477-482 (2002).

30. Polich, J. \& Kok, A. Cognitive and biological determinants of P300: an integrative review. Biol Psychol 41, 103-146 (1995).

31. Meador, K. J., Loring, D. W., Thompson, E. E. \& Thompson, W. O. Differential cognitive effects of terfenadine and chlorpheniramine. J Allergy Clin Immunol 84, 322-325 (1989).

32. Polich, J. Updating P300: an integrative theory of P3a and P3b. Clin Neurophysiol 118, 2128-2148 (2007).

33. Shete, S. et al. Effect of winsorization on power and type 1 error of variance components and related methods of QTL detection. Behaviour Genetics 34, 153-159 (2004).

34. Tassi, P. \& Muzet, A. Sleep inertia. Sleep Med Rev 4, 341-353 (2000).

35. Baraldo, M. The influence of circadian rhythms on the kinetics of drugs in humans. Expert Opin Drug Metab Toxicol 4, 175-192 (2008). 


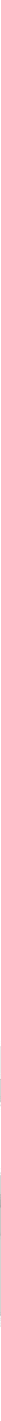




\section{Chapter 7}

\section{General discussion and concluding remarks}



$\mathrm{H} 1$-antihistamines are agents that are widely used in the treatment of allergies, as well as in the treatment of disorders such as insomnia and anxiety. They can act both peripherally and in the CNS. The capacity of $\mathrm{Hl}$-antihistamines to cause CNS effects such as sleepiness and drowsiness is unwelcome in allergy treatment, but wanted in the treatment of insomnia and anxiety. CNS effects of antihistamines are caused by inverse agonism of the $\mathrm{H} 1$ receptors in the brain. The present dissertation focused on genetic and neuropharmacological factors that are believed to contribute to the magnitude of central CNS effects.

\section{Behavioral effects of centrally acting $\mathrm{H} 1$-antihistamines}

\section{Actual driving performance}

Driving a car is a complex, goal-directed behavior where several cognitive and psychomotor skills are used simultaneously ${ }^{1,2}$. Medications that cause sedation can impair driving performance and consequently can increase the risk of traffic accidents ${ }^{1}$. Results on driving performance presented in chapters 2 and 3 show the effects of a first generation and second generation antihistamine, and an agent with antihistaminergic properties on driving. Second generation antihistamines bilastine 20 and $40 \mathrm{mg}$ did not increase the amount of weaving (i.e. SDLP) from placebo after single and repeated dosing (chapter 2). First generation $\mathrm{Hl}$-antihistamine hydroxyzine $50 \mathrm{mg}$, on the other hand, did impair driving performance, as the mean increase in the amount of weaving from placebo was significant after single dosing as well as after 1 week dosing (chapter 2). Esmirtazapine $4.5 \mathrm{mg}$, an agent with $\mathrm{Hl}$-antihistaminergic properties, did show impaired driving performance after single-dose administration which resolved after 1 week of dosing (chapter 3). However, when focusing on poor metabolizers, driving performance after a single dose of esmirtazapine $1.5 \mathrm{mg}$ impaired driving as well, and $4.5 \mathrm{mg}$ of esmirtazapine did also still produce an increment in driving performance after 1 week of dosing (chapter 3 ).

Bilastine is known to be an $\mathrm{Hl}$-antihistamine that is believed not to cross the $\mathrm{BBB}$, because it consists of larger molecules compared with $1^{\text {st }}$ generation antihistamines and because it is a P-gp substrate ${ }^{3}$. The latter ensures that even if bilastine would be able to enter the brain, it will be pumped out of it by the P-gp transporter. Hydroxyzine is known to cross the BBB and to occupy up to $70 \%$ of H1Rs in the prefrontal and cingulate cortices ${ }^{4}$. Esmirtazapine is also known to penetrate the $\mathrm{BBB}$ and bind to $\mathrm{H} 1$ receptors in the brain. The driving studies presented in chapters 2 and 3 thus confirm that driving impairment of antihistamines largely depends on the ability of these drugs to cross the BBB and to cause CNS sedation. 
The categorization system of the International Council on Alcohol, Drugs and Traffic Safety ${ }^{5}$ is an important guideline of prescribing physicians and patients. The classification system ranks the propensity of individual drugs to cause driving impairment. Drugs are assigned to one of the following categories: (I) Presumed to be safe or unlikely to produce an effect; (II) Likely to produce minor or moderate adverse effects; (III) Likely to produce severe effects or presumed to be potentially dangerous. In order to illustrate the practical implications of these categories, the effects within the categories are compared with effects of different blood alcohol concentrations (BACs) 5. Driving impairment in categories (I), (II), and (III) is assumed to be equivalent to BACs $<0.5 \mathrm{~g} / \mathrm{l}, 0.5-0.8 \mathrm{~g} / \mathrm{l}$, and $>0.8 \mathrm{~g} / \mathrm{l}$, respectively.

The lack of bilastine effects on driving performance $(\mathrm{BAC}<0.5 \mathrm{~g} / \mathrm{l})$ indicates that it is safe to operate a car during bilastine treatment and that bilastine should be categorized in category I. A single dose of hydroxyzine impaired driving comparable to impairment caused by a BAC of $0.8 \mathrm{~g} / \mathrm{l}$. These data imply that hydroxyzine should be categorized in category II. Our results show that even after 8 days of treatment, hydroxyzine is still close to a BAC of $0.5 \mathrm{~g} / \mathrm{l}$. These findings strongly suggest not to drive after a single dose of hydroxyzine as this can minor to moderate effects, and to consult a healthcare professional, even after repeated doses, in order to evaluate whether starting to drive is safe. The driving data of esmirtazapine after a night's sleep demonstrated overall that a single dose of $4.5 \mathrm{mg}$ is likely to produce minor or moderate adverse events, and should be classified in the second category, meaning that driving after this dosage should first be discussed with a health care professional. However, driving performance after a single dose of esmirtazapine $1.5 \mathrm{mg}$ moves from being presumed to be safe in the overall population (category I), to being likely to produce even possible severe effects in poor metabolizers (category III). Also, when focusing on poor metabolizers, $4.5 \mathrm{mg}$ of esmirtazapine still produced an increment in driving performance after 1 week of dosing. Taken together, the driving data presented in this dissertation underline the importance of advising users of antihistamines about potential hazardous effects.

A substantial difference between the studies described in chapter 2 and chapter 3 is that different statistical analyses were used. In chapter 2 the effects of bilastine on driving performance were tested and analyzed using repeated measures ANOVA in a between-group design. This analysis is useful to determine if group outcomes are different from each other, and tells us whether the difference between two groups is zero or not ${ }^{6,7}$. The study described in chapter 3, on the other hand, used a non-inferiority design in order to determine whether the effect of esmirtazapine on driving was similar to driving with a BAC of less than $0.5 \mathrm{~g} / \mathrm{l}$. Non-inferiority was concluded when the upper limit of a two-sided 95\% confidence interval of the mean difference in weaving between 
esmirtazapine and placebo was below $2.5 \mathrm{~cm}$. Even though the first method of repeated measures ANOVA is widely used, it might be advantageous to use the more strict and informative method of analysis such as the non-inferiority design when investigating driving safety, because this method gives, by being more conservative, more information about possible clinically relevant effects.

\section{Attention}

Attention is a broad term and can refer to many phenomena and processes ${ }^{8}$, ${ }^{9}$, and can be thought of as the allocation of processing resources in order to select relevant stimuli. Attention is related to arousal, which is a global state of the brain ranging from deep sleep to maximum wakefulness ${ }^{10}$. Attention and arousal are heterogeneous processes believed to be related in an inverted $\mathrm{U}$-shaped function ${ }^{8,10}$. Low levels of arousal are associated with inattentiveness, mid-arousal with effective attention, and high arousal with ineffective attention. Present dissertation investigated the sedative actions of $\mathrm{H} 1$-antihistamines (i.e. low levels of arousal) and measured these by focusing on 4 aspects of attention, i.e.: divided attention (measured with the divided attention task), alerting attention, orienting attention, and executive control (all three measured with the attention network test).

Divided attention is defined as dividing attention between two or more stimuli ${ }^{8}$ and was impaired after esmirtazapine administration (chapter 3) and after hydroxyzine administration (chapter 5). Hydroxyzine also affected P300 during divided attention task performance (chapter 6). P300 is associated with facilitating transmissions of stimulus information ${ }^{11}$ and is known to be modulated by attention ${ }^{8}$. Therefore, the ERP results support the conclusion that central antihistaminergic effects impair divided attention.

The attention network test (ANT) measures alerting, orienting, and executive control. Alerting is defined as response readiness to a warning cue (phasic alertness) as well as cognitive control of wakefulness and arousal (tonic alertness) ${ }^{12}$. Centrally acting cetirizine (caused by blocking the P-gp efflux transporter) did affect alerting. Cetirizine impaired the response to no-cue conditions as evidenced by prolonged reaction times and a decrement in brain activation in the right superior temporal gyrus (chapter 4). Both findings confirm that centrally acting cetirizine impairs wakefulness. Orienting is the allocation of attentional focus to a potentially relevant area. Hydroxyzine affected ERP measures of orienting (chapter 6) but did not impair behavioral measures (chapter 5). Executive control is the more complex operation of resolving conflict amongst responses. Hydroxyzine impaired behavioral measures of executive attention (chapter 5), but not ERP measures (chapter 6). The discrepancy between behavioral and ERP measures might be caused by using a shorter version of the 
ANT, thereby lessening the valid use of the test. It is suggested to repeat these studies using the complete attention network test.

The difference in behavior when comparing ANT results between centrally acting cetirizine and hydroxyzine might be caused by chemical and pharmacological differences between both $\mathrm{H} 1$-antihistamines. Cetirizine is the major metabolite of hydroxyzine and is more selective for $\mathrm{H} 1$ receptors. Hydroxyzine also affects other receptors that might be involved in sedation such as dopamine D2 receptors ${ }^{13}$. Indeed, it is believed that executive attention is modulated by dopamine ${ }^{12}$, 14, 15. Further research into the effects of hydroxyzine on the complete attention network test could confirm this assumption.

\section{Impulsivity and attention}

Impulsivity is a construct in personality theories associated with acting unplanned without considering the consequences ${ }^{16}$. Behaviors reflecting impulsivity are, amongst other, (lack of) response inhibition and attention switching ${ }^{16,17}$, and these can be affected by pharmacological factors ${ }^{18}$. In the present dissertation, response inhibition was measured by means of a Stop Signal Task, and attention switching by means of an Attention Switch Task.

Esmirtazapine did not affect response inhibition (chapter 3), which could mean that impulsivity is not affected by central $\mathrm{H} 1$-antihistamine. Hydroxyzine, on the other hand, did affect the Stop Signal Task outcomes (chapter 4). However, hydroxyzine did not affect the parameter representing response inhibition, but increased reaction times and decreased the number of correct responses. These effects can be explained by a general decrease in attention, indicating again that impulsivity was not affected. That this general decrease in attention was only present after hydroxyzine treatment and not present after treatment with esmirtazapine, can be explained by the fact that hydroxyzine also affects other receptors that might be involved in sedation such as dopamine D2 receptors ${ }^{13}$. Attention switching was impaired by central antihistamine effects caused by hydroxyzine (chapter 4). Switching between two tasks reflects the degree of readiness to perform a task, as well as the ability to inhibit earlier information. It is therefore believed that attention switching poses high demands on impulsivity, but also on attention ${ }^{16,19}$. It could be argued that the impairment in attention switching after hydroxyzine may therefore indicate that lower levels of arousal increased the time needed to inhibit a previous task set (i.e. impaired impulsivity), but also that attention may have been impaired. 


\section{Subjective measurements}

Subjective feelings of sedation were measured using visual analogue scales. Results show that participants did not acknowledge sedative central antihistamine effects (chapter 2, 4, 5) even though sedation was demonstrated objectively. Participants did not expect that hydroxyzine would affect their driving ability, but acknowledged that their driving had been impaired after completion of the driving test (chapter 2). The lack of subjective awareness of impairments caused by antihistamines has also been found in previous research ${ }^{20,21}$, and further underscores the notion that users of sedative antihistamines should receive explicit warnings about possible deleterious effects.

\section{Mechanisms of central H1-antihistamine action}

\section{Human variability in CYP2D6 metabolism}

It was hypothesized that the variability in CYP2D6 metabolism also produces variation in central antihistamine actions (chapter 3). As mentioned before, data indeed showed that poor metabolizers of CYP2D6 experienced greater driving impairments as compared with extensive metabolizers after treatment with the CYP2D6 substrate esmirtazapine. These findings confirm the role of CYP2D6 metabolism in central H1-antihistamine effects, as in poor metabolizers the exposure to esmirtazapine is higher, resulting in higher central antihistamine action and consequently more sedation. Moreover, these findings stress the importance of taking individual genetic variances into account when administering $\mathrm{Hl}$-antihistamines. The results suggest that it is of importance to consider the distinction between poor and extensive metabolizers in future studies related to drugs and traffic safety which may lead to an extended ICADTS classification system that includes those genetic differences. Also, assessing CYP2D6 phenotypes before starting treatment can be beneficial and is thought to be an important step in moving towards tailor-made treatments.

Besides for antihistamines, CYP2D6 is the major route of metabolism for 20-25\% of clinically used drugs such as antidepressants, antipsychotics, and opioids ${ }^{22}$, Our results indicate that poor metabolizers may be in general at risk of being exposed to higher levels of CYP2D6 substrates which have the potential to impair car driving as well as other performances, emphasizing all the more the importance of taking inter-individual variability into account in drug treatments. 


\section{P-glycoprotein at the blood-brain barrier}

P-glycoprotein is a mechanism at the blood-brain barrier that is believed to play a role in central actions of antihistamines. Even though a substrate for P-glycoprotein can enter the brain through diffusion, the penetration of brain tissue can be decreased by this efflux transport. Cetirizine is a mildly-sedative $\mathrm{H} 1$-antihistamine causing slight sedation at low $\operatorname{doses}^{4}$, meaning it can (partially) enter the brain through diffusion. Cetirizine is also known to be a P-glycoprotein substrate ${ }^{23}$, which is thought to be a reason for the lack of highly sedative effects. Chapter 4 confirms that P-glycoprotein plays a role in central effects of cetirizine, as the combination of blocking the transporter and administering cetirizine increased sedative effects on alerting. Besides in the blood-brain barrier, P-glycoprotein is expressed in the small intestine, liver and kidney ${ }^{24}$, resulting in reduced absorption and enhanced elimination of substrates. Therefore, P-glycoprotein inhibition was expected to increase plasma concentrations of cetirizine. Besides behavioral effects, an increase of cetirizine after blocking P-glycoprotein was indeed present in plasma concentrations, confirming data from animal models ${ }^{25-27}$. Both the behavioral and pharmacokinetic data confirm that P-glycoprotein is a mechanism playing a substantial role in the presence and/or absence of central antihistamine effects.

Similar to CYP2D6, there are genetic differences in P-glycoprotein activity. P-glycoprotein is encoded by the ABCB1 gene and individuals with a TT genotype show lower activity of the transporter ${ }^{28}$. The frequency in the healthy population of low P-gp activity is between 17 en 30\% ${ }^{29}$. This genetic variation may play a role in response differences such as seen in polymorphisms of CYP2D6 (chapter 3). In individuals with lower P-gp activity substrates will be pumped out of the brain less, and will therefore show increased action in the brain. For instance, even though $2^{\text {nd }}$ generation antihistamines are known to impair driving performance to a lesser degree than $1^{\text {st }}$ generation antihistamines, the amount of impairment caused by $2^{\text {nd }}$ generation antihistamines can still differ greatly among individuals ${ }^{30}$. This variation could be linked to a difference in P-gp activity. More knowledge about genetic variations is therefore important in order to fully understand variations in treatment response.

P-glycoprotein also plays a role in the distribution of many drugs besides antihistamines, such as antipsychotics, antidepressants and anti-cancer treatments. Concerning those treatments, P-glycoprotein may play a role in treatment resistance. Research has shown that, for instance, antipsychotics appear to be P-gp substrates, which makes them less effective in the treatment of schizophrenia as P-gp reduces their distribution in the CNS and consequently their effectiveness ${ }^{31,32}$. Additionally, research suggests that individual differences 
in P-gp activity caused by genetic variation may play a role in this difference in response. In patients with lower P-gp activity, antipsychotics appear more effective, because in those patients the ability to pump an antipsychotic out of the brain is less ${ }^{28}$. More knowledge about these individual genetic variations is imperative in order to fully understand the variation in antipsychotic response. These results emphasize again the importance of taking inter-individual variances into account in drug treatments. Investigating the variation in P-gp expression is of additional interest because research has shown that, for instance, during a longer, more chronic course of schizophrenia P-gp activity increases ${ }^{33}$. The magnitude of the consequences of increased P-gp function for treatment is not well known, but it shows that p-glycoprotein is an important mechanism in central treatment effects, and is becoming a more and more significant research area concerning pharmacological treatments.

P-gp inhibitors are also apparent in certain foods. For instance, flavanoids (plant pigments that are anti-oxidants) are relatively specific inhibitors of P-glycoprotein that are found in, amongst others, apples, onioins, red fruits and chocolate ${ }^{34}$. These types of food could therefore interact with substrates such as cetirizine. These possible interactions can change the amount of the substrate in the CNS, and can consequently change the effectiveness or toxicity of treatments. Therefore, possible interactions should be further investigated, to ensure that patients do not unknowingly (and perhaps unwantedly) increase the amount of certain medication in the CNS.

\section{Circadian fluctuations in brain histamine levels}

It was expected that circadian variation in histamine firing rate might be another mechanism playing a role in central antihistamine actions. It was expected that the sedative effects of first generation antihistamine hydroxyzine would be maximal in the evening when histamine levels were assumed to be low, and less in the morning when histamine levels were assumed to be high, as a result of increased competition between histamine and hydroxyzine in the CNS in the morning. Results indicated however that hydroxyzine induced impairment is more prominent after morning doses as compared to evening doses (chapter 5 and 6). A recent post-mortem study confirms that histamine release in the active period is higher as compared to the sleep period. However, it was also found that maximal expression of histamine was apparent in the early evening, and minimal expression shortly after midnight ${ }^{35}$. These results may account for the opposite findings from our hypotheses in chapter 5 and 6 . Taken these findings and our findings together, circadian histamine fluctuations may account for differences in central antihistamine effects, and it is suggested to use sedating $\mathrm{H} 1$-antihistamines in the evening and not in the morning, in order to minimize 
CNS impairment during the day. But nonetheless, it is strongly encouraged to further investigate the precise action of histamine release in healthy volunteers in order to verify our findings.

\section{Concluding remarks and future directions}

Since the identification of histamine in 1907 and the discovery of the first antihistamines in the 1930s, the knowledge and subsequent improvement of antihistamines has increased drastically. However, further improvements are still paramount in the treatment of human diseases with antihistamines.

Our results underline the presence of sedative central effects of H1antihistamines, because centrally acting antihistamines can significantly impair driving performance and attention. These behavioral central effects were confirmed by ERP and fMRI measures of brain responses to antihistamine treatment. Furthermore, our results suggest and confirm the role of a number of neuropharmacological mechanisms that contribute to the magnitude of central actions of $\mathrm{Hl}$-antihistamines in humans. The role of P-glycoprotein in central histamine effects has shown to be an important quality for minimizing central effects of antihistamines. Additionally, the role of genetic variation in CYP2D6 metabolism emphasizes the importance of taking individual variances in treatments into account, as genetic inter-individual variation affects treatment response. This genetic variation is also suggested to be present in P-glycoprotein activity. Furthermore, both mechanisms play a role in a broad range of treatments such as depression, schizophrenia and cancer. It is therefore recommended to further investigate the (possible) consequences of individual variations, not only in regards to antihistamines, but also regarding other treatments concerning both CYP2D6 and P-glycoprotein.

Overall, findings in present thesis (i) underline the importance of moving towards tailor-made H1-antihistamines treatments, and (ii) help the understanding of mechanisms causing sedation by antihistamines, which may in the future result in the improvement of treatments with antihistamines, whether the central antihistamine actions are wanted or unwanted.

\section{References}

1. Kay, G. G. \& Logan, B. K. National Highway Traffic Safety Administration, Washington DC, (2011).

2. Tanida, K. \& Poppel, E. A hierarchical model of operational anticipation windows in driving an automobile. Cogn Process 7, 275-287 (2006). 
3. Montoro, J. et al. Bilastine and the central nervous system. J Investig Allergol Clin Immunol 21 Suppl 3, 9-15 (2011).

4. Tashiro, M. et al. Dose dependency of brain histamine H(1) receptor occupancy following oral administration of cetirizine hydrochloride measured using PET with [11C] doxepin. Hum Psychopharmaco 24, 540-8 (2009).

5. ICADTS. Catergorization system for medicinal drugs affecting driving performance (Oslo, 2007).

6. Greene, C. J., Morland, L. A., Durkalski, V. L. \& Frueh, B. C. Noninferiority and equivalence designs: issues and implications for mental health research. J Trauma Stress 21, 433439 (2008).

7. Sackett, D. L. Superiority trials, noninferiority trials, and prisoners of the 2-sided null hypothesis. ACP J Club 140, A11 (2004).

8. Coull, J. T. Neural correlates of attention and arousal: insights from electrophysiology, functional neuroimaging and psychopharmacology. Prog Neurobiol 55, 343-361 (1998).

9. Styles, E. A. The psychology of attention (Psychology Press, New York, 2006).

10. Purves, D. et al. Principles of cognitive neuroscience (Sinauer Associates, Sunderland, M.A., 2008).

11. Polich, J. Updating P300: an integrative theory of P3a and P3b. Clin Neurophysiol 118, 2128-2148 (2007).

12. Fan, J. \& Posner, M. Human attentional networks. Psychiatr Prax 31 Suppl 2, S210-S214 (2004).

13. Snowman, A. M. \& Snyder, S. H. Cetirizine: actions on neurotransmitter receptors. J Allergy Clin Immunol 86, 1025-8 (1990).

14. Fan, J., McCandliss, B. D., Fossella, J., Flombaum, J. I. \& Posner, M. I. The activation of attentional networks. Neuroimage 26, 471-9 (2005).

15. Posner, M. I. \& Rothbart, M. K. Research on attention networks as a model for the integration of psychological science. Annu Rev Psychol 58, 1-23 (2007).

16. Markus, C. R. \& Jonkman, L. M. Attention switching after dietary brain 5-HT challenge in high impulsive subjects. J Psychopharmacol 21, 700-708 (2007).

17. Theunissen, E. L., van Kroonenburgh, M. J., van Deursen, J. A., Blom-Coenjaerts, C. \& Ramaekers, J. G. Stimulating effects of fexofenadine: testing the dopamine transporter hypothesis. Psychopharmacology 187, 95-102 (2006).

18. Gvion, Y. \& Apter, A. Aggression, impulsivity, and suicide behavior: a review of the literature. Arch Suicide Res 15, 93-112 (2011).

19. Johnson, A. \& Proctor, R. W. Attention: Theory and practice (Sage Publications, Inc, Thousand Oaks, 2004).

20. Theunissen, E. L., Jonkman, L. M., Kuypers, K. P. \& Ramaekers, J. G. A combined neurophysiological and behavioural study into the stimulating effects of fexofenadine on performance. J Psychopharmacol 20, 496-505 (2006).

21. Vermeeren, A., Ramaekers, J. G. \& O’Hanlon, J. F. Effects of emedastine and cetirizine, 
alone and with alcohol, on actual driving of males and females. J Psychopharmacol 16, 57-64 (2002).

22. Ingelman-Sundberg, M., Sim, S. C., Gomez, A. \& Rodriguez-Antona, C. Influence of cytochrome $\mathrm{P} 450$ polymorphisms on drug therapies: pharmacogenetic, pharmacoepigenetic and clinical aspects. Pharmacol Ther 116, 496-526 (2007).

23. Obradovic, T., Dobson, G. G., Shingaki, T., Kungu, T. \& Hidalgo, I. J. Assessment of the first and second generation antihistamines brain penetration and role of P-glycoprotein. Pharm Res 24, 318-327 (2007).

24. Fromm, M. F. Importance of P-glycoprotein at blood-tissue barriers. Trends Pharmacol Sci 25, 423-429 (2004)

25. Kim, K. A., Park, P. W. \& Park, J. Y. Short-term effect of quercetin on the pharmacokinetics of fexofenadine, a substrate of P-glycoprotein, in healthy volunteers. Eur J Clin Pharmacol 65, 609-614 (2009).

26. Sakugawa, T. et al. Enantioselective disposition of fexofenadine with the P-glycoprotein inhibitor verapamil. Br J Clin Pharmacol 67, 535-540 (2009).

27. Yasui-Furukori, N., Uno, T., Sugawara, K. \& Tateishi, T. Different effects of three transporting inhibitors, verapamil, cimetidine, and probenecid, on fexofenadine pharmacokinetics. Clin Pharmacol Ther 77, 17-23 (2005).

28. Xing, Q. et al. Polymorphisms of the ABCB1 gene are associated with the therapeutic response to risperidone in Chinese schizophrenia patients. Pharmacogenomics 7, 987-993 (2006).

29. Cascorbi, I. et al. Frequency of single nucleotide polymorphisms in the P-glycoprotein drug transporter MDR1 gene in white subjects. Clin Pharmacol Ther 69, 169-174 (2001)

30. O'Hanlon, J. F. \& Ramaekers, J. G. Antihistamine effects on actual driving performance in a standard test: a summary of Dutch experience, 1989-94. Allergy 50, 234-242 (1995).

31. El Ela, A. A. et al. Identification of P-glycoprotein substrates and inhibitors among psychoactive compounds - implications for pharmacokinetics of selected substrates. $J$ Pharm Pharmacol 56, 967-975 (2004)

32. Wang, J. S. et al. Aripiprazole brain concentration is altered in P-glycoprotein deficient mice. Schizophr Res 110, 90-94 (2009).

33. de Klerk, O. L. et al. Regional increase in P-glycoprotein function in the blood-brain barrier of patients with chronic schizophrenia: a PET study with [(11)C]verapamil as a probe for P-glycoprotein function. Psychiatry Res 183, 151-156 (2010).

34. Bansal, T., Jaggi, M., Khar, R. K. \& Talegaonkar, S. Emerging significance of flavonoids as P-glycoprotein inhibitors in cancer chemotherapy. J Pharm Pharm Sci 12, 46-78 (2009)

35. Shan, L. et al. Diurnal fluctuation in histidine decarboxylase expression, the rate limiting enzyme for histamine production, and its disorder in neurodegenerative diseases. Sleep 35, 713-5 (2012). 


Summary

H1-antihistamines acting in the central nervous system can cause sedation by inhibiting the wake-promoting effects of histamine in the brain. In case of allergy treatment this sedation is considered an unwanted non-therapeutic effect. However, the same sedative action is widely used and wanted in the treatment of insomnia and anxiety. Recent research indicates that several mechanisms contribute to (possible) sedative effects of antihistamines i.e.: (i) the metabolism of $\mathrm{Hl}$-antihistamines; (ii) the ability of antihistamines to bind at the P-glycoprotein transporter; and (iii) the time of administration relative to circadian fluctuation in brain histamine levels. Gaining further knowledge about these mechanisms and their effects in humans may lead to an optimization of antihistaminergic treatments.

The aim of this dissertation is to (i) reestablish the pharmacodynamics of centrally acting antihistamines, and to (ii) investigate three possible pharmacokinetic mechanisms of central action.

Chapter 1 gives a general introduction on the function of histamine and antihistamines, as well as on the three possible mechanisms that might play a role in central effects of antihistamines. Finally, the aim and the outline of the dissertation are described. 
Chapter 2 describes a study investigating the role of $\mathrm{H} 1$-antihistamines on actual driving performance in order to establish the difference between centrally and not centrally acting antihistamines. The effects of two doses of bilastine (20 and $40 \mathrm{mg}$ ) on actual driving after single and repeated dosing were assessed. Hydroxyzine $50 \mathrm{mg}$, a highly sedative antihistamine, was included as a control treatment to demonstrate the sensitivity of the performance measures. Twentytwo healthy volunteers (11 female and 11 males) were included and the study was conducted according to a randomized, double-blind, 4-way cross-over design. Participants were treated with once daily doses for 8 consecutive days. On day 1 and 8 of each treatment period participants conducted the actual highway driving test. In this standardized driving test participants operate a specially instrumented automobile over a $100 \mathrm{~km}$ (62 mile) primary highway circuit. The participants task was to maintain a constant speed of $95 \mathrm{~km} / \mathrm{hour}$ (59 miles/hour), and a steady lateral position between the delineated boundaries of the right (slower) traffic lane. A licensed driving instructor accompanied the participants.

Contrasting each drug with the placebo showed that weaving, the primary measure of the highway driving test, was significantly increased after treatment with hydroxyzine on both day 1 and day 8 , but not after treatment with either bilastine $20 \mathrm{mg}$ or $40 \mathrm{mg}$. It was concluded that bilastine $20 \mathrm{mg}$ and $40 \mathrm{mg}$ had no significant impairing effects on driving performance. However, hydroxyzine 50 mg produced impairing effects on driving performance, with no development of full tolerance after one week of treatment.

Chapter 3 presents the results of a study on the effects of antihistamine action on driving and the additional role of CYP2D6 phenotype on those effects. Thirtytwo healthy subjects ( 16 females and 16 males) participated in a randomized, double-blind, placebo-controlled study in order to assess effects of single and repeated doses of esmirtazapine $1.5 \mathrm{mg}$ and $4.5 \mathrm{mg}$ on driving performance. Zopiclone $7.5 \mathrm{mg}$ was included as an active control. All subjects were subjected to P450 2D6 (CYP2D6) phenotyping in order to distinguish poor metabolizers from extensive metabolizers of esmirtazapine. Performance was assessed using the afore-mentioned standardized on-the-road driving test. Treatment conditions were defined as follows: (i) $1.5 \mathrm{mg}$ esmirtazapine on Day 1-7; (ii) 4.5 mg esmirtazapine on Day 1-7; (iii) placebo on Day 1-7; and (iv) placebo on Day 1-6 and zopiclone 7.5 mg on Day 7. All treatments were administered as nocturnal doses.

Overall, low doses of esmirtazapine $(1.5 \mathrm{mg})$ did not produce any clinically relevant change in weaving after single and repeated dosing compared to placebo. Driving impairment, i.e. a significant rise in the amount of weaving, did occur after a single-dose administration of the higher esmirtazapine dose 
$(4.5 \mathrm{mg}$ ), but was resolved after repeated doses. A single dose zopiclone $7.5 \mathrm{mg}$ also increased weaving (i.e. impaired driving) as expected. It was concluded that single and repeated evening administration of esmirtazapine $1.5 \mathrm{mg}$ are generally not associated with impaired driving the next morning. A single-dose of esmirtazapine $4.5 \mathrm{mg}$ significantly impaired driving, but generally resolved after repeated administration. Exploratory analysis in a small group of poor CYP2D6 metabolizers $(\mathrm{N}=7)$ suggested that these subjects are more sensitive to the impairing effects of esmirtazapine on car driving. Acute driving impairment was more pronounced after both doses of esmirtazapine in that select group of poor metabolizers. These results emphasize the need to take factors into account which cause inter-individual variability in either treatment response or drug metabolism when investigating the drug effects on driving performance.

Chapter 4 focuses on a study investigating the role of P-glycoprotein (P-gp) in central antihistamine effects. An fMRI study was conducted according to a double-blind, randomized, placebo-controlled, cross-over design in 13 healthy volunteers. Participants received cetirizine $15 \mathrm{mg}$ (an antihistamine); verapamil $120 \mathrm{mg}$ (a P-gp blocker); a combination of cetirizine + verapamil; and a placebo on different days. Brain activity was assessed while conducting an attention network task (ANT) in a 3-T magnetic resonance scanner. The ANT measures 3 independent attention domains: i.e. alerting, orienting and executive attention. It was expected that the combined treatment of cetirizine with verapamil would prevent efflux of cetirizine from the CNS and would therefore increase attentional impairment, as compared to cetirizine when administered alone. The reason for this expected impairment increase is that when a non-sedative antihistamine is not pumped out of the brain by the Pgp transporter, the antihistamine is able to bind at the histamine 1 receptors and will cause cognitive side effects comparable with sedative antihistamines.

The study provided evidence that the P-gp transporter is involved in central antihistamine effects in humans. Subjects were less alert during the combination of cetirizine and verapamil as indicated by longer reaction times and decreased BOLD response in the right superior temporal gyrus. It is concluded that the P-gp affinity of antihistamines plays a major role in the absence or occurrence of CNS sedation.

Chapter 5 comprises a study exploring the effects of evening and morning doses on cognition. It was expected that the sedative effect of hydroxyzine would be apparent in the evening after an evening dose, but would be smaller in the morning after a morning dose due to the greater release of histamine shortly after awakening. Eighteen participants ( 9 females and 9 males) participated in a placebo-controlled, randomized, double-blind, 3-way cross-over design. 
Cognitive performance was assessed using attention and impulsivity tests. Treatment periods consisted of (i) hydroxyzine in the evening and placebo in the morning, (ii) placebo in the evening and hydroxyzine in the morning, and (iii) placebo in the evening and in the morning. Tests were performed one hour following drug or placebo intake in the evening, and one hour following drug or placebo intake in the morning.

In the evening, the sedative effects were only apparent in some variables of the tasks, whereas in the morning hydroxyzine impairment was prevalent in most of the performance outcomes. Moreover, performance impairments observed after a morning dose were significantly larger than those observed after an evening dose of hydroxyzine for several tasks. It was concluded that hydroxyzine-induced impairment is more prominent after morning doses as compared to evening doses, and that the present study could not find direct evidence to substantiate the hypothesis that histamine availability inversely affects the magnitude of antihistamine impairment.

In chapter 6 it is evaluated to what extend event-related potentials (ERPs) are affected by time of administration of a $1^{\text {st }}$ generation $\mathrm{Hl}$-antihistamine such as described in the former chapter. Hydroxyzine effects on ERPs in the attention network test were limited in number, but in line with our hypotheses. However, these results contrast with hydroxyzine effects on behavioral parameters of the attention network test. ERP data of a divided attention test indicate that hydroxyzine induced impairment was more prominent after morning doses as compared to evening doses and supports previous behavioral data. Therefore, no unambiguous evidence could be provided to confirm the hypothesis that histamine availability inversely affects magnitude of antihistamine impairment.

Chapter 7 summarizes and discusses the results from the studies described in the previous chapters, and puts these results in a broader perspective. The effects of central actions of $\mathrm{Hl}$-antihistamines are discussed, focusing on driving performance, attention, impulsivity and subjective measurements. Additionally, the three mechanisms of central action (i.e. (i) human variability in CYP2D6 metabolism; (ii) P-glycoprotein at the blood-brain barrier; and (iii) circadian fluctuations in brain histamine levels) are discussed. From this chapter, it becomes clear that variations in CYP2D6 phenotype and P-glycoprotein may play an essential role in central histamine effects, additionally emphasizing the role of inter-individual differences in antihistaminergic treatments. 


\section{Samenvatting}

Antihistamines met effecten in het centrale zenuwstelsel kunnen sedatie veroorzaken, omdat zij de waakbevorderende effecten van histamine in de hersenen afremmen. Bij de behandeling van allergieën wordt deze sedatie als een bijwerking beschouwd en wordt getracht deze te voorkomen. Echter, hetzelfde sederende effect is gewild in de behandeling van insomnie en angsten. Recent onderzoek heeft aangetoond dat verscheidene mechanismen bijdragen tot (mogelijke) sederende effecten van antihistaminica zoals: (i) het metabolisme van $\mathrm{Hl}$-antihistaminica, (ii) het vermogen van antihistaminica om te binden aan de P-glycoproteïne transporter, en (iii) de tijd van administratie ten opzichte van de circadiaanse fluctuatie van histamine niveaus in het brein. Meer kennis opdoen over deze mechanismen en hun effecten op mensen kan leiden tot een optimalisatie van behandelingen met antihistaminica.

Het doel van dit proefschrift is om (i) farmacodynamiek van centraalwerkende antihistaminica te herbepalen, en om (ii) drie mogelijke farmacokinetische mechanismen van de centrale werking van antihistaminica te onderzoeken.

In hoofdstuk 1 wordt een algemene introductie gegeven over de functie van histamine en antihistamines, en wordt ingegaan op 3 mechanismen die betrokken kunnen zijn bij de centrale effecten van antihistaminica. Ten laatste wordt het doel van het proefschrift besproken en opgesomd wat er per hoofdstuk 
beschreven staat.

In hoofdstuk 2 wordt een studie naar de effecten van H1-antihistamines op rijgedrag besproken, om de verschillen tussen centraal werkende en niet centraal werkende antihistaminica te bepalen. De effecten van twee doseringen van bilastine (20 en $40 \mathrm{mg}$ ) op rijgedrag werden onderzocht na eenmalige en herhaalde doseringen. Hydroxyzine $(50 \mathrm{mg}$ ) is een zeer sederend antihistaminicum, en was daarom geïncludeerd als controle behandeling om de gevoeligheid van de rijtest aan te tonen.

Tweeëntwintig gezonde vrijwilligers ( 11 vrouwen en 11 mannen) werden getest, en de studie werd uitgevoerd volgens een gerandomiseerd, dubbelblind, 4-wegs gekruist design. Deelnemers werden behandeld met eenmalige doseringen tijdens 8 opeenvolgende dagen. Op dag 1 en 8 van elke periode voerden de deelnemers de snelwegrit uit. Tijdens deze gestandariseerde rijtest besturen de deelnemers een geinstrumenteerde auto voor $100 \mathrm{~km}$ op de snelweg. De taak van de deelnemers was om een constante snelheid van $95 \mathrm{~km} / \mathrm{uur}$ aan te houden, en om een zo constant mogelijke laterale positie te houden op de rechter rijbaan tussen de aangegeven lijnen. Een hiervoor opgeleide rijinstructeur begeleidde de deelnemers.

Door elke conditie te vergelijken met de placebo conditie, werd duidelijk dat het slingeren van de auto, de primaire maat van de snelwegrit, significant gestegen was na de behandeling met hydroxyzine, op zowel dag 1 als dag 8 , maar niet na behandeling met bilastine 20 of $40 \mathrm{mg}$. De conclusie was dat bilastine in een dosering van 20 en $40 \mathrm{mg}$ geen schadelijke effecten heeft op rijgedrag. Hydroxyzine, aan de andere kant, zorgde voor verslechterd rijgedrag, en na toediening gedurende een week was nog steeds geen volledige tolerantie aanwezig.

Hoofdstuk 3 laat de resultaten zien van een studie naar de effecten van antihistamines op rijgedrag, en de functie die het CYP2D6 fenotype heeft op deze effecten. Tweeendertig gezonde vrijwilligers (16 vrouwen en 16 mannen) namen deel in deze dubbel-blinde, placebo-gecontroleerde studie om de effecten van eenmalige en herhaalde doseringen van esmirtazapine $1.5 \mathrm{mg}$ en $4.5 \mathrm{mg}$ op rijgedrag de dag na inname te meten. Zopiclone $7.5 \mathrm{mg}$ werd als active controle gebruikt. Het P450 2D6 (CYP2D6) fenotype van de deelnemers werd geanalyseerd om een onderscheidt te kunnen maken tussen deelnemers met een snel of vertraagd metabolisme van esmirtazapine. Prestatievermogen werd gemeten met de al eerder genoemde snelwegrit. Er waren de volgende condities: (i) esmirtazapine $1.5 \mathrm{mg}$ op dag 1-7; (ii) esmirtazapine $4.5 \mathrm{mg}$ op dag 1-7; (iii) placebo op dag 1-7; en (iv) placebo op dag 1-6 en zopiclone $7.5 \mathrm{mg}$ op dag 7. Alle middelen werden als avonddosering toegediend. 
Over het algemeen zorgde de lage dosering van esmirtazapine (1.5 mg), zowel na dag 1 als na dag 7 , niet voor klinisch relevante veranderingen in de mate van slingering vergeleken met placebo. Na eenmalige toediening van de hogere dosering van esmirtazapine $(4.5 \mathrm{mg})$ werd wel een significante stijging in slingering gevonden. Deze verslechtering in rijgedrag was na herhaalde dosering verdwenen. Een eenmalige toediening van zopiclone $7.5 \mathrm{mg}$ zorgde, zoals verwacht, voor een stijging in slingering. De uiteindelijke conclusie was dat eenmalige en herhaalde toediening van $1.5 \mathrm{mg}$ esmirtazapine over het algemeen niet word geassocieerd met verslechterd rijgedrag de volgende ochtend. Eenmalige toediening van esmirtazapine $4.5 \mathrm{mg}$ zorgde voor een significante verslechtering van rijgedrag, maar deze verslechtering verdween naar herhaalde toedieningen. Verdere analyse in een kleine groep van deelnemers met een vertraagd CYP2D6 metabolisme $(\mathrm{N}=7)$ geeft aan dat deze deelnemers gevoeliger zijn voor de verslechterende effecten die esmirtazapine kan hebben op rijgedrag. Acute verslechtering in rijgedrag was sterker aanwezig na beide esmirtazapine doseringen in deze selecte groep deelnemers met een vertraagd metabolisme. Deze resultaten benadrukken het belang om in studies die de effecten van medicatie op rijgedrag meten, rekening te houden met factoren die kunnen zorgen voor inter-individuele variabliteit met betrekking tot de reactie op medicatie, zoals het metabolisme.

Hoofdstuk 4 richt zich op een studie naar de rol van P-glycoporteïne (P-gp) bij centrale effecten van antihistamines. Een fMRI studie werd uitgevoerd met een dubbel-blind, gerandomizeerd, placebo-gecontroleerd gekruist design in 13 gezonde vrijwilligers. Deelnemers kregen cetirizine $15 \mathrm{mg}$ (een anthistaminicum); verapamil $120 \mathrm{mg}$ (een P-gp blokker); een combinatie van cetirizine + verapamil; en een placebo toegediend op verschillende dagen. Hersenactiviteit werd in een 3-T scanner gemeten terwijl de deelnemers de aandacht netwerk test (ANT) uitvoerden. De ANT meet 3 onafhankelijke aandachtsgebieden, zijnde alertheid, aandacht richten naar een bepaalde lokatie (oriëntatie), en executieve aandacht. Het werd verwacht dat de combinatie van cetirizine en verapamil de efflux van cetirizine uit het brein zou voorkomen. Dit zou zorgen voor een verslechtering in aandacht in vergelijking tot de toediening van alleen maar cetirizine. De reden hiervoor zou zijn dat door de P-gp transporter te blokkeren een normaal niet sederend antihistaminicum niet meer uit het brein vervoerd wordt en hierdoor aan histamine 1 receptoren in het brein kan binden, en zodoende cognitieve bijwerkingen kan veroorzaken die vergelijkbaar zijn met sederende antihistamines.

De studie leverde bewijs dat de P-gp transporter betrokken is bij centrale effecten van antihistaminica in mensen. Deelnemers waren minder alert na 
toediening van de combinatie van cetirizine en verapamil, als werd aangegeven door langere reactie tijden en een daling in herenactiviteit in de rechter superieure temporale gyrus. Er werd geconcludeerd dat affiniteit van antihistamines voor de P-gp transporter een belangrijke rol speelt in de aan- en afwezigheid van sederende effecten.

Hoofdstuk 5 beschrijft een studie die de effecten van ochtend en avond doseringen van antihistamines op cognitie onderzocht. Er werd verwacht dat de sederende effecten van hydroxyzine aanwezig zouden zijn in de avond na een avonddosering, en minder zouden zijn in de ochtend na een ochtenddosering, vanwege de sterkere vrijlating van histamine kort na het ontwaken. Achttien vrijwilligers ( 9 vrouwen en 9 mannen) namen deel aan een placebo gecontroleerd, gerandomiseerd, dubbel-blind 3-wegs gekruist design. Cognitieve prestaties werden gemeten door aandachtstaken en impulsiviteitstaken te gebruiken. Er waren de volgende condities: (i) hydroxyzine in de avond en placebo in de ochtend; (ii) placebo in de avond en hydroxyzine in de ochtend; (iii) placebo in de avond en in de ochtend. De taken werden een uur na medicatie inname in de avond, en een uur na medicatie inname in de ochtend uitgevoerd.

In de avondconditie waren de sederende effecten alleen aanwezig in sommige onderdelen van de taken, in de ochtend waren de verslechterende effecten van hydroxyzine sterker aanwezig. Verder waren de sederende effecten van hydroxyzine significant sterker na de ochtenddosering dan na een avonddosering in de meeste taken. Er werd geconcludeerd dat de sederende effecten van hydroxyzine sterker aanwezig waren in de ochtend vergeleken met de avond, en dat geen direct bewijs gevonden kon worden voor de hypothese dat de hoeveelheid histamine een omkerend effect heeft op de mate van sedatie veroorzaakt door antihistamines.

In hoofdstuk 6 word besproken in welke mate zogenaamde event-related potentials (ERPs) beïnvloedt worden door de toediening van een $1^{\mathrm{e}}$ generatie $\mathrm{H} 1$-antihistamine zoals in het vorige hoofdstuk besproken. Er waren slechts een aantal hydroxyzine effecten op ERPs in de aandacht netwerk test, maar deze effecten kwamen overeen met onze hypothese. Deze resultaten kwamen echter niet overeen met de gedragsdata van dezelfde taak. ERP data van een verdeelde aandachtstaak lieten zien dat verslechtering door hydroxyzine sterker aanwezig was na ochtend doseringen dan na avond doseringen, en staan wel in lijn met de gedragsdata. Hierdoor kon geen eenduidig bewijs geleverd worden voor de hypothese dat de aanwezigheid van histamine de mate van door antihistamine veroorzaakte verslechtering kan verminderen. 
In hoofdstuk 7 worden de resultaten van de studies die in de vorige hoofdstukken beschreven zijn samengevat en besproken, en in een breder perspectief gezet. De effecten van centraal werkende H1-antihistamines worden besproken met betrekking tot rijgedrag, aandacht, impulsiviteit en subjectieve maten. Verder worden de drie al eerder genoemde mechanismen besproken die een rol kunnen spelen in de centrale effecten van anthistamines (zijnde (i) variabiliteit in CYP2D6 metabolisme; (ii) P-glycoproteïne aan de bloed-hersen barriere; en (iii) circardiaanse fluctuaties in histamine niveaus in het brein). Hierdoor wordt in dit hoofdstuk duidelijk dat variaties in CYP2D6 fenotype en in P-glycoproteïne activiteit een essentiële rol kunnen spelen in de mate van centrale antihistamine effecten, waardoor de rol van inter-individuele verschillen in behandelingen met antihistaminica benadrukt wordt. 



\section{Dankwoord}

Thank you all!! 
...Just kidding! Well, to be honest it did cross my mind to leave it by just saying 'thank you all', but there are so many amazing people that have helped directly or indirectly with my PhD-project that I need to elaborate my thanks more.

Ten eerste wil ik Jan Ramaekers, mijn promotor, bedanken. Jan, bedankt voor alles: bedankt voor mij de kans te geven dit project te doen, mij meer te leren over psychopharmaca, mij te leren kritisch te denken, beter te leren schrijven, sneller knopen door te hakken, en vooral bedankt dat je mij de vrijheid hebt gegeven in het uitvoeren van onderzoek en in alle andere activiteiten daar omheen.

Bij deze wil ik ook graag mijn co-promotor Eef Theunissen bedanken. Eef, ik ben blij jou als co-promotor te hebben gehad. Je nam altijd de tijd om naar mij te luisteren, mij te helpen met vragen en om goede adviezen te geven. Dit deed je niet alleen met betrekking tot onderzoek, maar ook met betrekking tot onderwijs én zelfs privé-zaken, en dit heeft altijd motiverend gewerkt. Annemiek, ik ben blij dat ook jij mijn co-promotor was! Bedankt voor alle adviezen, je kritische blik en alles wat je mij geleerd hebt over aandacht en psychofarmaca.

Ook wil ik graag de leden van de beoordelingscommissie, Prof. Dr. Wim Riedel, Dr. Arjan Blokland, Prof. Dr. Karel Brookhuis, Dr. Mitul Mehta en Prof Dr. Jos Smits, bedanken voor hun tijd en moeite. Mitul, also big thanks for all your advice concerning the writing of the proposals and the P-glycoprotein study.

Anke S. en Fren wil ik bij deze bedanken voor alle adviezen met betrekking tot de ERP-metingen. Peter S. En Peter v. R: bedankt voor alle uitleg en hulp bij de fMRI analyses. Rob en Lisa wil ik graag bedanken voor alle uitleg over de attention switch task.

Het uitvoeren van de studies tijdens mijn project was niet mogelijk geweest zonder de hulp van de volgende mensen: de rij-instructeurs Henk Brauers, Willy Jeurissen, Jo Gorissen en Hans Sleebe, wil ik bedanken voor het uitvoeren van de rijtesten en voor de zorg voor het veilig aankomen van alle proefpersonen. Irma Brauers, bedankt voor alle logistieke werkzaamheden tijdens de studies en het begeleiden van de proefpersonen tijdens hun deelname. Cees van Leeuwen wil ik graag bedanken voor de medische supervisie. Anita, bedankt voor je onmisbare hulp bij alle studies! Verder wil ik graag de student-assistenten en stagiaires, Natalie Valle Guzman, Lieke Heil, Eva Drexler, Emma Kremer, Melinda Ravlic en Ilja Croymans, bedanken voor hun inzet en tijd. De mannen van de instrumentatie wil ik bedanken voor hun hulp en geduld bij het aanpassen van de taken. Michiel en Charlie wil ik hierbij ook bedanken voor hun inzet bij het Groot Nationaal Onderzoek. De mannen van de ICT wil ik ook voor hun geduld bedanken en voor alle hulp bij hard-en software problemen. Extra dank aan Maurice: ik denk dat ik nog nooit zo hard gelachen heb over mail met betrekking tot ICT en oma's met rollators. Ook wil ik alle proefpersonen danken voor hun deelname. 
Marcel Schrijnemaekers, dank je dat je altijd enthousiast gereageerd hebt op onze plannen en ons altijd gesteund hebt om deze te realiseren. Zonder jouw hulp waren veel activiteiten niet mogelijk geweest.

The last four years wouldn't have been such a great experience without the talks and laughs with all the colleagues in the Neuropsychology and Psychopharmacology department: Rob, Wim, Zoe, Esther, Aimee, Rosa, Alex, Luciana, Ellen, Anique, Christine, Janelle, Anne, Katja, Inge, Anke L., Eliza, Wendy, Petra, Erik, Kim, Joep, Eef, Anke S., Maria, Lisbeth, Jeroen, Elian, Anita, Sven, Arjan, Jan, Caroline, Annemiek \& Pascal, thank you! En lieve Ellen, je wordt gemist. Also thanks to the best Maastricht-roomies: Tim, Peter and Stefan (ofwel Timmie, Pjotr en Nefats), thanks for the great advice and the good times!

Aimee en Anke S., ik ben blij dat we samenwerken aan het Groot Nationaal Onderzoek, en Tim en Anke S., hetzelfde geldt voor ons studentenjournal. Jullie enthousiasme in wat jullie doen en hoe jullie projecten aanpakken heeft altijd inspirerend gewerkt. Also a special thanks to Luciana for organizing crazy parties and girl nights. Kim, Inge, Anke L. en Aimee bedankt voor de te gekke congressen, het lijkt me leuk om nog eens samen naar een te gaan. Ik heb altijd enorm met jullie kunnen lachen en goed met jullie kunnen praten, dank jullie wel! Wendy, wie had gedacht dat nachten achter elkaar proefpersonen wakker houden zo vermakelijk zou zijn. Maar ook daarna was het altijd super samenwerken en gezellig om samen uit eten te gaan en natuurlijk ook bedankt voor alle fijne gesprekken. Katja, ik ben blij dat ik je op het werk heb leren kennen en dat we nog steeds vrienden zijn, zonder jou waren de vier jaar beslist minder makkelijk geweest.

I would also like to thank Prof. Bill Deakin for giving me the opportunity to work at his department in Manchester, and all the new colleagues (especially my new roomies Richard, Emma and Holly) at the Neuroscience and Psychiatry Unit for making me feel at home.

Lieve paranimfen Janneke (pnimf) en Tim (ptimf), ik vind het een eer dat jullie mij bijstaan tijdens mijn promotie. Ik had mij geen betere paranimfen kunnen wensen, dank jullie wel, jullie zijn te gek!

Ik heb het geluk dat ik geweldige vrienden heb die mij steunen door dik en dun: dank jullie allemaal voor te gekke gesprekken, fijne avonden en gestoorde feesten! Jullie zijn met teveel om iedereen op te noemen. Een aantal wil ik toch bij naam noemen, omdat zij het meeste mijn promotie-perikelen moesten verdragen, dit dapper hebben gedaan en ook nog kans zagen om mij als nodig op te vrolijken: Janneke, Linda, Marijn, Keetje, Erik, Toon, Kimberly, Maries, Wouter, Jaro, Jeroen, Krullen-Wouter, Evelien, Liv, Marcel, Ruudje, Jacob en Floris...dank jullie wel! Jaro ook bedankt voor het te gekke ontwerp van de omslag van dit proefschrift. 
Gerdine, Harald, Bram, Simon, Nina, Astrid, Stef en Boris wil ik bij deze bedanken voor de altijd gezellige en fijne avonden in Brabant.

To the best sisters in the world: Nicole, Jeannie und Sonja, vielen Dank für alles: dass Ihr immer Tag und Nacht für mich da seit, mich immer tröstet wenn nötig, guten feedback gibt, und auch noch extrem witzig in all dem seit! Natürlich auch viel Dank an Mehmet, Fabienne, Kaya und Tarik, die auch immer bereit sind, sich allen Quatsch an zu hören.

Liebe Mama und lieber Jürgen, ihr seit immer für mich da und habt mich immer in allem was ich machen wollte unterstützt. Ihr seit beide eine riesige Inspiration für mich: Danke für alles.

Lieve lieve Joris, ik zou niet weten wat ik zonder jou zou moeten doen, maar ik weet wel dat zonder jou alles minder mooi zou zijn. You're my boilin' pot! 


\section{Curriculum Vitae}

Silke Conen was born on December 24, 1980 in Aachen (Germany). After her graduation from secondary school (Sophianum, Gulpen \& Arcus College, Heerlen) in 1999, she studied Psychology at Maastricht University. She obtained her degree in Biological Psychology after her internship at the department of Neuropsychology and Psychopharmacology, where she investigated gender differences in cognition and mood after administration of an antidepressant. During her studies Silke worked as a student assistant at the department of Experimental Psychology at Maastricht University. After her graduation she worked, amongst others, at the Centre for Brain \& Learning (Maastricht). Afterwards, she became a research assistant at the department of Psychology and Neuroscience where she assisted in a study on the effects of MDMA on psychomotor function, actual driving, and mood before, during, and after a night of sleep loss. In 2008, she started her $\mathrm{PhD}$ project at the same department, investigating the mechanisms playing a role in central effects of antihistamines, under supervision of Prof. Dr. J. G. Ramaekers, Dr. E. L. Theunissen, and Dr. A. Vermeeren. Currently she is working as a post-doctoral researcher at the Neuroscience and Psychiatry Unit of the Manchester University School of Psychiatry and Behavioural Sciences.

Silke Conen werd geboren op 24 december 1980 in Aken (Duitsland). In 1998 behaalde zij haar HAVO diploma aan scholengemeenschap Sophianum te Gulpen, en in 1999 behaalde zei haar VWO diploma aan het Arcus College te 
Heerlen. Aansluitend begon zij met de opleiding Psychologie aan de Universiteit Maatricht, met als afstudeerrichting biologische psychologie. Hiervoor heeft zij onderzoek gedaan naar geslachtsverschillen in gemoedstoestand en cognitie na toediening van een antidepressivum bij de capaciteitsgroep Neuropsychologie en Psychofarmacologie aan dezelfde universiteit. Tijdens deze opleiding werkte zij als student assistent bij de afdeling Experimentele Psychologie van de Universiteit Maastricht. Na haar opleiding werkte zij onder andere als onderzoeksmedewerker bij het centrum voor hersenen en leren (Maastricht). Hierna werd zij onderzoeksmedewerker bij de capaciteitsgroep Neuropsychologie en Psychofarmacologie waar zij meewerkte aan een studie naar de effecten van MDMA op rijgedrag en gemoed tijdens en na een nacht slaapdeprivatie. In 2008 is zij op dezelfde afdeling begonnen aan haar promotie onderzoek naar de mechanismen die zorgen voor de centrale, sederende effecten van antihistamines, onder leiding van Prof. Dr. J.G. Ramaekers, Dr. E.L. Theunissen en Dr. A. Vermeeren. Tegenwoordig is zij werkzaam als post-doc onderzoeker bij de Neuroscience and Psychiatry Unit van de Manchester University School of Psychiatry and Behavioural Sciences. 


\section{Publications}

Bosker, W., Theunissen, E., Conen, S., Kuypers, K., Jeffery, W., Walls, H., Kauert, G., Toennes, S., Moeller, M. and Ramaekers, J. (2012). A placebo controlled study to assess Standardized Field Sobriety Tests performance during alcohol and cannabis intoxication in heavy cannabis users and accuracy of point of collection testing devices for detecting THC in oral fluid. Psychopharmacology (Berl), 223(4), 439-446.

Bosker, W.M., Kuypers, K.P., Conen, S., Kauert, G.F., Toennes, S.W., Skopp, G., and Ramaekers, J.G. (2011). MDMA (ecstasy) effects on actual driving performance before and after sleep deprivation, as function of dose and concentration in blood and oral fluid. Psychopharmacology (Berl), 222(3), 367-376.

Conen, S., Theunissen, E.L., Vermeeren, A., and Ramaekers, J.G. (2011). Acute effects of morning versus evening dose of hydroxyzine $50 \mathrm{mg}$ on cognition in healthy subjects. Journal of Clinical Psychopharmacology, 31(3):294-301.

Ramaekers, J.G., Conen, S., De Kam, P.J., Braat, S., Peeters, P., Theunissen, E.L., and Ivgymay, N. (2011). Residual effects of esmirtazapine on actual driving performance: overall findings and an exploratory analysis into the role of CYP2D6 phenotype. Psychopharmacology (Berl), 215(2):321-332

Conen S., Theunissen E.L., Van Oers A.C., Valiente R, and Ramaekers J.G. (2011) Acute and subchronic effects of bilastine (20 and $40 \mathrm{mg}$ ) and hydroxyzine $(50 \mathrm{mg})$ on actual driving performance in healthy volunteers. Journal of Psychopharmacology, 25(11):1517-23.

Bosker, W.M., Kuypers, K.P.C., Conen, S., and Ramaekers, J.G. (2010). Dose related effects of MDMA on psychomotor function and mood before, during, and after a night of sleep loss. Psychopharmacology (Berl), 209(1), 69-76.

In press

Conen, S., Theunissen, E. L., Sambeth, A., Vermeeren, and A. Ramaekers, J.G. (In Press). CNS impairing effects of hydroxyzine as a function of histamine availability. Journal of Clinical Psychopharmacology.

\section{Submitted}

Conen, S., Theunissen, E.L., Vermeeren, A., and Ramaekers, J.G. (In Prep). Affinity for P-gp transporter determines CNS sedation of antihistamines. Sumbitted for publication. 
